\author{
UNIVERSIDADE DE SÃO PAULO \\ ESCOLA DE ENFERMAGEM DE RIBEIRÃO PRETO
}

JULIANA VILLELA BUENO

\title{
Avaliação da intensidade e característica da dor no trabalho de parto e a ação do misoprostol
}

RIBEIRÃO PRETO 


\title{
Avaliação da intensidade e característica da dor no trabalho de parto e a ação do misoprostol
}

\begin{abstract}
Dissertação apresentada ao Programa de Pós-Graduação do Departamento de Enfermagem Materno-Infantil e Saúde Pública da Escola de Enfermagem de Ribeirão Preto da Universidade de São Paulo, inserida na linha de pesquisa: Assistência à Saúde da Mulher no ciclo vital.
\end{abstract}

Orientadora: Profa. Dra. Ana Márcia S. Nakano 
Autorizo a reprodução e divulgação total ou parcial deste trabalho, por qualquer meio convencional ou eletrônico, para fins de estudo e pesquisa desde que citada a fonte.

FICHA CATALOGRÁFICA

Preparada pela Biblioteca Central do Campus - USP

Administrativo de Ribeirão Preto

Bueno, Juliana Villela

Avaliação da intensidade e característica da dor no trabalho de parto e a ação do misoprostol

Dissertação de Mestrado, apresentada à Escola de Enfermagem de Ribeirão Preto/USP - Departamento de Enfermagem Materno-Infantil e Saúde Pública.

Orientadora: Nakano, Ana Márcia Spanó

1. Misoprostol 2. Dor 3. Trabalho de Parto 


\section{FOLHA DE APROVAÇÃO}

Juliana Villela Bueno

Título: Avaliação da intensidade e característica da dor no trabalho de parto e a ação do misoprostol.

Dissertação apresentada à Escola de Enfermagem de Ribeirão Preto da Universidade de São Paulo, para obtenção do Título de Mestre em Enfermagem em Saúde Pública, junto ao Departamento de Enfermagem MaternoInfantil e Saúde Pública, inserida na Linha de Pesquisa: Assistência à Saúde da Mulher e o ciclo vital.

Aprovado em:

Banca Examinadora

Prof. Dr.

Instituição: Assinatura:

Prof. Dr.

Instituição: Assinatura:

Prof. Dr.

Instituição: Assinatura: 


\section{Dedico este trabalho}

Aos meus filfinhos, Willinho $e$ Marquinho, que me fizeram compreender o poder do Criador, por vocês é que arrumo forças para continuar seguindo esta vida. Obrigada pelos dias infinitamente felizes.

Dá-me um sorriso a brincar Dá-me uma palavra a rir, Eu tenho por feliz Só de te ver e ouvir. Fernando Pessoa 


\section{Dedico este trabalho}

Aos meus pais Willie e Sônia,

Fontes de sabedoria e acolhimento, exemplos de vida e luta, agradeço pelo amor, pelo exemplo de luta constante e por muitas vezes cuidarem dos meus filhos como a mim mesma. A vocês devo mais esta conquista. Em reconhecimento do privilégio de ser sua filha. 


\section{Dedico este trabalho}

Aos meus queridos irmãos,

Luciana, Adriano e Cristiana e a meus adoráveis cunhados Rodrigo, Patrícia e Lucas por quem nutro grande admiração e pelo suporte emocional que nossa união nos oferece. Pela minha ausência nas conversas de família, por cuidarem com tanto carinho dos meus filhinhos neste momento de luta.

Ao Ricardo,

grande amigo de todas as horas, pelo incentivo nos momentos mais difíceis, o meu carinho e admiração. 


\section{Agradecimento Especial}

À Ana Márcia, minha orientadora, pela tolerância, pela sabedoria, pelas importantes contribuições e por ter me ajudado em momentos em que achava impossível finalizar esta etapa. Sinto-me privilegiada por tê-la como orientadora. Agradeço imensamente pela realização deste sonho. Que Deus a ilumine hoje e sempre! 


\section{Agradecimentos}

A Deus, pelo dom da vida.

A toda minha família, pela alegria de um convívio gostoso.

Á Maria Helena, amiga e companheira de todo dia, me serve de grande exemplo pela competência e pelos ensinamentos que contribuem diariamente em minha vida profissional e pessoal. Obrigada pelas boas conversas sinceras.

Às enfermeiras residentes da Mater pela disponibilidade em me ajudar e por entenderem as minhas ausências. Em especial a Paula, Daniela e Lílian, pela grande responsabilidade.

Às parturientes que aceitaram participar desta investigação, sem elas seria impossível este trabalho.

A toda a equipe de enfermeiras, médicos e funcionárias da Maternidade do Complexo Aeroporto (Mater) que de alguma forma contribuíram para viabilizar este trabalho. Guardarei comigo um pouco de cada um deles. Em especial a Mônica pela ajuda e incentivo, a Clarice pela disponibilidade e carinho ao providenciar os prontuários, a Andréia pela boa vontade em ajudar quanto a informações sobre o misoprostol e a Gislaine pela disponibilidade e rapidez ao encaminhar as fotos.

Agradeço a todos da EERP sem distinção de cargos ou setores, aqueles que de alguma forma contribuíram para viabilizar este trabalho e colaboraram para meu aprendizado.

À Professora Doutora Cristine Hosmi Jorge Ferreira grande incentivadora, pela disponibilidade, pelo carinho e dedicação que me proporcionou desde o início do desenvolvimento deste trabalho e ao Dr. Marcos Roberto Ymayo pela disposição e pelas valiosas sugestões que enriqueceram esta pesquisa.

À Professora Doutora Fátima Emm Faleiros Sousa, pelas importantes sugestões sobre o projeto no exame de qualificação.

Ao Professor Doutor Vanderlei José Haas, pela fundamental ajuda na análise dos dados.

À Professora Doutora Adriana Moraes Leite, exemplar Enfermeira Obstétrica, pelas contribuições na finalização deste trabalho que só fizeram enriquecer esta pesquisa. Obrigada pela sua amizade.

A Liliane Nascimento de Santi e a Roxana Isabel Cardozo Gonzáles pela rapidez com que realizaram com tanto carinho a tradução dos resumos em inglês e espanhol. 
À Maria do Socorro pela revisão do texto em português.

Às docentes da área da Saúde da Mulher da Escola de Enfermagem de Ribeirão Preto, Professoras Doutoras Ana Maria de Almeida, Fabiana Villela Mamede, Flávia Azevedo Gomes, Maria José Clapis, Marislei Sanches Panobianc e Marli Villela Mamede, por ajudarem a tornar meu sonho realidade.

À Maria Antonieta Spinoso Prado. pela disponibilidade e imprescindível colaboração na elaboração do banco de dados.

À secretária Andréa da Pós-Graduação do Departamento de Enfermagem Materno-Infantil e Saúde Pública da Escola de Enfermagem de Ribeirão Preto, pela atenção e apoio dispensados em todos os momentos.

Ao Willians Braz Romano da documentação técnico científica, pela disponibilidade na realização das fotos.

À Marta Célere da Biblioteca Central do Campus da USP, pela revisão das referências e citações bibliográficas.

Aos amigos Ricardo, Mônica, Juliana Virgílio, Juliana Monteiro, Lucília, Regina, Adriana, Liliane, Paula Hino, Tatá, por me motivarem a seguir este caminho, pelo apoio, pela amizade sincera e pelo carinho.

A todos os colegas do mestrado, especialmente Ricardo, Regina, Nelma, Aline, Marilu, Anne, Liliane, Taila pelo apoio e companheirismo.

A minha segunda família Dona Lourdes, Rose, Daiane, Edy, Josi, Fer, Jaque, tia Lo, Suemi e Gu. Obrigada por me acolherem como filha e por cuidarem tão bem dos meus filhinhos. Amo vocês.

À Profa. Dra. Carmem Gracinda Silvan Scochi, Coordenadora do Programa de Pós-Graduação da Escola de Enfermagem da Universidade de São Paulo, pelo apoio prestado e compreensão nos momentos difíceis.

O meu muito obrigado! 


\section{RESUMO}

BUENO, J.V. Avaliação da intensidade e característica da dor no trabalho de parto e a ação do misoprostol (2006) $130 \mathrm{f}$. Dissertação (mestrado) - Escola de Enfermagem de Ribeirão Preto, Universidade de São Paulo, Ribeirão Preto, 2006.

O uso do misoprostol tem se tornado um procedimento de rotina nos casos de indução do trabalho de parto (TP), pelo seu efeito relaxante sobre o músculo liso do colo, alterando a estrutura do colágeno, particularmente nos casos de pós-datismo. O objetivo deste estudo observacional e comparativo foi avaliar os efeitos do uso do misoprostol no TP em relação à intensidade e à característica da dor manifestada pelas parturientes. Participaram do estudo 40 parturientes, 20 fizeram parte do grupo com indicação de indução do TP com uso de misoprostol, e 20 fizeram parte do grupo de evolução espontânea, todas assistidas em uma maternidade que atende clientela SUS na cidade de Ribeirão Preto-SP. Os grupos foram formados por indicação clínica, atendendo ao protocolo da instituição para resolução da gravidez, e pelos critérios de inclusão. O estudo foi desenvolvido em duas fases. A primeira (fase latente do TP - FLTP), com a participação apenas do grupo I (misoprostol), e a segunda fase (fase ativa do TP - FATP), com ambos os grupos, para comparar a dor manifestada pelas parturientes. A dor foi avaliada por meio dos instrumentos: Diagrama do corpo (DC) para identificação das regiões dolorosas; Estimação de categorias/ ordenação das posições dos descritores de dor (DD) e Escala Analógica Visual (VAS). Para a análise do DC e DD, foram considerados a freqüência e o percentual. Para a VAS, foram calculados a média aritmética, a mediana, o desvio-padrão, o mínimo e o máximo. $\mathrm{Na}$ análise comparativa, foram utilizados teste Mann-Whitney, teste Quiquadrado $(\alpha 0,05)$ e análise de Variância (ANOVA) com medidas repetidas. Na FLTP, a maioria das parturientes (grupo I) referiu dor na região pubiana; a lista de 15 descritores da dor não se mostrou adequada a este momento do TP; a mensuração da intensidade da dor pela VAS, após a primeira manifestação de dor na FLTP, revelou padrão de dor ascendente, o que corrobora para o efetivo efeito do misoprostol em ativar as contrações uterinas. Na FATP, a localização da dor para ambos os grupos foi nas regiões: pubiana, inguinal, quadril anterior e sacra. A qualificação da dor, por meio dos descritores, para ambos os grupos, apresenta similaridades, visto que a maioria das parturientes de cada grupo a descreve como sensitiva. Outra semelhança é a predominância de descritores de qualidade afetiva, entre os cinco primeiros classificados. Na mensuração da intensidade da dor, pela VAS, os resultados sugerem que a intensidade da dor se apresenta ascendente para ambos os grupos. A mensuração de maiores intensidades de dor às contrações uterinas para o grupo II está relacionada a um maior número de contrações uterinas apresentadas por este grupo. Diante desses achados, não é possível afirmar que o misoprostol manifeste na parturiente maiores intensidades de dor durante o TP, comparativamente à dor manifestada em um TP de evolução espontânea, conforme suposto no início deste estudo.

Palavras-chaves: dor, parto, misoprostol. 


\begin{abstract}
BUENO, J.V. Evaluation of intensity and characteristics of labor pain and action of the misoprostol (2006) 130 p. Dissertation (Master) - Nursing School of Ribeirao Preto, Sao Paulo University, Ribeirao Preto, 2006.
\end{abstract}

The misoprostol is been used as a drug of routine in cases of induce labor, because it has a relaxing effect in muscles and it alters collagen structures, specially in cases of post dactism. Based on empiric observations in our practice, in where we observed that women submitted to this drug reffered more indexes of pain during labor, the effects of the misoprostol use are our object of investigation. The objective of this observational and comparative study was to evaluated the effects of misoprostol and the intensity of pain. Forty patients participated in this study, 20 had indication to labor induction with misoprostol, and 20 had spontaneous labor. All of them were from the same maternity cover by SUS in Ribeirão Preto city. All of them were from the same maternity cover by SUS. Groups were established following clinical conditions for institution delivery protocols and also inclusion criteria of that. The study has two phases: the first phase (latent phase of labor obstetric - LPLD) in which only group I (misoprostol) was included, and the second phase (active phase of labor obstetric- APLD), to compare pain in both groups. The pain was evaluated by using instruments: body diagram (BD) in order to identify regions of pain, estimation of categories/ positions of descriptors of pain (DD) and visual analogical scale (VAS). To analyze BD and DD, it was considered the frequency and percentage. For the VAS were calculated arithmetic media, median, standard deviation, minimum and maximum. In comparative analyses it was used Mann Whitney and Chi -Square test and ANOVA with repetitive measures. On LPLD most of women (group I) refers pain on pubis region; the list of 15 descriptors was not adequate in this phase; after the first pain signal, the VAS on LPLD showed that pain has an ascendant model, what reveal that misoprostol active uterine contractions. On APLD, the pain local for both groups was on pubis region, also on: ignal, hype, sacral. The qualification of pain is very similar for both groups, because most of the patients describe it as sensitive. Another aspect very similar in both group was the affective adjective in the first 5 descriptors. In measuring the pain intensity using VAS, the results suggest that the intensity of pain is ascendant for both groups. The higher scores for group II is associated to a bigger number of uterine contractions. In front of thise results is not possible to say that misoprostol induces higher levels of pain in women during labor as we supposed in the beginning of this study.

Key words: pain, labor, misoprostol. 


\section{RESUMEN}

BUENO, J.V. Evaluación de la intensidad y característica del dolor en el trabajo de parto y la acción del misoprostol (2006) $130 \mathrm{~h}$. Dissertação (mestrado) - Escola de Enfermagem de Ribeirão Preto, Universidade de São Paulo, Ribeirão Preto, 2006.

El uso de misoprostol se convirtió en un procedimiento de rutina en los casos de inducción del trabalho de parto (TP) por el efecto relajante sobre el musculo liso del colón, alterando la estructura del colágeno, particularmente en los casos de embarazo postérmino. El objetivo del estudio observacional y comparativo fue evaluar los efectos del uso del misoprostol en el trabajo de Parto en relación a la intensidad e caracterisiticas del dolor manifestado por las mujeres embarazadas. Participaron del estudio 40 parturientas, 20 formaron parte del grupo con indicación de inducción del TP con uso de misoprostol y las otras 20 del grupo con evolución espontânea, todas atendidas en una maternidad del SUS en la cuidad de Ribeirão Preto. Los grupos fueron formados por indicación clínica, atendiendo al protocolo de la institución para resolución de la gravidez, y por los critérios de inclusión. El estudio fue desarrollado en dos fases. En la primera (fase latente del TP FLTP) solamente participaron las parturientes del grupo I (misoprostol), en la segunda fase (fase activa del TP - FATP), y tubo como objetivo comparar el dolor manifestado por las parturientas de ambos grupos. El dolor fue evaluado por medio de los instrumentos: Diagrama del cuerpo (DC) para identificación de las regiones dolorosas; Estimación de categorias/ ordenación de las posiciones de los descriptores del dolor (DD) y Escala Analógica Visual (VAS). Se realizó análisis estadístico para calcular la frecuencia y el percentual de DC y DD y para la VAS fue calculado la média aritmética, la mediana, desvio padrón, mínimo e máximo. En el análisis comparativo fue utilizado teste MannWhitney, teste de Chi cuadrado $(\alpha 0,05)$ y análisis de Varianza (ANOVA) con medidas repetidas. En la FLTP, la mayoría de las parturientas (grupo I), referió dolor en la región pubica; la lista de 15 descriptores del dolor no se mostró adecuada a este momento del TP; la mensuración de la intensidad del dolor a través de la VAS después de la primera manifestación del dolor en la FLTP, reveló padrón del dolor ascendente, lo que corrobora para la efectiva acción del misoprostol (activar las contracciones uterinas). En la FATP, la localización del dolor para ambos grupos fue en la región: pubica, inguinal, cuadril anterior y sacra. La calificación del dolor, a través de los descriptores, para ambos grupos, se presenta de forma similar, en vista que la mayoria de las parturientas de cada grupo la describe como sensitiva. Otra semejanza es la predominancia de descriptores de calidad afectiva, entre los 5 primeros clasificados. En la mensuración de la intensidad del dolor, a través de la VAS, los resultados sugieren que la intensidad del dolor se presenta ascendente para ambos grupos. La mensuración de mayores intensidades del dolor a contracciones uterinas para el grupo II está relacionada a un mayor número de contracciones presentadas por este grupo. En función de los resultados, no es posible afirmar que el misoprostol manifieste en la parturienta mayores intensidades del dolor durante el TP, comparativamente al dolor manifestado en un TP de evolución espontanea.

Descriptores: dolor, parto, misoprostol. 
Quadro 1 - Parâmetros cervicais e da apresentação fetal utilizados para o cálculo do Índice de Bishop modificado....

Quadro 2 - Freqüência $(F)$ e Percentual $(P)$ das variáveis sóciodemográficas dos grupos de parturientes estudadas. Ribeirão Preto, 2006

Quadro 3 - Freqüência (F) e Percentual $(P)$ das variáveis obstétricas dos grupos de parturientes estudadas. Ribeirão Preto, 2006

Quadro 4 - Freqüência $(F)$, percentual $(P)$ e ordenação em postos (OP) dos cinco descritores de dor, do grupo I (misoprostol), ordenados pelas parturientes na fase latente do trabalho de parto. Ribeirão Preto, 2006.........

Quadro 5 - Média aritmética, mediana, desvio-padrão, mínimo e máximo, da intensidade da dor manifestada pela parturiente, por meio da VAS, na primeira meia hora (T1) e no término da coleta de dados (T2), na primeira fase do estudo. Ribeirão Preto, 2006

Quadro 6 - Freqüência $(F)$, percentual $(P)$ e ordenação em postos (OP) dos cinco descritores de dor, ordenados pelas parturientes, no início da coleta de dados (T0). Ribeirão Preto, 2006

Quadro 7 - Freqüência $(F)$, percentual $(P)$ e ordenação em postos (OP) dos cinco descritores de dor ordenados pelas parturientes, durante a primeira meia hora (T1) da coleta de dados. Ribeirão Preto, 2006

Quadro 8 - Freqüência $(F)$, percentual $(P)$ e ordenação em postos (OP) dos cinco descritores de dor ordenados pelas parturientes, ao completar uma hora (T2) da coleta de dados. Ribeirão Preto, 2006

Quadro 9 - Média aritmética, mediana, desvio-padrão, mínimo e máximo, da intensidade da dor manifestada pela parturiente, por meio da VAS, na primeira meia hora (T1) e no término (T2) da coleta de dados, na segunda fase do estudo. Ribeirão Preto, 2006 
Tabela 1 - Freqüência $(F)$ e Percentual $(P)$ da manifestação de dor, do grupo I (misoprostol), segundo a topografia das regiões do corpo, nos três momentos do estudo, na fase latente do trabalho de parto. Ribeirão Preto, 2006

Tabela 2 - Freqüência $(F)$ e Percentual $(P)$ da manifestação de dor, segundo a topografia das regiões do corpo, nos três momentos da coleta de dados, na fase ativa do trabalho de parto. Ribeirão Preto, 2006

Tabela 3 - Intensidade de dor da contração uterina, manifestada pelas parturientes, por meio da VAS, em relação ao número de contrações, durante a primeira meia hora (T1) da coleta de dados. Ribeirão Preto, 2006

Tabela 4 - Intensidade de dor da contração uterina, manifestada pelas parturientes por meio da Escala Analógica Visual, em relação ao número de contrações uterinas durante a primeira hora da coleta de dados. Ribeirão Preto, 2006........................ 
Figura 1 - Diagrama do corpo para identificação das regiões dolorosas em vista anterior e posterior.

Figura 2 - Painel ilustrativo, apresentado às gestantes/parturientes para a identificação das regiões dolorosas em vista anterior e posterior, a Escala Analógica Visual e os descritores de dor.

Figura 3 - Número de comprimidos de misoprostol utilizados durante todo o trabalho de parto e o tipo de parto, na segunda fase do estudo. Ribeirão Preto, 2006

Figura 4 - Intensidade de dor manifestada pela parturiente, por meio da Escala Analógica Visual (VAS), do início ao fim da coleta de dados, na segunda fase do estudo. Ribeirão Preto, 2006 


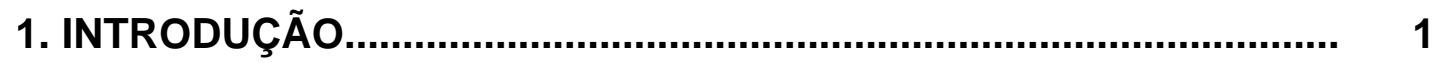

2. CONSTRUÇÃO DO OBJETO DE ESTUDO...................................... 5

2.1. Fisiologia da dor no trabalho de parto.......................................... 6

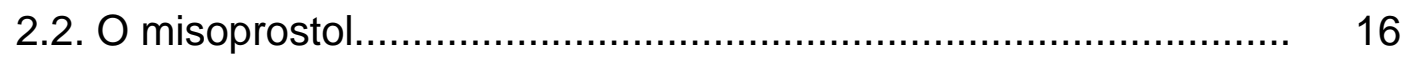

2.3. Medidas de avaliação e mensuração da dor................................ 29

3. OBJETIVO DO ESTUDO........................................................... 35

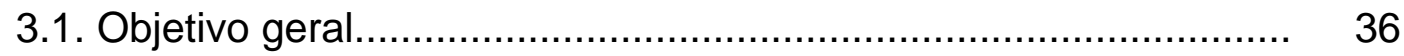

3.1.1. Objetivos específicos..................................................... 36

4. PERCURSO METODOLÓGICO.................................................... 37

4.1. Tipo de estudo.............................................................. 38

4.2. Aspectos éticos da pesquisa................................................. 38

4.3. Campo de estudo............................................................. $\quad 39$

4.4. Amostra

4.5. Critérios de inclusão............................................................ 40

4.6. Critérios de exclusão.................................................................. 40

4.7. Instrumentos de coleta de dados................................................ 41

4.7.1. Instrumento de registro de dados.................................... 41

4.7.2. Instrumento de avaliação de dor....................................... 42

4.8. Teste-Piloto .................................................................... 45

4.9. Procedimento para coleta de dados........................................... 46

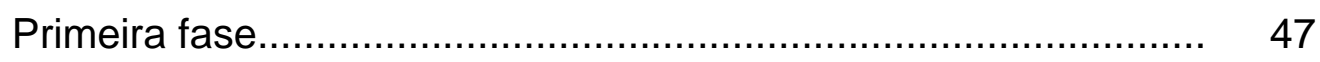

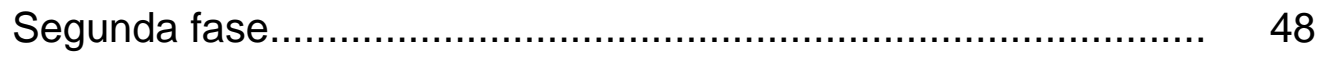

4.10. Categorização das variáveis................................................. 50

4.11. Tratamento e análise dos dados............................................... 51

Análise descritiva............................................................. 51

Análise comparativa....................................................... 52

4.12. Dificuldades metodológicas.................................................. 53 
5. RESULTADOS

5.1. Caracterização dos grupos estudados em relação às variáveis sociodemográficas.

5.2. Caracterização dos grupos estudados com relação às variáveis obstétricas......

5.3. Avaliação da dor das contrações uterinas manifestadas pelas parturientes durante 0 trabalho de parto para os grupos estudados.

Primeira fase do estudo. 58

Avaliação da topografia da dor. 58

Avaliação dos descritores da dor. 59

Avaliação da intensidade da dor por meio da VAS. 60

Segunda fase do estudo 61

Avaliação da topografia da dor. 62

Avaliação dos descritores da dor 67

Avaliação da intensidade da dor por meio da VAS.

6. DISCUSSÃO. 71

7. CONCLUSÃO. 74

8. REFERÊNCIAS BIBLIOGRÁFICAS. 101 
1.Introdução 
Dentre as inovações tecnológicas, temos nos deparado na atualidade com a utilização de drogas que produzem efeitos na redução do tempo do trabalho de parto (TP) e esvaecimento rápido do colo uterino, tais como o misoprostol que tem sido amplamente empregado na indução do TP. Atuando como enfermeira obstétrica em uma maternidade que atende clientela SUS (Sistema Único de Saúde), observamos que o misoprostol se tornou um procedimento de rotina, conforme protocolo de indicação médica nos casos de pós-datismo. Nas observações clínicas frente às gestantes submetidas ao uso da droga, chamou-nos a atenção os efeitos que esta produzia, ou seja, as mulheres submetidas a esta droga se apresentavam mais queixosas com relação à dor sentida durante o trabalho de parto. Tal fato, entretanto, pareceu-nos menos evidente quando a dosagem desta droga foi melhor ajustada. Vale informar que, inicialmente, não eram disponibilizados os comprimidos em dose ideal de aplicação, sendo o mesmo dividido em partes, que nem sempre se apresentavam em concentração exata à requerida. Atualmente, os comprimidos são disponibilizados pela indústria farmacêutica, em dosagem padronizada para o uso.

Reportando a literatura científica sobre o efeito do misoprostol no TP, identificamos a existência de inúmeros estudos sobre os efeitos do misoprostol na duração do trabalho de parto, no esvaecimento e dilatação do colo, e sobre avaliação de dosagens da droga, entre outras variáveis de estudo (CAMPOS, 1994; WING,1995; ESCUDERO \& CONTRERAS, 1997; WARE, 2000; CANO, 2000; AQUINO, 2003; HOFMEYR, 2003; SAMPAIO,2004; BUCCELLATO, 2000). Sobre os efeitos desta droga na manifestação de dor no TP, não encontramos estudos indexados nas principais bases de dados. 
Assim, frente a estas observações e respaldando-nos nas proposições da Humanização e no Projeto Maternidade Segura da Organização Mundial de Saúde (BRASIL, 2001) que fundamenta o novo modelo de cuidado no nascimento e parto, considera-se a dor do trabalho de parto e o seu alívio um dos indicadores merecedores de atenção especial. Preconiza-se a utilização de meios de suporte emocional, de alívio de dor, recuperando práticas fisiológicas capazes de acompanhar os ritmos da mãe e do bebê, contribuindo para um parto e um nascimento saudáveis, com menor intervenção. Pelo Projeto Maternidade Segura, as práticas médicas devem ser restringidas ao estritamente necessário para que a segurança seja garantida. Contrariando o que se acreditava no passado, ou seja, que a dor tinha uma função biológica importante, não devendo ser aliviada, na atualidade, reconhece-se que as respostas fisiológicas à dor podem acarretar prejuízo a algumas mulheres e ao feto.

Nesse sentido é que buscamos estudar os efeitos do uso do misoprostol no trabalho de parto em relação à intensidade e à característica da dor manifestada pelas parturientes.

Dentre as repercussões materno-fetais estão incluídas: vasoconstricção reflexa induzida pela dor, com contração muscular e perpetuação do quadro doloroso, decorrente do espasmo reflexo dos músculos e hipóxia tecidual. A resposta supra-segmentar é caracterizada por ampla e complexa resposta endocrinometabólica, produzindo importantes efeitos deletérios sobre vários órgãos e sistemas maternos e repercutindo direta ou indiretamente no bem-estar fetal. Destaca-se dentre as importantes respostas endocrinometabólicas à dor: a hiperatividade adrenérgica, as alterações da ventilação pulmonar e oxigenação e do débito cardíaco (BRASIL, 2001). 
A elevação das catecolaminas bem como de norepinefrina materna, durante o trabalho de parto, pode exercer efeitos nocivos à mãe e ao feto de duas maneiras: alterando a dinâmica uterina e/ou reduzindo a circulação uteroplacentária. A elevação dos níveis de epinefrina diminui a atividade uterina, e a elevação dos níveis de norepinefrina pode acarretar na prática tanto hipo como hiperatividade uterina (MATHIAS \& TORRES, 2000). Esses níveis aumentam ainda mais em partos prolongados e são relatados como extremamente dolorosos.

Sabendo-se dos efeitos nocivos da dor à mãe e ao feto, atualmente tem se investido em estratégias de alívio, o que requer considerar, também, a importância de avaliar a dor mediante a utilização de procedimentos, tais como o uso do misoprostol durante o processo de parturição. Isto somado à escassez de dados científicos sobre o assunto justifica a relevância de se estudarem efeitos desta droga durante o trabalho de parto em relação à intensidade e ás características da dor manifestada pelas parturientes. 


\section{Construção do objeto de estudo}




\section{1 - Fisiologia da dor no trabalho de parto}

Uma das sensações mais experimentadas e temidas pelo ser humano é a dor. É uma experiência desagradável e universal, a que todos estão sujeitos. A dor envolve vários componentes: sensoriais, afetivos, cognitivos, sociais e comportamentais (DIAS, 1996).

É importante destacar que a dor, como tudo que é subjetivo, não permite um entendimento preciso que viabilize uma definição, pois apenas o indivíduo que a sente é capaz de percebê-la. Thomas Leais, citado por Posner (1993), descreveu a situação da seguinte forma: "a dor é conhecida por nós, por experiência e descrita por ilustração".

Ao longo do tempo, muitos estudiosos vêm se preocupando com a construção de uma definição de dor que possa contemplar todas as interfaces dessa experiência universal. Em 1979, o Comitê de Taxonomia da Associação Internacional de Estudos da Dor propôs a seguinte definição: "Dor é uma experiência sensorial e emocional desagradável, associada a um dano tissular real ou potencial, ou descrita em termos deste dano".

Após analisar a definição anterior, Bond (1993) sugeriu que fosse acrescentado que a "dor é uma experiência que se expressa e se reconhece por determinados padrões de comportamento".

Marshall apud Claro (1993), filósofo e psicólogo, afirma que “a dor é uma qualidade emocional que dá colorido a todos os eventos sensitivos”. Para Loeser (1999) e Lowe (2002), a dor é complexa, subjetiva e multidimensional.

Sobre estudos de dor, a literatura científica apresenta elucidações quanto aos aspectos fisiológicos, classificando-a quanto à estrutura anatômica e funcional de origem e 
transmissão, bem como sob a forma como esta se manifesta em termos temporais (aguda, crônica). A dor de uma forma geral pode ser classificada, conforme Hanson (2001), como:

Nociceptiva, ou seja, aquela resultante da ativação direta dos receptores da pele ou tecidos moles em resposta à injúria tecidual, e geralmente é acompanhada de inflamação, e só responde a estímulos de alta intensidade, ou seja, quando há estímulo e/ou sensibilização dos nociceptores e das fibras aferentes primárias motoras. Neuropática, aquela decorrente de uma lesão primária do Sistema Nervoso Central ou Periférico, quando os nervos periféricos são acometidos por alguma doença. Central, quando ocorrem lesões ou doenças do sistema nervoso central. Visceral, geralmente quando decorre de um ou mais fatores como: distensões, contrações e/ou trações, traumatismos, necroses de estruturas, torções, irritações das superfícies mucosas e serosas das vísceras. É caracterizada por um tipo de dor intensa, uma cólica profunda, desconfortável, difusa, e de difícil localização. Esse tipo de dor pode ser acompanhado de dor referida, isto é, dor em pontos da pele, distantes do local anatomicamente acometido. A dor da contração uterina é uma dor visceral (BAJAJ, 2002).

Somática, aquela proveniente da excitação de aferentes nociceptivos que inervam estruturas profundas como o periósteo, músculos, articulações, tendões e fascias. É uma dor particularmente intensa, contínua e de fácil localização, sendo proporcional à área lesada (BONICA, 1953; COUSIN \& PHILLIPS, 1986). Idiopática, aquela sem nenhuma evidência de ativação dos nociceptores e/ou presença de mecanismos de geração de dor neuropática, na presença de um problema psicológico evidente.

Reconhece-se que existem dois tipos de dor, classificada em relação ao tempo de duração como aguda e crônica. A aguda resulta da estimulação nociva intensa ou 
potencialmente injuriante, é bem localizada e transitória quando não ocorre dano tecidual, sendo acompanhada de reações fisiológicas de alerta, como a dilatação das pupilas oculares, sudorese aumentada e aumento das freqüências cardíacas e respiratórias; e a crônica representa a perpetuação da dor aguda que, por sua vez, inicia-se subitamente tendo um término previsível (SOAFER, 1994; CARDOSO,2004).

Recortando para dor no trabalho de parto e parto, objeto de nosso estudo, esta é identificada como uma dor aguda com características bastante peculiares. A este respeito, Melzack (1984, 1993) refere que, apesar do trabalho de parto ser considerado uma ocorrência fisiológica, é um dos fenômenos dolorosos mais intensos, experimentado pelas mulheres, e que se assemelha ao arrancamento de um dedo.

A dor no trabalho de parto parece estar ligada a vários fatores que se somam tais como: dilatação do colo uterino, contração e distensão das fibras uterinas, distensão do canal do parto, tração dos anexos e do peritônio, pressão da uretra, bexiga e outras estruturas pélvicas e a pressão sobre as raízes do plexo lombossacro (BRASIL, 2001). Corroborando com tal consideração, Abushaikha (2005) indica que os fatores que mais contribuem para a dor, durante o trabalho de parto, são de ordem psicológica, as contrações uterinas, a dilatação e o esvaecimento cervical. Ainda Fishuburne (1999) refere que a percepção da dor do trabalho de parto é influenciada por inúmeros fatores, incluindo o tamanho e a posição fetal, a força das contrações uterinas, o ambiente, o estado físico e psicológico, a experiência da gravidez e o processo do nascimento. Para ele, muitos eventos causam essa dor, a contração do útero, a dilatação da cérvix e o estiramento da vagina e do assoalho pélvico. 
Sobre a dor manifestada durante as contrações uterinas, Oxorn (1989) observa que é a presença do estado isquêmico do músculo que ocorre especialmente quando o tônus uterino ou quando as contrações são muito freqüentes e duradouras que resultam em manifestação de dor. O que também é aceito por Sabatino et al. (2000) que referem a contração e distensão uterina do miométrio que contribuem muito pouco para dor da parturição, em razão da não-comprovação da hipótese de que a compressão das terminações nervosas, situadas no miométrio, e a isquemia durante a contração, possam ser estímulos de dor.

Ainda sobre os componentes que contribuiriam para manifestar a dor no trabalho de parto, admite-se a possibilidade de que a compressão e tensão dos músculos miometriais possam estimular nociceptores mecânicos de alto limiar de excitação. No entanto, esses receptores apresentam redução do seu limiar de excitação quando estimulados repetidamente, sendo mais provável que eles sejam responsáveis por boa parte do comportamento doloroso naquelas parturientes com hiperatividade uterina. (MATHIAS \& TORRES, 2000).

Autores como Rezende (1998), Neme (2000) e Mathias \& Torres (2000) caracterizam a dor com base nos períodos clínicos do trabalho de parto (dilatação, expulsão, dequitação e quarto período). O período de dilatação é o primeiro período do trabalho de parto, é o mais longo de todos, caracterizado pela presença de contrações uterinas rítmicas e dolorosas. Neste período, a dor é devida à distensão, estiramento e talvez a lesões do colo uterino. Estas conjecturas são baseadas nas seguintes observações: estiramento de qualquer músculo liso é estímulo comum de dor visceral; existência de 
estreita correlação entre a intensidade dolorosa do trabalho de parto e o grau de dilatação cervical; presença de retardo entre o início da contração uterina e o começo da percepção dolorosa (15 a 30 segundos) que seria o tempo necessário para uma contração efetiva causar a distensão do colo.

Pereira (1998) observou que, no segundo estágio do trabalho de parto, a dor é produzida no canal de parto e no períneo, sendo transmitida pelo nervo pudendo, que é formado pelas raízes do $2^{\circ}, 3^{\circ}$ e $4^{\circ}$ nervo sacral, caracterizando uma dor somática. O nervo pudendo é quem realiza a inervação sensitiva e motora de todo o canal do parto. As vias sensitivas que partem do útero têm trajeto paralelo às fibras simpáticas, atravessando o plexo uterino, cervical e hipogástrico inferior, médio e superior e ascendendo pela cadeia látero-vertebral do simpático. Por meio dos ramos brancos, atingem a raiz dorsal dos nervos T1 e T2, conduzindo, aos centros superiores, o estímulo doloroso de todo o útero. (FLACKSTEIN, 1950; HOUSSAY, 1972). Quando a dilatação cervical está mais adiantada, os estímulos alcançam a medula espinhal também pelos segmentos adjacentes de T10 e L1 (BONICA, 1979).

No período expulsivo, a distensão e a compressão de terminações sensitivas somáticas das estruturas perineais, somadas a certo grau de lesão mecânica ou isquêmica, provavelmente sejam as causas da dor (SABATINO, 2000).

Para Goetzl (2002), as contrações uterinas e a dilatação cervical resultam em dor visceral (T10 até L1). A progressão do trabalho de parto, a descida da apresentação fetal e a compressão do assoalho pélvico, da vagina e do períneo geram uma dor transmitida pelo nervo pudendo (S2-4). 
Para a transmissão nervosa do estímulo doloroso e a resposta à dor, o organismo dispõe de um complexo sistema nervoso. Para a informação nociva chegar à medula espinhal, é necessária a participação do neurônio aferente primário (NAP). Os NAPs que inervam regiões abaixo da cabeça são células bipolares, cujos corpos celulares se encontram no gânglio da raiz dorsal. Os NAPs que inervam a região cefálica possuem corpos celulares nos gânglios sensoriais dos nervos cranianos V, VII, IX e X. O axônio periférico do NAP possui terminações livres, denominadas nociceptores, capazes de detectar estímulos dolorosos. A informação gerada nos nociceptores é conduzida antidromicamente até o gânglio da raiz dorsal. A partir deste gânglio, a informação continua sendo conduzida até a medula espinhal, agora ortodonticamente, ao longo do axônio central do NAP. O ramo central do NAP adentra à medula espinhal, principalmente pelo trato de Lissauer, e suas terminações contraem sinapses com células espinais de segunda ordem, localizadas no corno dorsal da medula espinal. Estas células são encontradas nas camadas mais superficiais e profundas do corno dorsal da medula espinal. (BONICA, 1990; PRADO, 2001).

Assim, no trabalho de parto, estímulos são transmitidos à coluna espinhal por fibras viscerais aferentes que têm origem na parte lateral do útero e passam pela parte inferior, média e superior do plexo hipogástrico, pela cadeia simpática torácica e lombar, pelos nervos posteriores da $10^{\mathrm{a}}, 11^{\mathrm{a}}$ e $12^{\mathrm{a}}$ vértebras torácicas e pelo nervo da $1^{\mathrm{a}}$ vértebra lombar, durante o primeiro estágio do trabalho de parto. A dor manifestada neste período deve-se, principalmente, à distensão, ao estiramento e talvez a lesões do colo uterino. 
A dor no trabalho de parto é caracterizada ainda com base na fase do trabalho de parto que a parturiente se encontra, ou seja, fases latente e ativa (BRASIL, 2001), mais especificamente no primeiro período (dilatação) do trabalho de parto.

De acordo com os ensinamentos de Greenhill \& Friedman (1976), o processo de parturição divide-se classicamente em períodos: o primeiro período estende-se do início das contrações uterinas regulares até que o orifício externo do colo uterino esteja completamente dilatado e se nivele com a vagina, completando assim um canal contínuo chamado o canal do parto. Este é considerado como o período de dilatação.

Greenhill \& Friedman (1976) subdividem o período de dilatação em duas fases: a fase latente que se estende desde o início do trabalho de parto até o momento em que a curva da dilatação muda de forma aguda (a partir de $2-3 \mathrm{~cm}$, aproximadamente); e a fase ativa que começa com a subida da curva e termina com a dilatação e retração completas do colo uterino, no início do segundo estágio.

A fase latente promove mudanças relacionadas à orientação e coordenação da contratilidade uterina e amolecimento e apagamento do colo. De acordo com os mesmos autores, a fase latente em nulíparas (entendidas neste contexto como mulheres que jamais passaram pela experiência do parto pela via vaginal) dura em média 8,6 horas e normalmente não excede 20 horas; em multíparas é de, em média, 5,3 horas e não vai além de 14 horas (GREENHILL \& FRIEDMAN, 1976). Para Doenges (1988), a fase latente é lenta, o colo uterino encontra-se de fechado para aproximadamente 3 centímetros de dilatação, e as contrações são fracas e regulares, aumentando regularmente sua freqüência, intensidade e duração. Almeida (2005) refere que, em primíparas, acontece o apagamento 
do colo uterino antes de iniciar a dilatação e que o processo fisiológico da dor, na parturição, está associado à evolução do trabalho de parto, onde inicialmente o padrão de dor da contração uterina é menor nesta fase.

Na fase ativa, ocorre uma aceleração no processo de dilatação da cérvice; acontece $100 \%$ do apagamento do colo uterino, tem em média contrações com freqüência, intensidade e duração progressivas, passando a ocorrer de duas a cinco contrações a cada dez minutos, com duração de 30 a 45 segundos (DOENGES, 1988; ALMEIDA, 2005). A dilatação se processa a uma velocidade de $3 \mathrm{~cm}$ por hora e não menor que $1,2 \mathrm{~cm}$ por hora em nulíparas em condições normais; em multíparas, é de $5,7 \mathrm{~cm}$ por hora e raramente é menor que $1,5 \mathrm{~cm}$ por hora. Como a fase ativa inicia com $3 \mathrm{~cm}$, aproximadamente, e termina com a dilatação completa $(10 \mathrm{~cm})$, podemos deduzir que a duração média da mesma é de 2,33 horas em nulíparas, não devendo ser maior que 5,83 horas. Em multíparas, a duração da fase ativa da dilatação deve gastar um tempo médio de 1,23 hora, não devendo exceder a 4,66 horas. O'brien \& Cefalo (1996) nos informam ser a duração média total do trabalho de parto de 10,1 horas em nulíparas e de 6,2 horas em multíparas, sendo que os valores superiores da normalidade para essas duas situações são de 25,8 horas e de 19,5 horas respectivamente. Levando em consideração apenas os dados do primeiro estágio ou período de dilatação, os mesmos autores informam que a fase latente tem duração média de 6,4 horas em nulíparas e de 4,8 horas em multíparas, com o limite superior da normalidade de 20,6 horas em nulíparas e de 13,6 horas em multíparas. Os valores da velocidade de dilatação na fase ativa são exatamente os mesmos estabelecidos por Greenhill \& Friedman (1976). Portanto, de acordo com a literatura, podemos inferir que 
o estágio de dilatação (incluindo a fase latente e a fase ativa) pode ser considerado prolongado, se superior a 25,8 horas em nulíparas e superior a 18,6 horas em multíparas.

Burroughs (1995) refere que se deve levar em consideração, durante o TP, a dilatação cervical, a intensidade dolorosa e a duração das contrações.

Durante a fase latente e a ativa do TP, a dor é predominantemente mediada por mecanismos de distensão do segmento uterino com a contribuição dos mecanismos de dilatação da cérvice e da própria contração uterina. No final do TP, a dor já é mais localizada no períneo, ânus e reto, podendo também ser sentida nas coxas e pernas (ROWLANDS, 1998).

A menor ou maior intensidade da dor sentida, durante as contrações, pode variar de acordo com cada momento, em uma mesma mulher. Isto se deve à possibilidade de a mulher secretar substâncias endógenas analgésicas. Sabe-se que a concentração plasmática de beta-endorfina é significativamente maior na gestante a termo, quando comparada com paciente não grávida, elevando-se ainda mais no trabalho de parto e reduzindo-se mediante analgesia peridural (MATHIAS \& TORRES, 2000).

Sobre as diferentes percepções de dor, a literatura científica tem apontado para outros fatores além dos determinantes fisiológicos do processo de parturição. A este respeito, entende-se que a expressão da dor varia não somente de um indivíduo para o outro, mas também de acordo com as diferentes culturas, ou seja, independente de seus elementos anatômicos e físiológicos (FRIDH, 1988; BROWN, 1989; CARDOSO, 2004).

A dor do trabalho de parto é uma experiência comum a quase toda a população feminina. Por décadas, meninas crescem aterrorizadas em relação à dor do trabalho de 
parto, culturalmente transmitida entre as gerações. As mulheres levam este medo para a sala de parto, dificultando o nascimento do bebê. Para muitas mulheres, parto é sinônimo de dor e sofrimento (AFONSO, 2005).

Estudar sobre a dor do trabalho de parto, para Alexander (2001), é muito difícil e complexo, visto que são múltiplos os fatores que afetam a percepção desta dor, incluindo a ansiedade, as experiências ruins anteriores e a heterogeneidade inerente do trabalho de parto. Existem ainda fatores cognitivos e emocionais que influenciados pelo estímulo da dor visceral afetam a intensidade dela. Este autor ainda enfatiza que para cada mulher a experiência é única.

Afonso (2005) considera ser a dor no trabalho de parto e parto uma experiência pessoal e subjetiva, relacionada ao sofrimento físico, psicológico e espiritual. Lins (1988) relata que a subjetividade dessa dor é causada pela pouca oxigenação e pela distensão de tecidos, associada às emoções, medos, tabus, mitos, crendices, tensões, inseguranças e numerosos fatores culturais que tornam a intensidade, tolerância e a reação à dor extremamente variável. Essa variação é notável desde um parto completamente indolor até o mais absoluto descontrole psicomotor, inviabilizando completamente o parto normal.

O estado psicológico, o estresse, a ansiedade, o medo, a sensação de perder o controle e de ser abandonada contribuem para a dor do trabalho de parto (LOWE, 2002).

Frente ao exposto, no que se refere à dor manifestada no trabalho de parto, é importante considerar que os impulsos nociceptores em sua condução sofrem modulação de impulsos vindos de centros superiores, os quais dependem de fatores afetivos e culturais (MATHIAS \& TORRES, 2000; BRASIL,2001). 


\section{2 - O misoprostol}

$\mathrm{Na}$ prática obstétrica, existem várias condições que impõem a indicação da interrupção da gravidez. Esta, pode acontecer em qualquer idade gestacional antes do início espontâneo do trabalho de parto. As indicações mais freqüentes da interrupção da gravidez são: pós-datismo, síndromes hipertensivas, diabetes, restrição do crescimento intra-uterino, comprometimento da vitalidade fetal, óbito fetal, isoimunização, condições de insuficiência placentária, ruptura prematura de membranas, corioamnionite, oligorâmnio entre outras (BRASIL, 2001; DUARTE, 2003; MORAES FILHO, 2005; FEITOSA, 2006). As contraindicações são praticamente as mesmas que contra-indicam o parto vaginal: macrossomia, apresentações anômalas, desproporção cefalopélvica, duas ou mais cicatrizes uterinas prévias, sofrimento fetal, placenta prévia completa e parcial, vasa prévia, prolapso de cordão umbilical, sorologia HIV+ e herpes genital em atividade. Estima-se que mais de 15\% de todas as gestantes apresentem indicação de indução do parto (WING, 1999; ACOG. 2000; FEITOSA, 2006).

A indicação da indução do trabalho de parto se dá nas situações em que a continuação da gravidez pode ser perigosa para a mãe, feto ou ambos (SANCHES RAMOS, 1993; ARAÚJO, 1999; AQUINO, 2001).

A indução do parto representa uma estratégia importante para redução das taxas de cesariana que aumentaram progressivamente nas duas últimas décadas, na maioria dos países (BRASIL, 2001). 
Passini Júnior (2000) relata que as modificações biológicas e bioquímicas que torna a cérvice, macia e complacente, ocorre em geral, nos últimos dias que antecedem o parto. $\mathrm{O}$ determinismo do parto é complexo e envolve alterações no eixo hipotálamo-hipófise-suprarenal do feto (levando a modificações na produção de esteróides placentários, composição do líquido amniótico e secreção renal do feto), apagamento da junção fibro-muscular do útero (esvaecimento) e processo de maturação natural do colo uterino (mediado pelas prostaglandinas). Quando esta maturação do colo uterino ainda não ocorreu naturalmente, diz-se que ele é desfavorável à indução e necessitaria de preparo prévio, para diminuir a ocorrência de falhas de indução e a indicação da cesárea .

Induzir é promover o início do trabalho de parto por meio de métodos artificiais, enquanto estimular o trabalho de parto é ativar as contrações que desenvolveram inércia uterina durante o decorrer do trabalho de parto, utilizando recursos artificiais (REZENDE, 1988; ZIEGEL, 1980; DUARTE, 2003).

O sucesso da indução do trabalho de parto se dá pela obtenção da contratibilidade uterina regular e a dilatação progressiva do colo (BRASIL, 2001; AQUINO, 2001).

Para indução do TP, utilizam-se, na atualidade, três principais métodos, a saber: a ocitocina, as prostaglandinas e a amniotomia. Apesar da ocitocina ser amplamente utilizada como iniciador seguro e efetivo das contrações uterinas, seu sucesso depende da condição do colo uterino no início da indução. Sua suspensão possibilita reverter o aumento das contrações, ou seja, é dose dependente. Com base na revisão sistematizada disponível na Biblioteca Cochrane, conclui-se que o misoprostol (prostaglandinas) é o mais efetivo dos 
métodos convencionais para o amadurecimento do colo e indução do trabalho de parto (HOFMEYR, 2003; MORAES FILHO, 2005).

O papel fisiológico das prostaglandinas na parturição é ter um efeito relaxante direto sobre o músculo liso da cérvice, alterando a estrutura do colágeno, facilitando a dilatação, ao mesmo tempo em que permite o acréscimo do cálcio intracelular, promovendo contrações uterinas. Todos estes mecanismos permitem a evolução do trabalho de parto: progressivo esvaecimento e a dilatação cervical, concomitante ao aumento da atividade uterina, o que garante na maior parte dos casos, uma indução bem-sucedida do trabalho de parto (ROUSE, 2000; MORAES FILHO, 2005). Da mesma forma que ocorre com a ocitocina, a sensibilidade do músculo uterino às prostaglandinas aumenta, à medida que a gestação progride (GRAVES, 1996). No útero, as prostaglandinas são sintetizadas primariamente pelo endométrio e atuam sobre a musculatura lisa miometrial (GOLDYNE, 1986).

No sistema reprodutor feminino, as prostaglandinas são encontradas no ovário, miométrio e líquido menstrual, em concentrações que variam com o ciclo ovulatório e nas membranas fetais. Em idade gestacional a termo e durante o trabalho de parto, as concentrações de prostaglandina se elevam no líquido amniótico, no sangue do cordão umbilical e no sangue materno (GRAVES, 1996).

O misoprostol é um análogo sintético da prostaglandina $\mathrm{E}_{1}$ natural $\left(\operatorname{PgE}_{1}\right)$. Produz uma inibição dose-dependente da secreção do ácido gástrico e da pepsina e aumenta a resistência da mucosa à lesão. É um eficaz agente na profilaxia e no tratamento da úlcera péptica. Como a ação da prostaglandina afeta vários tecidos, foram identificadas outras 
ações do misoprostol, na prática obstétrica como a indução do TP e o amadurecimento do colo uterino (AQUINO, 2003; MORAES FILHO, 2005).

O misoprostol foi lançado no Brasil, em 1984, para tratamento e prevenção de úlceras gástricas e duodenais (BRASIL, 2001). Em função do seu uso indiscriminado, como abortivo no Brasil, a sua comercialização foi restrita e suspensa no país durante alguns períodos (BRASIL, 2001). Os primeiros trabalhos, evidenciando o uso indiscriminado do misoprostol, como abortivo no Brasil, foram realizados pelo Grupo de Prevenção ao Uso Indevido de Medicamentos da Universidade Federal do Ceará, em 19901994 (COELHO, 1991; FONSECA, 1991). O misoprostol teve suas vendas suspensas por decisão judicial em julho de 1992 e submetidas ao controle da Portaria 27, em todo o território nacional, e cada Estado tomou medidas diferenciadas para o controle da comercialização do produto. Nessa época, as vendas do misoprostol no País caíram em cerca de 80\% logo após essas determinações (COELHO, 1993).

A partir do início da década de 1990, vários trabalhos científicos forneceram evidências baseadas em experiências clínicas que justificavam seu uso de forma rotineira para o preparo cervical e indução do trabalho de parto em gestações com feto vivo (CAMPOS PEREZ, 1994; WING,1995; BUSER, 1997; ESCUDERO, 1997; WARE, 2000;

CANO, 2000; BUCELLATO, STIKA, FREDERIKSEN， 2000; AQUINO， 2003; HOFMEYR, 2003; SAMPAIO,2004; SURITA, 2004).

As prostaglandinas têm sido amplamente utilizadas na maioria dos países, entretanto, no Brasil apenas a PgE1 metil-análoga (misoprostol) está disponível comercialmente, e seu uso na obstetrícia tem aumentado significativamente em virtude de 
seu custo mais baixo em relação às outras prostaglandinas e com eficácia comparável. (SURITA, 2002; SAMPAIO, 2004; SURITA, 2004). Eram comercializados, comprimidos de $200 \mu \mathrm{g}$, hoje no mercado, apresenta-se apenas o comprimido vaginal de $25 \mu \mathrm{g}$. Segundo Brasil (2001), em 1998, o Ministério da Saúde restringiu a venda do produto apenas para hospitais credenciados (ANEXO II).

Dentre as prostaglandinas disponíveis comercialmente, naturais ou sintéticas, o misoprostol parece representar uma ótima alternativa. Têm-se como principais vantagens a estabilidade térmica e de estocagem, menor risco de efeitos colaterais e custo reduzido, quando comparado às prostaglandinas naturais (SONG,2000; BLANCHARD, 2002; MORAES FILHO, 2005). Hofmeyr (2005), acrescenta outra vantagem: o tempo de meiavida alargado e a facilidade na administração. De acordo com Katz (2000), o custo hospitalar de uma dose de $50 \mu \mathrm{g}$ de misoprostol é de US\$ 0,28 , ao passo que o custo de uma dose de $1,0 \mathrm{mg}$ de dinoprostona (prostaglandina natural E2) é 400 a 800 vezes mais elevado, em torno de US\$200,00.

A indução do parto não é um método muito freqüente no Brasil. Geralmente tem sido usado em hospitais universitários. Principalmente porque nunca houve no país uma política de disponibilizar métodos de indução de trabalho de parto e de preparo do colo uterino (AQUINO, 2001; MORAES FILHO, 2005). O método está ganhando popularidade, principalmente pela sua eficácia e baixo custo, sendo já recomendada sua utilização em manuais do Ministério da Saúde e pela Federação Brasileira das Sociedades de Ginecologia e Obstetrícia (Febrasgo). Além do mais, já existe um consenso internacional sobre sua utilidade, como maturador do colo e indutor do trabalho de parto em mulheres com colo 
desfavorável. Várias são as indicações quanto ao seu uso, antes do início espontâneo do trabalho de parto, entre elas, as mais freqüentes são os pós-datismos, as roturas prematuras de membranas, as síndromes hipertensivas, o comprometimento da vitalidade fetal, diabetes, restrição do crescimento intra-uterino (RCIU) e óbito fetal. Não deve ser utilizado em mulheres com cicatriz uterina pelos prováveis riscos de ruptura uterina e em casos de óbito fetal ou em situações em que a vitalidade fetal não seja importante, ou seja, malformações incompatíveis com a vida. (BRASIL, 2001; AQUINO, 2003; MORAES FILHO, 2005).

A grande maioria dos estudos publicados recomenda a dose de $25 \mu \mathrm{g}$ a cada 4 a 6 horas, na dose total máxima de $100 \mu \mathrm{g}$, como já é recomendada pelo Colégio Americano de Obstetras e Ginecologistas (ACOG, 2000). O Ministério da Saúde, o Instituto Brasileiro de Defesa do Consumidor (IDEC) e a Febrasgo reconhecem a importância de existir no Brasil comprimidos e/ou óvulos vaginais de misoprostol com dose de $25 \mu \mathrm{g}$, para uso em Obstetrícia, com a finalidade de indução do parto em gestantes com feto vivo e vêm tentando solucionar e legalizar esta situação. No momento atual, existe a solicitação oficial para o registro de óvulos vaginais de misoprostol com $25 \mu \mathrm{g}$, com a perspectiva de lançamento do produto no mercado brasileiro. Por enquanto, estão sendo realizados estudos de bioequivalência do produto (FAÚNDES, CECATTI \& BESTETI PIRES, 2001). O Brasil foi o primeiro país do mundo a disponibilizar comercialmente o misoprostol preparado especificamente para o uso vaginal, na forma de comprimidos de $25 \mu \mathrm{g}$. Este preparado mostrou efetividade e segurança similar a doses equivalentes de misoprostol 
obtida do fracionamento de comprimidos de $200 \mu \mathrm{g}$ comercializado para seu uso via oral. (CECCATI, 2005).

Vários são os esquemas posológicos e as vias de administração disponíveis, mas a via vaginal oferece vantagens em relação à oral, devido ao perfil farmacocinético mais favorável (ZIEMAN, 1997; BOULVAIN, 2001; RUST, 2001; HOW, 2001; FISHER, 2001; TANG, 2003). Sobre as dosagens da droga, não identificamos nos estudos uma descrição sobre o fracionamento do comprimido de misoprostol em doses $12,5 \mu \mathrm{g}, 25 \mu \mathrm{g}$ e $50 \mu \mathrm{g}$, visto que no mercado, anteriormente só existiam os comprimidos de $200 \mu \mathrm{g}$,

Muitos autores chamam atenção para seu uso rotineiro e sem controle desta droga, pois há um aparente aumento de hiperestimulação uterina o que torna preocupante seu uso (HOFMEYER, 2000). A dose de 50 $\mathrm{g}$ via vaginal resulta em um trabalho de parto mais curto, porém tem sido relatado um aumento na incidência de taquissistolia e hiperatividade uterina. (SANCHES, 2002; HOFMEYR, 2003; SAMPAIO, 2004). Intervalos de 3 a 6 horas têm sido utilizados, porém doses e intervalos geralmente se baseiam nos resultados dos estudos farmacocinéticos, bem como em estudos clínicos comparando a eficácia dos diversos esquemas (WING, 1999). Entretanto, poucos estudos têm sido publicados, considerando possíveis fatores maternos ou gestacionais que podem interferir nas características dose-resposta do misoprostol utilizado por via vaginal(WING, 2002).

O estudo descritivo de Maia Filho (1998) foi realizado em São Paulo e avaliou o uso de misoprostol, $25 \mu \mathrm{g}$ a cada 3 horas, para o amadurecimento do colo uterino e indução do trabalho de parto em 13 gestantes com feto vivo e colo não preparado. Como resultados 
principais, encontrou incidência de parto vaginal de $84,6 \%$ em 24 horas, ausência de falha de indução, efeitos colaterais e de resultado perinatal desfavorável. Conclui que o misoprostol é droga eficiente, mesmo em baixa dose, na indução do parto com colo nãoamadurecido.

Outro estudo nacional, realizado em Minas Gerais, comparou a efetividade e segurança de duas doses de misoprostol administradas por via vaginal para amadurecimento cervical e indução do parto em gestantes de termo com feto vivo e colo uterino desfavorável. Estudaram-se 61 mulheres das quais 28 foram alocadas no grupo de $25 \mu \mathrm{g}$ e 33 no grupo de $50 \mu \mathrm{g}$. Em ambos os grupos, o intervalo de administração foi de 4 horas, até um período máximo de 24 horas. Não houve diferença significativa entre os grupos com relação ao intervalo médio de tempo do início da indução até o parto vaginal, via de parto e complicações maternas e neonatais. Os autores concluíram que misoprostol por via vaginal é um método eficiente e seguro para preparo cervical e indução do trabalho de parto, e que a dose de $25 \mu \mathrm{g}$ mostrou ter efetividade e segurança comparáveis à dose de $50 \mu \mathrm{g}$ (ARAÚJO, 1999).

Tedesco (2002) comparou a efetividade e a segurança do misoprostol em duas dosagens $12,5 \mu \mathrm{g}$ e $25 \mu \mathrm{g}$. A administração foi por via vaginal, para o preparo cervical e indução do parto em gestações a termo com indicação para antecipação do parto. Utilizou um ensaio clínico controlado aleatorizado unicego, incluindo 40 gestantes tratadas com uma das duas doses de misoprostol. A variável independente foi a dose do misoprostol, e as variáveis dependentes foram o tipo de parto, tempo entre o início da indução e o parto, complicações perinatais e efeitos maternos adversos. As principais variáveis de controle foram idade materna, idade gestacional, escolaridade, paridade, cor e estado do colo uterino 
no início da indução. Na análise dos dados, foram utilizados os testes $t$ de Student, exato de Fisher, Wilcoxon, Kolmogorov-Smirnof e análise de sobrevivência. Para os grupos que utilizaram de 12,5 e $25 \mathrm{mg}$ de misoprostol, não houve diferenças significativas no tempo de início de atividade uterina $(20,9 \pm 20,4$ e $16,6 \pm 9,8 \mathrm{~h}$ respectivamente), tempo entre o início da atividade uterina até o parto $(7,8 \pm 3,4$ e $6,9 \pm 5,0$ h, respectivamente), parto vaginal ( $65 \%$ e $80 \%$, respectivamente) e efeitos indesejados maternos e perinatais (índice de Apgar e síndrome de hiperestimulação uterina tiveram resultados similares). Embora não significativas tais diferenças, vale lembrar que o grupo de $25 \mu \mathrm{g}$ apresentou a maior taxa de partos vaginais e menor tempo para o parto.

Sobre as dosagens de misoprostol, Duarte et al. (2003), consideram ser necessário avaliar a idade gestacional, a maturidade e vitalidade fetal, a excitabilidade uterina e as condições do colo.

A primeira classificação clínica das condições do amadurecimento do colo uterino foi realizada por Bishop (1964) que desenvolveu um escore com cinco variáveis para estabelecer o estado do colo uterino. A partir desse estudo, o Índice de Bishop passou a ser utilizado com o propósito de se estabelecer a predição de sucesso à indução do trabalho de parto. Considera-se mais favorável ao sucesso do parto vaginal, em menor tempo, a presença de índice de Bishop maior ou igual a nove, como intermediário, um escore entre cinco e oito, e desfavorável um índice menor que cinco pontos (BRASIL, 2001). A soma destes escores nos mostra o quanto é favorável ou não a indução. Em escore menor que 6, a indução é favorável (DUARTE, 2003). 
Quadro 1. Parâmetros cervicais e da apresentação fetal utilizados para o cálculo do Índice de Bishop modificado (BISHOP,1964; Duarte, 2003)

\begin{tabular}{|l||c|c|c|c||}
\hline & \multicolumn{4}{c|}{ COLO UTERINO } \\
\hline \hline PARÂMETRO & $\mathbf{0}$ & $\mathbf{1}$ & $\mathbf{2}$ & $\mathbf{3}$ \\
\hline Posição & Posterior & Centrado & Anterior & - \\
\hline Consistência & Firme & Médio & Amolecido & - \\
\hline Encurtamento & Longo & Médio & Curto & Fino \\
& $>1,5 \mathrm{~cm}$ & 0,5 a $1,5 \mathrm{~cm}$ & $<0,5 \mathrm{~cm}$ & Apagado \\
\hline $\begin{array}{l}\text { Altura da } \\
\text { apresentação }\end{array}$ & -3 & -2 & -1 a 0 & +1 e 2 \\
\hline Dilatação & 0 até 1 polpa & 1 a 2 polpas & 3 a 4 polpas & 4 polpas \\
\hline
\end{tabular}

$\mathrm{Na}$ presença do colo uterino desfavorável (Bishop menor que 6), considera-se fundamental a realização do preparo cervical prévio. Para este preparo, é realizada a indução do trabalho de parto. A indução da contratibilidade uterina sem o preparo cervical prévio está associada a altas taxas de falhas de indução e de parto cesárea.

Wing (2002) analisou os diversos fatores que podem afetar a ação do misoprostol intravaginal na dilatação cervical e na indução do trabalho de parto. Para tanto, foram estudadas diversas variáveis, como: indicação da indução, idade, idade gestacional, paridade, peso, altura, índice de massa corpórea, dilatação cervical e escore de Bishop iniciais, dose total de misoprostol, necessidade de uso de ocitocina, anestesia peridural e peso ao nascer. Definiu-se o sucesso da indução na ocorrência de parto vaginal dentro de 24 horas depois da dose inicial de misoprostol. Encontrou associação estatisticamente significante para as variáveis: idade gestacional, paridade, dilatação cervical e escore de 
Bishop como preditores do sucesso da indução, porém depois do ajuste para possíveis fatores de confusão em modelo de regressão logística múltipla, persistiram como fatores associados ao sucesso da indução apenas as características clínicas paridade, dilatação cervical inicial e idade gestacional na admissão.

Estudo comparativo do uso do misoprostol vaginal ( $25 \mu \mathrm{g}$ a cada 6 horas) com ocitocina endovenosa na indução do parto não encontrou diferença significativa entre os grupos com relação à média de tempo para o sucesso da indução, incidência de parto vaginal em 24 horas, de taquissistolia e de índice de Apgar $<7$ ao quinto minuto. (WING \& PAUL, 1998).

Borré (2000) realizou um estudo prospectivo e randomizado comparando a eficácia do uso do misoprostol e da ocitocina para a indução do trabalho de parto no Hospital e Maternidade Rafael Calvo de Cartagena - Colômbia, de setembro de 1998 a fevereiro de 1999. De 136 pacientes, 100 cumpriram os critérios de seleção, 50 usaram misoprostol e 50, ocitocina. Não houve diferença estatisticamente significante nas complicações com o uso das drogas e observou-se um menor tempo entre a indução e a ocorrência do parto entre as pacientes que usaram o misoprostol.

Para Aquino \& Cecatti, (2003), este estudo compara a efetividade e segurança do misoprostol intravaginal versus ocitocina endovenosa no amadurecimento cervical e indução do parto, em gestantes com colo uterino desfavorável. Constitui-se de um ensaio clínico controlado e aleatorizado, realizado no Hospital Maternidade Leonor Mendes de Barros, em São Paulo, no período de novembro de 1998 a dezembro de 2000. Foram sujeitos do estudo 210 gestantes, com idade gestacional igual ou superior a 37 semanas e 
membranas íntegras, que necessitaram de indução do trabalho de parto, as quais receberam, de acordo com a randomização, $25 \mu \mathrm{g}$ de misoprostol a cada 4 horas até 8 doses (105 mulheres), ou infusão contínua de ocitocina (2-20mU/min; 105 mulheres). As principais variáveis estudadas foram: período de latência, tempo do início da indução até o parto vaginal, tipo de parto, incidência de parto vaginal em 24 horas, alterações da contratilidade uterina, hipóxia e morbidade neonatal e indução do trabalho de parto. Os procedimentos estatísticos utilizados foram: cálculo de médias, desvio-padrão e teste t para as variáveis numéricas contínuas, $\div 2$ para as variáveis categóricas, $\div 2$ trend para as categóricas ordenadas e Mann-Whitnney para as variáveis discretas. Para avaliar período de latência e tempo da indução ao parto vaginal, foi utilizada análise de sobrevivência, pelas tabelas de vida, com a significância estatística avaliada pelo método de Kaplan-Meyer pelo teste de log-rank. O valor de significância estatística adotado foi 5\%. Sobre os resultados do referido estudo, não houve diferença significativa entre os grupos com relação à indicação da indução, idade, escolaridade, cor, paridade, índice de Bishop inicial e peso do recémnascido. O índice de cesárea, o período de latência e o tempo da indução ao parto vaginal foram significativamente menores para o grupo do misoprostol. Com relação às alterações da contratilidade uterina, a taquissistolia foi significativamente mais freqüente no grupo do misoprostol. Entretanto, quanto à hipóxia e morbidade neonatal entre os grupos estudados, não se verificou diferença significativa. Segundo esses autores, o misoprostol em dose apropriada e a intervalos de 4 horas é seguro e eficiente para amadurecimento cervical e indução do trabalho de parto. 
Uma meta-análise, realizada em 1998, conclui que o misoprostol vaginal tem se mostrado um método efetivo em relação ao esvaecimento cervical e o melhor método de indução do trabalho de parto, porém enfatiza a necessidade de estudos complementares (HOFMEYER, 2000).

Agrupando os melhores ensaios clínicos aleatorizados, revisão sistemática da literatura sobre misoprostol vaginal para amadurecimento cervical e indução do trabalho de parto na gravidez de termo, conclui-se que o misoprostol parece ser mais efetivo na indução do trabalho de parto do que os métodos convencionais. Deve-se, entretanto, levar em conta o aparente incremento na hiperestimulação uterina. Porém, os autores chamam a atenção para o fato de que os estudos não têm o tamanho amostral suficiente para concluir sobre os efeitos adversos (HOFMEYER \& GULMEZOGLU, 2000).

Outro aspecto a ser considerado, sobre os estudos realizados, é a inexistência de investigações que avaliem os efeitos do misoprostrol com relação à manifestação da dor pela parturiente, visto que sua ação sobre o músculo liso do colo, estimulando o amadurecimento cervical, poderá intensificar a dor referida pelas parturientes, tendo por base a fisiologia da dor no trabalho de parto. Vale salientar que a literatura científica tem apresentado a distensão, estiramento e talvez a lesão do colo uterino como um dos fatores causais na manifestação da dor no trabalho de parto (REZENDE, 1992; NEME, 2000; MATHIAS \& TORRES, 2000; ABUSHAIKHA, 2005). 


\section{3 - Medidas de avaliação e mensuração da dor}

A avaliação da dor é de importante contribuição à clínica, por facilitar a comunicação entre o paciente e o profissional de saúde e medir o alívio obtido mediante terapias (MELZACK, 1990; PIMENTA E TEIXEIRA, 1997) bem como, na pesquisa, utilizando-se de escalas de avaliação da dor que permitem tratamento estatístico, possibilitando a compreensão da experiência dolorosa e suas repercussões, além de avaliarem a eficácia de proposições de terapias de alívio (TEIXEIRA, 1999). Segundo esses autores, são os objetivos da avaliação da dor que determinam a natureza da escala e o nível de mensuração (atribuição de número e valores aos eventos).

A dor é de difícil mensuração, pelo seu caráter subjetivo, a literatura científica disponibiliza métodos/ instrumentos para mensurar a percepção, a dimensão e a sensação da dor. Há, entretanto, um número limitado de instrumentos validados e fidedignos que mensuram a dor como refere McGuire (1984). O mesmo autor considera como fator limitante à mensuração a existência de multiplicidade de doenças clínicas com diferentes tipos de dor, diversidade de causas e especificidades de características individuais.

Melzack e Wall (1965), a despeito de outros pesquisadores que se preocuparam em explicá-la como objeto de um tráfico codificado no seio de uma rede de ligações nervosas específicas, privada de sentimentos, buscaram compreender o fenômeno da dor em seus três componentes: sensorial, afetivo e cognitivo. 
O componente sensorial refere-se à capacidade que o indivíduo tem de analisar a natureza, localização, intensidade e duração do estímulo doloroso. Ele é transportado pelos cordões laterais da medula.

O componente afetivo faz da dor o antídoto do prazer. Utiliza as regiões medianas do tronco cerebral e do cérebro em conexão com as estruturas límbidas.

O componente cognitivo tem o caráter avaliador da dor. Nele estão contidos os fenômenos de antecipação, atenção, sugestão, memória e experiência anterior. Isto se deve à ação do neocórtex.

Em 1971, Melzack e Torgerson desenvolveram o questionário de avaliação clínica de dor McGill (The McGILL Pain Questionnaire). Este constitui um instrumento que permite a obtenção de dados quantitativos e qualitativos. Foi desenvolvido o questionário, a partir de uma busca, na literatura, de vocábulos que pudessem ajudar o indivíduo a se comunicar sobre o fenômeno da dor. Tudo teve início com uma lista de 102 palavras que traduziam os diferentes aspectos da experiência dolorosa.

Em 1975, Melzack desenvolveu um outro estudo sobre dor, utilizando, para a coleta de dados, o questionário McGill, com um grupo de 297 clientes, com os mais variados tipos de dor e englobando inúmeras situações. Em seguida, foi realizada uma categorização dessas palavras, resultando na formação de três classes principais com 16 subclasses.

A primeira classe foi denominada de sensorial, e se encontra constituída de palavras que descrevem as qualidades sensoriais da experiência em termo de propriedades temporais, espaciais, pressão, térmica e outras. A segunda classe, a afetiva, engloba palavras que descrevem situações afetivas, em termo de tensão, medo e propriedades 
autônomas. A terceira classe foi denominada de avaliativa, sendo composta de palavras que descrevem a intensidade global subjetiva da experiência total da dor.

Cada subclasse consiste de um grupo de palavras consideradas pela maioria dos sujeitos como qualitativas semelhantes. Algumas dessas palavras são tidas como sinônimas; outras parecem ser sinônimas, mas variam de intensidade, enquanto outras fornecem diferenças sutis ou nuances, mas que (apesar de sua similaridade) foram mantidas pela importância dada por cada indivíduo que estava tentando desesperadamente se comunicar.

A segunda parte desse estudo foi uma tentativa para determinar a intensidade da dor implícita nas palavras dentro de cada subclasse. Sendo assim, foi desenvolvido um grupo de estudo em que se atribuiu valor de intensidade a cada palavra, utilizando uma escala numérica de 0 a 5 , variando da menor (ou leve) à pior dor (ou excruciante).

Com a utilização do instrumento, foi surgindo a necessidade do emprego de novas palavras no questionário, pois muitos clientes envolvidos sentiram que palavras-chave estavam ausentes. Assim, quatro subclasses suplementares foram adicionadas às listas preliminares de palavras, e a classificação final, portanto, apresenta-se totalizando 78 descritores, 4 classes principais e 20 subclasses de palavras que descrevem dimensões : sensoriais com as subclasses de $1-10$ (42 descritores); afetivas de $11-15$ (14 descritores); avaliativas a 16 (5 descritores) e miscelâneas de $17-20$ (17 descritores). Esses descritores descrevem qualidades sensoriais da dor de um paciente e das emoções correspondentes (MELZACK; TORGERSON, 1971; WALL; MELZACK, 1990; DIAS, 1996, CARDOSO, 2004) (ANEXO III). 
Melzack (1987) utilizou, no seu trabalho, os descritores de dor da versão reduzida do questionário de dor McGill, os que obtiveram maior atribuição em relação à dor no primeiro estágio do trabalho de parto foram cólica, dolorida e exaustiva, tendo como qualidade sensitiva os dois primeiros descritores, e afetivo o outro.

As medidas multidimensionais da dor propostas por McGuire (1984) incluem a escala de dois componentes: o método de classificação de cartão e o questionário de dor McGill. Para Pimenta (1995), o questionário de dor McGill é o mais utilizado por caracterizar e discernir vários componentes da dor (afetivo, sensitivo e avaliativo), quando se pretende obter informações quantitativas a partir de descrições verbais.

Utilizando de medidas multidimensionais da dor, outros estudos foram desenvolvidos para avaliar os descritores de dor em diferentes situações clínicas, como o de Pereira (2001). Nesse estudo, objetivou-se avaliar 119 descritores contidos no Instrumento de Descritores de Dor (IDD), elaborado por Pereira e Faleiros (1998), com intuito de identificar quais descritores eram os de maior e de menor atribuição relativos à dor pósoperatória. $\mathrm{O}$ estudo foi desenvolvido com enfermeiros com experiência mínima de um ano na assistência a pacientes pós-operados, e obteve-se como resultado os 20 descritores de maior atribuição. Posteriormente, utilizando-se dos 20 descritores, foi solicitado a 61 médicos cirurgiões e anestesiologistas, todos com experiência mínima de um ano com pacientes no período trans e pós-operatório, que apontassem como estes descritores eram considerados em relação às qualidades sensoriais, afetivas e avaliativas da experiência dolorosa. 
Sant'Ana (1999), em seu estudo, adaptou 15 descritores, oriundos da classificação do estudo de Pereira (2001) o qual identificou os seguintes descritores por qualidades: sensorial- fulminante, dilacerante e intensa; como afetiva- aniquiladora, alucinante, enlouquecedora, desumana, desesperadora, terrível, monstruosa e que cega; como avaliativa- colossal, insuportável, brutal e tremenda.

Ferreira (2004) utilizou destes 15 descritores em situação de trabalho de parto, o que se mostrou adequado e efetivo na avaliação da dor no processo de parturição, o que nos levou a utilizar também em nosso estudo, entretanto aplicado de forma diferente, conforme apresentado na metodologia .

Sabe-se que, além das medidas multidimensionais, existem vários instrumentos de avaliação de dor para adultos, tais como: escalas, medidas fisiológicas/ comportamentais (McGILL, 1984). Dentre as escalas, encontram-se a analógica visual (Visual Analogue Scale - VAS), as numéricas, as de categorias de expressões verbais e de representação gráfica não numérica (de face, de copos, com medidor luminoso, dentre outros). De acordo com Pimenta \& Teixeira (1997), esses instrumentos são unidimensionais e não avaliam outras variáveis como padrão cultural, experiências pregressas, significados das situações, personalidade e emoções, dentre outras que modificam a expressão da dor.

A Escala Analógica Visual é a mais utilizada. Esta escala consiste em uma linha que representa uma quantidade contínua de intensidade e dados verbais - nenhuma dor ou dor máxima. A linha é graduada no verso e tem freqüentemente $10 \mathrm{~cm}$. O paciente indica a intensidade de sua dor, posicionando o indicador na linha, exatamente no local em que considera estar a intensidade de sua dor. Segundo Melzack \& Katz (1994), apesar de esta 
escala ter a desvantagem de assumir a dor como uma experiência unidimensional, ela é provida de instruções claras e conceitos simples, sendo facilmente compreendida pelo paciente, o que permite uma administração rápida, com a mínima intervenção.

$\mathrm{Na}$ área de obstetrícia, os instrumentos mais utilizados são: o questionário de dor McGill e a Escala Analógica Visual (MCGUIRE 1984; FRIDH, 1988; WALDENSTRONM, 1996; LUDINGTON, 1998; BROWN, 1989; KLOSTERGAARD, 2001). Vale considerar que a dor no trabalho de parto se caracteriza como dor aguda, e a complexidade da avaliação é menor quando se trata de dor aguda, porque o quadro álgico é recente, bem localizado e a influência dos fatores emocionais e culturais, na maioria das vezes, é de menor magnitude (TEIXEIRA, 1999).

Entretanto, a avaliação da dor constitui um grande desafio para clínicos e pesquisadores, dada sua subjetividade. 
3. Os objetivos 


\subsection{Objetivo Geral}

Avaliar o efeito do misoprostol na manifestação da dor, referida pela parturiente, durante a indução do trabalho de parto (fase latente e início da fase ativa).

\subsubsection{Objetivos Específicos}

\section{* Na primeira fase do estudo (Grupo Misoprostol)}

- Determinar o tempo (em horas) decorrido da aplicação do misoprostol e a primeira manifestação de dor;

- identificar as regiões dolorosas atribuidas pelas parturientes, tendo por base o diagrama do corpo, no momento da primeira manifestação de dor (T0), após decorrido meia hora (T1) e uma hora (T2),

- caracterizar a dor manifestada pelas parturientes por meio de descritores da dor (sensorial, afetivo e avaliativo) no momento da primeira manifestação de dor (T0), após decorrido meia hora (T1) e uma hora (T2),

- Mensurar a intensidade da dor manifestada pelas parturientes (VAS) a cada contração uterina durante uma hora, após a primeira manifestação de dor;

\section{* Na segunda fase do estudo (a partir de $4 \mathrm{~cm}$ de dilatação)}

- Comparar a intensidade da dor (VAS), a caracterização dos descritores da dor e sua topografia em parturientes com evolução espontânea de trabalho de parto e em uso do misoprostol, na primeira hora do início da fase ativa do trabalho de parto, a partir de 4 centímetros de dilatação cervical. 
4.Percurso Metodológico 


\section{1 - Tipo de estudo}

Trata-se de um estudo comparativo e observacional.

\section{2 - Aspectos éticos da pesquisa}

O projeto de pesquisa foi apresentado na reunião administrativa e aprovado pelo Diretor Clínico da Mater - Maternidade do Complexo Aeroporto.

O mesmo foi submetido à apreciação do Comitê de Ética da Escola de Enfermagem de Ribeirão Preto-USP, conforme Protocolo n 0566/ 2005, respeitando a Resolução 196/ 96, sendo aprovado em $1^{\circ}$ de dezembro de 2005 (ANEXO IV).

A coleta de dados iniciou-se somente após a aprovação do referido Comitê de Ética, do esclarecimento geral sobre o estudo (ANEXO XII) e da assinatura do Termo de Consentimento Livre e Esclarecido (ANEXO XI) realizado pelas gestantes/parturientes, ao concordarem em participar do estudo. Aos sujeitos da pesquisa foi dada total liberdade para participar ou não da investigação, assegurando-lhes o direito de retirar-se do estudo em qualquer momento, sem que isto interferisse na assistência prestada a ela e ao recémnascido. Uma cópia foi dada à parturiente e a outra foi mantida com a pesquisadora (ANEXO XI). 


\section{3 - Campo de estudo}

O estudo foi desenvolvido na Maternidade do Complexo Aeroporto (Mater) da cidade de Ribeirão Preto.

É uma instituição filantrópica cujo objetivo social é a atenção à gestante carente, mantendo, para isso, atendimento exclusivo a pacientes oriundas do Sistema Único de Saúde e se adapta às recomendações do modelo de humanização do nascimento e parto.

\section{4 - Amostra}

Os grupos foram formados por indicação clínica, atendendo ao protocolo da instituição para resolução da gravidez, e que atendem aos critérios de inclusão.

A amostra do estudo foi constituída por um total de 40 parturientes, distribuídas, onde 20 fizeram parte do grupo evolução espontânea, que inclui parturientes com início e evolução do trabalho de parto de forma espontânea, ou seja, sem utilização de drogas para indução e/ou condução do trabalho de parto, e outras 20 fizeram parte do grupo de parturientes com indicação médica de indução do trabalho de parto com uso de misoprostol, grupo misoprostol.

Hoje, oficialmente, está autorizado pela Vigilância Sanitária o uso do comprimido do misoprostol na Mater, conforme publicação no Diário Oficial do dia 18 de dezembro de 2003, $\mathrm{n}^{0}$ da inscrição 25257 - UF: SP (ANEXO I). 


\section{5 - Critérios de inclusão}

- Nulíparas

- $\quad$ Maiores de 18 anos de idade

- Alfabetizadas

- $\quad$ Falar e entender a língua portuguesa

- Estar orientada quanto ao tempo e lugar

- $\quad$ Gestação $\geq 37$ semanas

- $\quad$ Bolsa íntegra

- $\quad$ Apresentação cefálica

- $\quad$ No caso do grupo misoprostol: ausência de contrações uterinas na internação

\section{6 - Critérios de exclusão}

- Intercorrências no trabalho de parto, tais como, sofrimento fetal agudo, mecôneo, distócias de trajeto, indicação de cesariana

- $\quad$ Patologias da gestação

- Uso de medicação antes e durante a coleta de dados; com exceção do misoprostol

- Ter sido submetidas à analgesia e a recursos não farmacológicos para o alívio de dor, apenas durante a coleta de dados

- No caso do grupo misoprostol, no momento da internação apresentar contrações uterinas 


\section{7- Instrumentos de coleta de dados}

\subsubsection{I nstrumento de registro de dados}

Foi utilizado, como instrumento de coleta de dados, um formulário que constou de três partes. A primeira parte composta por:

- Dados de identificação: iniciais, endereço, telefone, número do prontuário.

- Variáveis sóciodemográficas: idade, procedência, estado civil, ocupação, grau de escolaridade, raça, vícios.

- Variáveis obstétricas: idade gestacional, paridade, se realizou o pré-natal, local do pré-natal, com quantas semanas de gestação iniciou o pré-natal, quantas consultas realizou no pré-natal, fez curso de gestante, tempo de duração do trabalho de parto do $1^{\circ}$ misoprostol até a primeira manifestação de dor, tempo de duração do trabalho de parto até completar 4 centímetros de dilatação, tempo de duração do trabalho de parto do $1^{\circ}$ misoprostol até o nascimento, Índice de Bishop, dinâmica uterina no início na primeira hora da fase ativa, tipo de parto, uso de analgesia após término do estudo, uso de ocitocina, após o término do estudo, indicação da cesárea, tempo decorrido do início da fase ativa (4 cm de dilatação cervical) até o parto, doses de misoprostol utilizada.

Tais dados foram obtidos por meio do prontuário, do cartão de pré-natal e da própria participante (ANEXO V). 
A segunda parte refere-se aos instrumentos de avaliação da dor: diagrama do corpo, a estimação de categorias e a Escala Analógica Visual (VAS). A aplicação da segunda parte do instrumento é dirigida apenas ao grupo de parturientes submetidas ao misoprostol, o que inclui avaliar a primeira dor e a contração uterina manifestada pelas parturientes, após o uso do misoprostol (especificando horário de início e término do estudo, dilatação cervical no início e término do estudo, no momento da fase latente do trabalho de parto) (ANEXO VI).

A terceira parte do instrumento inclui os mesmos instrumentos de avaliação da dor da segunda parte. Neste momento, quando se completam 4 centímetros de dilatação, registram-se os dados referentes aos dois grupos: misoprostol e com evolução espontânea de trabalho de parto, para fins comparativos sobre a dor e a contração uterina manifestada (ANEXO VI).

\subsubsection{Instrumentos de avaliação da dor}

A dor será avaliada por meio dos instrumentos abaixo relacionados, considerando a especificidade de cada grupo de parturientes (grupo misoprostol e evolução espontânea), para os momentos de aplicação.

- Diagrama do corpo: para identificação das regiões dolorosas em vista anterior e posterior, as gestantes/parturientes foram orientadas a assinalar as regiões do corpo, relacionadas à dor da contração uterina manifestada por ela (Formulário de registro dos dados, ANEXO VI). 
Figura 1. Diagrama do corpo para identificação das regiões dolorosas em vista anterior e posterior

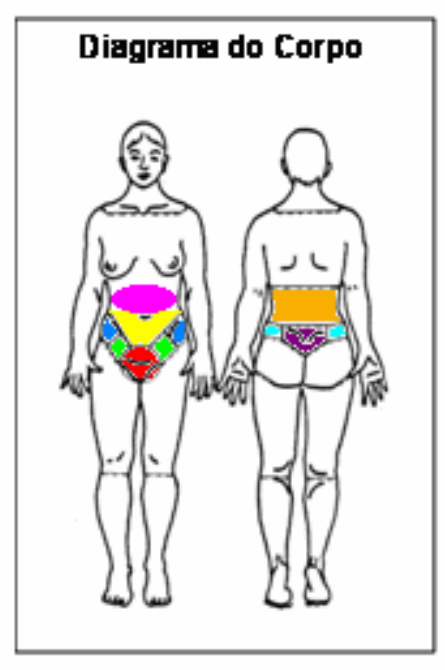

REGIŐES

$\square$ Pubiana
$\square \quad$ Inguinal
$\square$ Quadril anterior
$\square$ Baixo Ventre
$\square$ Abdominal
$\square$ Sacral
$\square$ Quadril posterior
$\square$ Lombar

- Estimação de categorias: foi apresentada às gestantes/parturientes a definição dos 15 descritores de dor (ANEXO VII), e pedido para gestante/parturiente escolher as cinco palavras que melhor definem a dor da contração uterina que está sentindo (Formulário de registro dos dados, ANEXO VI).

- Escala Analógica Visual (VAS): esta foi apresentada, desde a primeira à última dor relativa à contração uterina, referida pela parturiente. Esta escala constitui-se de uma linha de 10 centímetros, não graduada, cujas extremidades correspondem à ausência de dor à pior dor imaginável, sendo, em geral, na extremidade inferior, nas escalas dispostas verticalmente, o ponto de ausência de dor e à esquerda, naquelas escalas dispostas horizontalmente (Formulário de registro dos dados - ANEXO VI). 
A aplicação dos referidos instrumentos junto aos sujeitos do estudo foi apresentada sob forma de um painel ilustrativo medindo $30 \times 20 \mathrm{~cm}$, idealizado pela pesquisadora, para otimizar a aplicação dos mesmos durante a coleta de dados. Tal painel é feito de placa de metal pintada de branco. Neste encontra-se, na face anterior, desenhada a Escala Analógica Visual e o diagrama do corpo (frente e verso). No verso do painel, são colocados os 15 descritores de dor, onde cada descritor está apoiado sobre uma peça de ímã, o que facilita a movimentação dos mesmos sobre o painel. A parturiente pode escolher os cinco descritores que melhor representem a dor manifestada, e posicioná-los no centro do painel.

Figura 2. Painel ilustrativo, apresentado às gestantes/parturientes para a identificação das regiões dolorosas em vista anterior e posterior, a Escala AnalógicaVisual e os descritores de dor

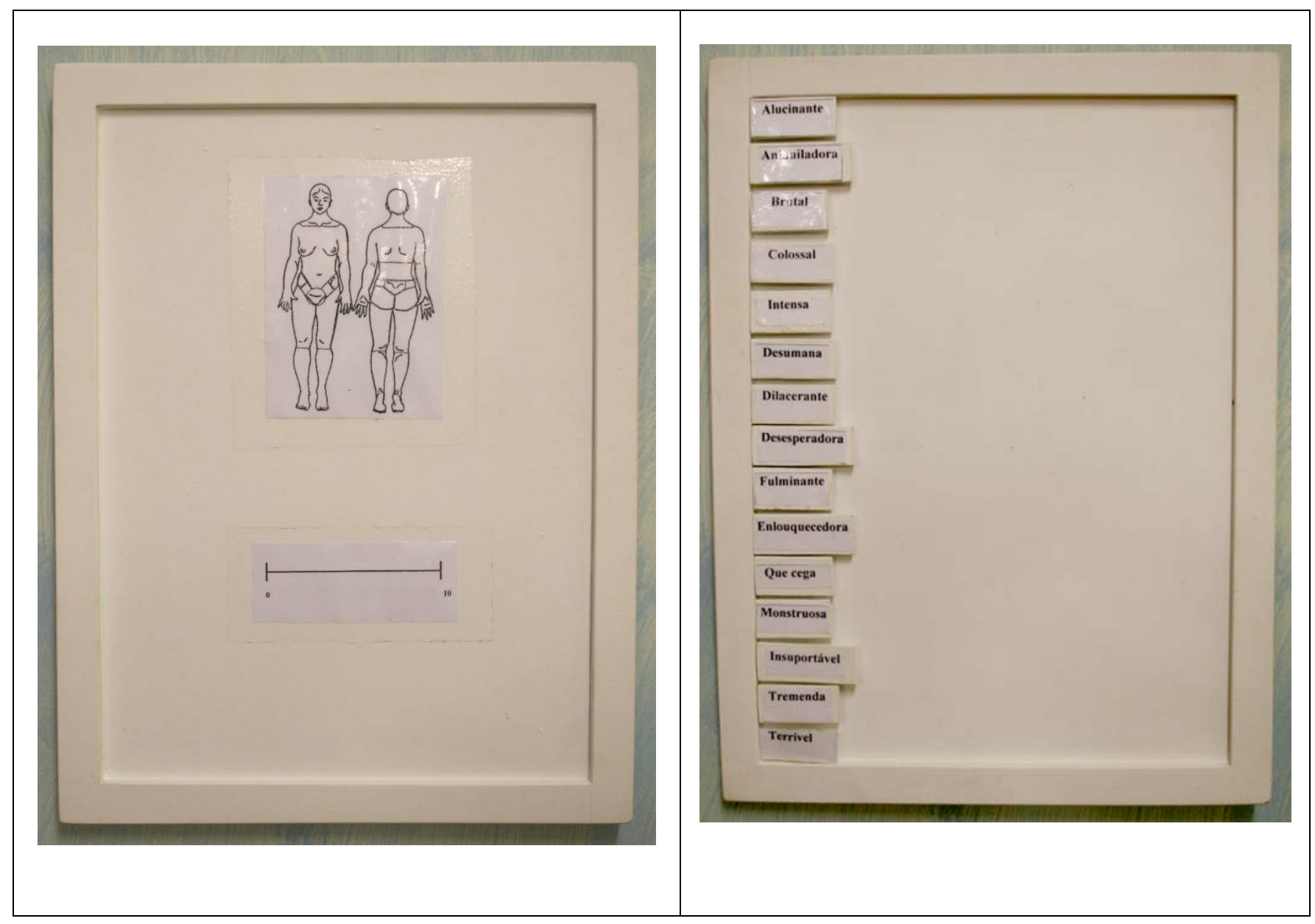




\section{8 - Teste-Piloto:}

Foi realizado teste-piloto em cinco parturientes, para verificar a compreensão das participantes em relação ao instrumento utilizado para coleta de dados.

Nesta fase da pesquisa, identificamos a necessidade de alterar etapas do procedimento de coleta de dados, bem como realizar algumas adequações aos instrumentos.

Houve restrição de tempo de coleta de dados na primeira fase do estudo, onde se previa acompanhar, da primeira dor à contração uterina até chegar à fase ativa, quando se iniciaria a segunda fase do estudo. Tal condição se mostrou inviável em razão de serem contrações bastante irregulares, com grandes períodos de ausência, chegando a durar mais de 12 horas até que completassem os 4 centímetros de dilatação (início da fase ativa).

Em relação à proposta inicial, que era avaliar os descritores de dor em cada contração no período de uma hora, se tornou inviável, por apresentar uma freqüência excessiva de contrações, em um curto espaço de tempo (lembrando que a cada 10 minutos a média de contrações é de 3), o que manifestou nas parturientes desmotivação e até mesmo desconforto em responder ao instrumento. Reduzimos a aplicação de tal instrumento a três momentos: após a primeira dor manifestada, depois de meia hora e uma hora decorrida do início da coleta. Das cinco parturientes que participaram do estudo, uma parturiente recusou dar continuidade na pesquisa e outras três verbalizaram sentir-se incomodadas, quando solicitadas a responder.

Adequação no formulário de registro dos dados relacionados aos instrumentos de avaliação da dor no que se refere à disposição dos itens que contemplam a avaliação da dor, de acordo com cada fase do estudo, pois na primeira versão (ANEXO VIII, IX e X), 
havia dificuldade com as anotações das informações, incorrendo em falhas no preenchimento e compreensão dos dados.

\section{9 - Procedimentos para coleta de dados}

A coleta de dados foi realizada pela pesquisadora.

As gestantes/parturientes admitidas no pré-parto que atenderam aos critérios de inclusão foram selecionadas a participar do grupo evolução espontânea e misoprostol, a depender da indicação clínica no momento da internação (conforme protocolo da instituição). As parturientes incluídas no estudo foram aquelas que aceitaram participar, após terem recebido as orientações gerais sobre o experimento (ANEXO XIIa, b, c, d) e mediante o Termo de Consentimento Livre e Esclarecido (ANEXO XI).

No momento da aceitação por parte dos sujeitos do estudo foram feitos os esclarecimentos sobre sua participação na coleta dos dados, de acordo com o grupo que pertencem (evolução espontânea ou misoprostol) (ANEXO XII).

- Misoprostol (Grupo I): parturientes fora de trabalho de parto (sem contrações uterinas) e que tiveram indicação de indução com uso do misoprostol no momento da internação. Estas participaram da primeira e da segunda fases do estudo.

- Evolução espontânea (Grupo II): parturientes com 4 cm de dilatação e evolução do trabalho de parto espontâneo, sem drogas indutoras/ condutoras/ analgésicas. Estas participaram apenas da segunda fase do estudo, visto que as mesmas não estavam presentes na fase latente do trabalho de parto, pois a indicação de internação é a 
partir do início da fase ativa do trabalho de parto espontâneo (4 centímetros de dilatação de colo, dinâmica uterina de 3 ou mais contrações em 10 minutos).

O estudo foi desenvolvido em duas fases:

\section{PRIMEIRA FASE}

O objetivo desta primeira fase do estudo é descrever como se comporta a manifestação da dor em uma parturiente que recebe o misoprostol, ainda na fase latente do trabalho de parto.

Participaram da coleta apenas as gestantes do grupo misoprostol. Aquelas que chegaram sem dinâmica uterina e tiverem indicação para indução do trabalho de parto com misoprostol, conforme protocolo (índice de Bishop menor que 6), a prescrição e a administração do comprimido de misoprostol $25 \mu \mathrm{g}$, no fórnice vaginal, são realizadas por médicos. As doses podem ser repetidas continuamente em intervalos de 4 horas, conforme protocolo do Departamento de Ginecologia e Obstetrícia da Faculdade de Medicina de Ribeirão Preto-USP, até a obtenção da atividade uterina.

O início da coleta ocorreu por ocasião da primeira dor referida pela parturiente, após a colocação do comprimido do misoprostol no fórnice vaginal, com tempo total de coleta de 1 hora. Realizou-se a avaliação da dilatação do colo uterino pelo toque vaginal, tempo decorrido entre a primeira dose de misoprostol e a primeira manifestação de dor e o total de doses no período.

$\mathrm{Na}$ avaliação da topografia da dor pelo desenho do diagrama do corpo, (ANEXO VI), a gestante/parturiente aponta qual a região do corpo é acometida pela dor durante a 
contração uterina, em três momentos: no início da coleta de dados (T0), decorrido meia hora (T1) e posteriormente 1 hora após o início da coleta de dados (T2) .

Em seguida foi apresentada a definição dos 15 descritores de dor (ANEXO VII), e estes foram expostos no painel ilustrativo (Figura 2), em ordem alfabética, onde a gestante/ parturiente escolhia e ordenava os cinco descritores que melhor definiam a dor da contração uterina que estava sentindo, em três momentos: frente à primeira manifestação de dor (T0), decorrida meia hora (T1) e após uma hora do início do estudo (T2).

A Escala Analógica Visual foi aplicada nas contrações uterinas manifestadas, durante uma hora da coleta de dados.

Para encerrar esta fase do estudo, foi realizado um outro toque vaginal, pela pesquisadora, com o objetivo de avaliar a evolução do trabalho de parto.

\section{SEGUNDA FASE}

O objetivo da segunda fase do estudo foi comparar dois grupos de parturientes: misoprostol (trabalho de parto induzido com misoprostol) - Grupo I e evolução espontânea (trabalho de parto com evolução espontânea) - Grupo II, destacando as diferenças entre si quanto à variável dor a contração uterina (pelo desenho das regiões do corpo que apresentam dor, da caracterização em postos dos descritores de dor e da intensidade de dor pela VAS).

A coleta de dados para ambos os grupos ocorreu no início da fase ativa do trabalho de parto, quando a parturiente completava 4 centímetros de dilatação, utilizando-se dos mesmos instrumentos de avaliação da dor e atendendo ao mesmo padrão de aplicação dos 
instrumentos, conforme a primeira fase, ou seja, a cada dor manifestada pela parturiente foi aplicada a VAS até completar uma hora do início da coleta de dados. Os demais instrumentos (diagrama do corpo para assinalar as regiões da dor e descritores da dor) foram aplicados no início da coleta de dados (T0), decorrida meia hora (T1) e uma hora do início da coleta de dados (T2).

Para encerrar esta fase do estudo, foi realizado um outro toque vaginal, pela pesquisadora, com o objetivo de avaliar a evolução do trabalho de parto.

Em ambas as fases do estudo, a coleta de dados deve atender aos critérios, como segue:

- A aplicação dos instrumentos de avaliação da dor e a mensuração, deve acontecer nos momentos dos intervalos das contrações.

- Se houver qualquer aplicação de recurso farmacológico ou não farmacológico para o alívio de dor durante a coleta de dados, a coleta será interrompida, com exclusão do sujeito da amostra.

- Se durante a coleta dos dados houver indicação de outras drogas como ocitocina, a coleta será interrompida, com exclusão do sujeito da amostra. 


\subsection{0 - Categorização das variáveis}

Na análise descritiva, as seguintes variáveis foram apresentadas:

Variáveis sóciodemográficas: idade, procedência, estado civil, ocupação, grau de escolaridade, raça e vício.

Variáveis obstétricas: idade gestacional, paridade, fez pré-natal, local do prénatal, com quantas semanas de gestação iniciou o pré-natal, quantas consultas realizou no pré-natal, fez curso de gestante, medo durante o trabalho de parto, tempo de duração do trabalho de parto do $1^{\circ}$ misoprostol até a primeira manifestação de dor, tempo de duração do trabalho de parto até completar 4 centímetros de dilatação, tempo de duração do trabalho de parto do $1^{\circ}$ misoprostol até o nascimento, Índice de Bishop, dinâmica uterina no início na primeira hora da fase ativa, tipo de parto, uso de analgesia após término do estudo, uso de ocitocina após o término do estudo, indicação da cesárea, tempo decorrido do início da fase ativa ( $4 \mathrm{~cm}$ de dilatação cervical) até o parto, doses de misoprostol utilizada.

$\mathrm{Na}$ análise comparativa, as seguintes variáveis foram consideradas:

Variável independente: usar ou não misoprostol.

Variáveis dependentes:

. Resposta principal: Intensidade da dor - avaliada por meio da Escala Analógica Visual (VAS).

. Respostas secundárias: descritores de dor, topografia da dor 


\subsection{1 - Tratamento e análise dos dados}

A análise dos dados foi precedida, inicialmente, da construção de um banco de dados, no aplicativo Excel, que foi utilizado tanto para a codificação das variáveis apresentadas anteriormente, em um dicionário de dados, quanto para o procedimento de validação mediante dupla entrada (digitação) de dados.

A análise exploratória e inferencial dos dados se efetivou por meio do programa Statistical Package for Social Scienses (SPSS, versão 10.1).

\section{Análise descritiva}

Inicialmente, foi realizada uma análise descritiva dos dados, permitindo a caracterização sóciodemográfica das parturientes do estudo, cujos dados estão apresentados desta forma:

Para as variáveis numéricas: idade, idade gestacional, dilatação do colo uterino, freqüência das contrações durante o estudo, tempo em horas de trabalho de parto, índice de Bishop, número de comprimidos de misoprostol utilizados, foram calculados: média, mediana, desvio-padrão, mínimo e máximo para indicar a variabilidade das mesmas.

Para as variáveis categóricas: estado civil, ocupação, procedência, escolaridade, cor, doenças durante a gestação, uso de medicamento durante a gestação, apresentava algun vício, local do pré-natal, início do pré-natal, quantas consultas de pré-natal, curso de gestante, uso de analgesia e ocitocina após término do estudo, tipo de parto, indicação do parto cesárea, foram calculados a freqüência absoluta e relativa ou percentual.

Para o diagrama do corpo, foram calculados a freqüência e o percentual. 
Para a estimação em postos (descritores de dor), foram calculados o percentual e freqüência. Como critério de prevalência mantiveram-se os cinco descritores de maior percentual nos três momentos do estudo: no início, meia hora depois e após uma hora.

Para a VAS, foram calculados a média aritmética, a mediana, o desvio-padrão, o mínimo e o máximo.

\section{Análise comparativa}

Para a análise das variáveis, foram utilizados os seguintes testes:

\section{. Variáveis numéricas:}

Para comparar o tempo de trabalho de parto a partir de 4 centímetros de dilatação, a freqüência das contrações, e a evolução da dilatação cervical a partir dos $4 \mathrm{~cm}$ de dilatação, foi utilizado teste Mann-Whitney.

. Variáveis categóricas:

Para comparar a indicação de ocitocina, analgesia e parto cesárea, foi utilizado o teste Quiquadrado.

Para o diagrama do corpo, foi utilizado o teste Quiquadrado.

Para VAS, na primeira fase do estudo, foi utilizado o teste Wilcoxon, para comparar a intensidade da dor do início da coleta de dados ao final.

Para a VAS, na segunda fase do estudo, foi realizada a análise dos escores de dor, do início ao fim do estudo (1 hora), entre os grupos, empregou-se uma análise de Variância (ANOVA) com medidas repetidas, considerando os seguintes fatores: a) tratamento (between-subject factor), isto é, análise entre os grupos; 
b) tempo (within-subject factor) designa o fator intragrupo, a medida repetida propriamente dita, que, neste caso, foram os escores de dor em dois tempos distintos.

Na comparação da VAS e o número de contrações, foi utilizado o teste MannWhitney.

Em todos os testes estatísticos, o nível de significância adotado foi $\alpha=0,05$. Quando o $\mathrm{p}<0,05$, foi considerado estatisticamente significante.

\subsection{2 - Dificuldades metodológicas}

- Limitações na composição da amostra: por ser este estudo comparativo e observacional, a composição da amostra dos sujeitos para o grupo evolução espontânea e misoprostol deve respeitar critérios preestabelecidos, nem sempre presentes no campo de investigação. Para tal condição, foi necessário um tempo maior de coleta de dados, para não comprometer metodologicamente o estudo.

- Aumento de internação de adolescentes, visto que a Mater tem sido reconhecida como serviço de referência ao atendimento desta clientela e em nossos critérios de inclusão somente participam as parturientes acima de 18 anos.

- Redução da demanda de indicação de uso do misoprostol devido a mudanças no protocolo da instituição. No novo protocolo, somente são internadas para indução as gestantes a partir de 42 semanas de gestação que não entraram em trabalho de parto, sendo que anteriormente a intervenção ocorria com 41 semanas completas de gestação. A extensão do prazo tem possibilitado um maior tempo para que o trabalho de parto evolua espontanemente, portanto diminuindo o número de indicações para a indução com misoprostol, e a maioria das internações nesta 
semana, das 41 para as 42 semanas, era por apresentarem ruptura da bolsa das águas (ANEXO XIII).

- Exclusão de sujeitos do estudo, no decorrer da coleta de dados: por introdução de outras drogas (ocitocina), indicação de analgesia, por ruptura espontânea da bolsa e/ ou indicação de cesárea antes dos 4 centímetros de dilatação.

- Exclusão das parturientes que, ao apresentar ruptura artificial ou espontânea da bolsa das águas, apresentaram líquido amniótico meconeal durante qualquer momento do trabalho de parto.

- Este estudo foi realizado durante uma hora (duas horas) de todo o trabalho de parto. Não foi viável neste momento uma investigação mais apurada por mais tempo, englobando todas as fases do trabalho de parto, portanto deixamos como sugestão para uma próxima pesquisa.

- Os descritores utilizados na primeira fase do estudo, fase latente, deveriam ter sido os de menor atribuição à dor, visto que a grande maioria não indicou nenhum descritor que definisse a dor que estava sentindo.

- A colocação do comprimido de misoprostol no fórnice vaginal nem sempre foi realizado pela mesma pessoa. Lembrando que a maternidade de estudo é uma matenidade-escola, onde temos atuando no pré-parto acadêmicos do $5^{\circ}$ e do $6^{\circ}$ anos de medicina, residentes da Ginecologia-Obstetrícia do $1^{\circ}$ e $2^{\circ}$ anos, enfermeiras residentes do $1^{\circ}$ e $2^{\circ}$ anos e enfermeiras obstétricas. 


\section{Resultados}




\subsection{Caracterização dos grupos estudados em relação às variáveis sociodemográficas}

A idade média das 20 gestantes/parturientes do grupo I (misoprostol) foi de 23,4 anos; mediana de 23 e desvio-padrão de 2,48 anos. A idade deste grupo variou de 20 a 28 anos. Quanto as 20 parturientes do grupo II (evolução espontânea), a média foi de 22,15 anos; 21 de mediana e desvio-padrão de 3,6 anos e variou de 19 a 30 anos.

Quadro 2 - Freqüência $(F)$ e percentual $(P)$ das variáveis sócio-demográficas dos grupos de parturientes estudadas. Ribeirão Preto, 2006

\begin{tabular}{|c|c|c|c|c|}
\hline \multirow{2}{*}{$\begin{array}{l}\text { Variáveis Sócio- } \\
\text { demográficas }\end{array}$} & \multicolumn{2}{|c|}{ Grupo I } & \multicolumn{2}{|c|}{ Grupo II } \\
\hline & $\mathbf{F}$ & $\mathbf{P}$ & $\mathbf{F}$ & $\mathbf{P}$ \\
\hline Estado conjugal & & & & \\
\hline Solteira & 1 & $5 \%$ & 8 & $40 \%$ \\
\hline Casada & 9 & $45 \%$ & 5 & $25 \%$ \\
\hline União consensual & 10 & $50 \%$ & 6 & $30 \%$ \\
\hline Separada & - & - & 1 & $5 \%$ \\
\hline Procedência & & & & \\
\hline Ribeirão Preto & 15 & $75 \%$ & 13 & $65 \%$ \\
\hline Região de Ribeirão Preto & 5 & $25 \%$ & 7 & $35 \%$ \\
\hline Cor & & & & \\
\hline Branca & 10 & $50 \%$ & 14 & $70 \%$ \\
\hline Preta & 6 & $30 \%$ & 5 & $25 \%$ \\
\hline Parda & 3 & $15 \%$ & 1 & $5 \%$ \\
\hline Amarela & 1 & $5 \%$ & - & - \\
\hline Ocupação & & & & \\
\hline Remunerada & 8 & $40 \%$ & 8 & $40 \%$ \\
\hline Não remunerada & 12 & $60 \%$ & 12 & $60 \%$ \\
\hline Vício & & & & \\
\hline Tabagista & 2 & $10 \%$ & 3 & $15 \%$ \\
\hline Etilista & - & - & 5 & $25 \%$ \\
\hline Usuária de drogas & - & - & 1 & $5 \%$ \\
\hline Não apresentavam vícios & 18 & $90 \%$ & 15 & $75 \%$ \\
\hline Nível de escolaridade & & & & \\
\hline Ensino médio incompleto & 6 & $30 \%$ & 5 & $25 \%$ \\
\hline Ensino médio completo & 10 & $50 \%$ & 9 & $45 \%$ \\
\hline Ensino fundamental incom. & 3 & $15 \%$ & 4 & $20 \%$ \\
\hline Ensino fundamental compl. & - & - & 2 & $10 \%$ \\
\hline Superior incompleto & - & - & - & - \\
\hline Superior completo & 1 & $5 \%$ & - & - \\
\hline
\end{tabular}




\subsection{Caracterização dos grupos estudados com relação às variáveis obstétricas}

As 40 parturientes participantes do estudo eram nulíparas, sendo uma delas secundigesta com um aborto anterior, pertencente ao grupo II.

A idade gestacional média no grupo I (misoprostol) foi de 41,05 semanas, com desvio-padrão de 0,68, mediana de 41, idade gestacional mínima de 40 e máxima de 42; no grupo II (evolução espontânea), média de 39,15 semanas com desvio-padrão de 1,13, mediana de 40, idade mínima de 37 e máxima de 40.

Quadro 3 - Freqüência (F) e percentual $(P)$ das variáveis obstétricas dos grupos de parturientes estudadas. Ribeirão Preto, 2006

\begin{tabular}{|c|c|c|c|c|}
\hline \multirow{2}{*}{ Variáveis Obstétricas } & \multicolumn{2}{|c|}{ Grupo I } & \multicolumn{2}{|c|}{ Grupo II } \\
\hline & $\mathbf{F}$ & $\mathbf{P}$ & $\mathbf{F}$ & $\mathbf{P}$ \\
\hline Local do Pré Natal & & & & \\
\hline Ribeirão Preto & 15 & $75 \%$ & 12 & $60 \%$ \\
\hline Região & 5 & $25 \%$ & 7 & $35 \%$ \\
\hline Outro estado & - & - & 1 & $5 \%$ \\
\hline Início do Pré Natal & & & & \\
\hline $1^{0}$ trimestre de gestação & 13 & $65 \%$ & 10 & $50 \%$ \\
\hline $2^{\circ}$ trimestre de gestação & 7 & $35 \%$ & 9 & $45 \%$ \\
\hline $3^{\circ}$ trimestre de gestação & - & - & 1 & $5 \%$ \\
\hline Número consultas Pré Natal & & & & \\
\hline Até 5 consultas & 1 & $5 \%$ & 1 & $5 \%$ \\
\hline Mais de 6 consultas & 19 & $95 \%$ & 19 & $95 \%$ \\
\hline Atividade educativa relaciona & & & & \\
\hline $\begin{array}{c}\text { da ao preparo para o parto } \\
\text { Participaram }\end{array}$ & 3 & $15 \%$ & 4 & $20 \%$ \\
\hline Não participaram & 17 & $85 \%$ & 16 & $80 \%$ \\
\hline Uso de medicação - Pré Natal & & & & \\
\hline Não fizeram uso & 12 & $60 \%$ & 9 & $45 \%$ \\
\hline Multivitamínicos & 8 & $40 \%$ & 10 & $50 \%$ \\
\hline Analgésicos & - & - & 1 & $5 \%$ \\
\hline Tipo de parto & & & & \\
\hline Parto Normal & 10 & $50 \%$ & 16 & $80 \%$ \\
\hline Parto Cesárea & 10 & $50 \%$ & 4 & $20 \%$ \\
\hline Parto Fórceps & - & - & - & - \\
\hline
\end{tabular}




\subsection{Avaliação da dor das contrações uterinas manifestadas pelas parturientes durante o trabalho de parto para os grupos estudados}

\section{PRIMEIRA FASE DO ESTUDO}

Para indicação do uso do comprimido de misoprostol, conforme protocolo da instituição, leva-se em consideração o índice de Bishop menor que 6. O menor índice indicado foi de 2 e o maior 4, média de 2,4 com desvio-padrão de 0,68 e mediana de 2 .

O tempo decorrido em horas entre a primeira dose de misoprostol e a primeira queixa de dor foi em média de 2,4, mediana de 2,5 e desvio-padrão de 1,43. Tempo mínimo de 1 hora e máximo de 6 horas.

A medicação foi utilizada em doses individuais, a depender da resposta uterina, sendo que a média de comprimidos aplicados intravaginal até a primeira manifestação de dor foi de 1,05 com desvio-padrão de 0,22 e mediana de 1 , com o número mínimo de comprimidos indicados foi de 1 e o máximo de 2 .

A dilatação média do colo uterino das parturientes, no momento da internação à primeira manifestação de dor e à contração uterina após a administração do comprimido de misoprostol, início da primeira fase, foi de 0,55 centímetros, mediana de $0,5 \mathrm{~cm}$ e com desvio-padrão de $0,6 \mathrm{~cm}$. Após 1 hora do início da coleta, a dilatação média do colo uterino foi de $1,05 \mathrm{~cm}$, mediana de $1 \mathrm{~cm}$ e o desvio-padrão de $0,6 \mathrm{~cm}$. A dilatação máxima foi de $2 \mathrm{~cm}$ e a mínima foi colo impérvio.

A avaliação da dor às contrações uterinas manifestadas pelas 20 parturientes do grupo I está abaixo descrita com base nos instrumentos utilizados para avaliar a dor. 


\section{Avaliação da topografia da dor}

Para avaliação da dor, segundo a topografia das regiões do corpo, utilizamos os dois diagramas corporais (vista anterior e posterior), apresentados às parturientes em três momentos no período de 1 hora de coleta de dados, ou seja: no início, quando houve a primeira manifestação de dor à contração uterina (T0), meia hora depois (T1) e ao completar uma hora (T2), após a primeira manifestação de dor.

Na tabela 1, estão apresentados a freqüência e o percentual de indicação pelas parturientes das regiões do corpo em que foi localizada a dor, durante a fase latente do trabalho de parto.

Tabela 1 - Freqüência (F) e Percentual $(P)$ da manifestação de dor, do grupo I (misoprostol), segundo a topografia das regiões do corpo nos três momentos da coleta de dados, na fase latente do trabalho de parto. Ribeirão Preto, 2006

\begin{tabular}{|c|c|c|c|c|c|c|}
\hline \multirow{3}{*}{$\begin{array}{l}\text { Regiões do } \\
\text { corpo }\end{array}$} & \multicolumn{6}{|c|}{ Momentos da coleta de dados } \\
\hline & \multicolumn{2}{|c|}{ T0 } & \multicolumn{2}{|c|}{ T1 } & \multicolumn{2}{|c|}{ T2 } \\
\hline & $\mathbf{F}$ & $\mathbf{P}$ & $\mathbf{F}$ & $\mathbf{P}$ & $\mathbf{F}$ & $\mathbf{P}$ \\
\hline 1. pubiana & 19 & $95 \%$ & 20 & $100 \%$ & 20 & $100 \%$ \\
\hline 2. inguinal & 1 & $5 \%$ & 3 & $15 \%$ & 5 & $25 \%$ \\
\hline 3. quadril ant. & - & - & - & - & 2 & $10 \%$ \\
\hline 4.baixo ventre & 1 & $5 \%$ & 1 & $5 \%$ & 1 & $5 \%$ \\
\hline 5. abdominal & - & - & - & - & - & - \\
\hline 6. lombar & - & - & - & - & - & - \\
\hline 7. sacral & 5 & $25 \%$ & 5 & $25 \%$ & 10 & $50 \%$ \\
\hline 8.quadril post. & - & - & - & - & - & - \\
\hline
\end{tabular}




\section{Avaliação dos descritores de dor}

Dentre as medidas multidimensionais da dor, buscou-se caracterizar e discernir vários componentes da dor (afetivo, sensitivo e avaliativo), a partir de descritores da dor. Utilizamos de 15 descritores da dor proposto por Pereira, Giuntini, Sant'Ana \& FaleirosSousa (2001) que são palavras apresentadas às parturientes de modo que estas selecionem cinco palavras que melhor definam a dor manifesta, colocando-as em postos/ordem. A avaliação dos descritores foi realizada nos três momentos já considerados durante a coleta de dados.

No quadro 4, estão indicados os cinco descritores que melhor definem a dor para cada momento da coleta, bem como a ordenação de posição de atribuições julgadas a cada descritor.

Quadro 4 - Freqüência $(F)$, percentual $(P)$ e ordenação em postos $(O P)$ dos cinco descritores de dor, do grupo I (misoprostol), ordenados pelas parturientes na fase latente do trabalho de parto. Ribeirão Preto, 2006

\begin{tabular}{|c|c|c|c|c|c|c|c|c|}
\hline \multicolumn{9}{|c|}{ Momentos da coleta de dados } \\
\hline \multicolumn{3}{|c|}{ TO } & \multicolumn{3}{|c|}{ T1 } & \multicolumn{3}{|c|}{ T2 } \\
\hline OP & $\mathbf{F}$ & $\mathbf{P}$ & OP & $\mathbf{F}$ & $\mathbf{P}$ & OP & $\mathbf{F}$ & $\mathbf{P}$ \\
\hline 1.Intensa & 1 & $5 \%$ & Intensa & 1 & $5 \%$ & Brutal & 3 & $15 \%$ \\
\hline 2.Terrível & 1 & $5 \%$ & Terrível & 1 & $5 \%$ & Intensa & 3 & $15 \%$ \\
\hline 3.Tremenda & 1 & $5 \%$ & Tremenda & 1 & $5 \%$ & Desumana & 2 & $10 \%$ \\
\hline$\star \star *$ & - & - & ** & - & - & Alucinante* $^{*}$ & 1 & $5 \%$ \\
\hline ** & - & - & ** & - & - & Terrível* & 1 & $5 \%$ \\
\hline & & & & & & Tremenda* & 1 & $5 \%$ \\
\hline
\end{tabular}

* Houve indicação de seis descritores, ao completar uma hora, visto que a freqüência e o percentual são os mesmos. ** Não houve indicação de descritores pelas parturientes. 


\section{Avaliação da intensidade da dor por meio da VAS}

$\mathrm{Na}$ avaliação da intensidade da dor manifestada pelas parturientes a cada contração uterina por meio da VAS, consideramos, conforme apresentado no quadro 5, as médias aritméticas (MA), mediana (M), desvio-padrão (DP), mínimo (Mi) e máximo (Má) referente a dois momentos: as queixas de dor às contrações uterinas, ocorridas na primeira meia hora (T1) e para as queixas de dor às contrações uterinas no final de uma hora (T2) de coleta de dados.

Quadro 5 - Média aritmética (MA), mediana (M), desvio-padrão (DP), mínimo (Mi) e máximo (Má) da intensidade da dor manifestada pela parturiente, por meio da VAS, na primeira meia hora (T1) e no término da coleta de dados (T2), na primeira fase do estudo, Ribeirão Preto, 2006

\begin{tabular}{|l|c|c|}
\hline \multirow{2}{*}{$\begin{array}{c}\text { Intensidade } \\
\text { de dor -VAS }\end{array}$} & T1 & T2 \\
\cline { 2 - 3 } & 2,06 & 2,56 \\
\hline Média & 2 & 2,16 \\
\hline Mediana & 0,95 & 1,31 \\
\hline Desvio-padrão & 1 & 1 \\
\hline Mínimo & 3,89 & 6 \\
\hline Máximo & & \\
\hline
\end{tabular}




\section{SEGUNDA FASE DO ESTUDO}

A segunda fase do estudo iniciou quando as parturientes de ambos os grupos (misoprostol e evolução espontânea) atingiram 4 centímetros de dilatação do colo uterino, portanto no início da fase ativa do trabalho de parto. Nesta fase, utilizamos os mesmos procedimentos e instrumentos de avaliação de dor aplicados na primeira fase do estudo.

Descrevemos, inicialmente, algumas variáveis obstétricas utilizadas como parâmetro de avaliação da evolução do trabalho de parto, tais como: freqüência das contrações uterinas; dilatação do colo uterino; duração do trabalho de parto em horas (do início da fase ativa do trabalho de parto ao parto); indicação de ocitocina e analgesia, após final da coleta de dados; resolução do parto (tipo de parto/indicação cesariana para cada grupo estudado).

A média da freqüência das contrações uterinas na primeira meia hora da coleta de dados foi de 9,65, mediana de 9 e desvio-padrão de 2,54 para o grupo I (misoprostol) e média de 10,7, mediana de 12 e desvio-padrão de 2,2 para o grupo II (evolução espontânea). O mínimo de contrações durante a dinâmica uterina foi de 2, e o máximo foi de 5 para ambos os grupos.

Do final da primeira meia hora até completar uma hora, da coleta de dados, verificamos que a média da freqüência de contrações foi de 9,95 , mediana de 9 e desviopadrão de 2,1 para o grupo I (misoprostol) e média de freqüência de contrações de 10,9, mediana de 12 e desvio-padrão de 2,07 para o grupo II (evolução espontânea).

$\mathrm{Na}$ análise comparativa dos dois grupos estudados, com relação à freqüência das contrações, pelo teste Mann-Whitney, o grupo I (misoprostol) apresentou posto médio de 19,52 e o grupo II (evolução espontânea) posto médio de 21,48, para tanto, verificamos que 
não houve diferença estatisticamente significante entre os grupos na primeira meia hora ( $p$ de 0,602), ou seja, apesar de o número de contrações nos primeiros trinta minutos da coleta de dados ser um pouco maior no grupo II (evolução espontânea), este número não é significativo. Ao completar uma hora da coleta de dados, o grupo I (misoprostol) apresentou posto médio de 16,33 e o grupo II (evolução espontânea) posto médio de 24,68. Neste caso, o teste foi estatisticamente significante $(p 0,023)$, ou seja, o grupo II (evolução espontânea) apresentou uma maior freqüência de contrações uterinas do que o grupo I (misoprostol).

Avaliando a evolução da dilatação cervical, em centímetros, no decorrer de uma hora de coleta de dados, considerando que a dilatação inicial no início da coleta foi de $4 \mathrm{~cm}$ para ambos os grupos, segundo critério de inclusão no estudo (segunda fase), verificamos que: no grupo I (misoprostol), a média foi de 1,3, mediana de 1 e desvio-padrão de 1,42, o mínimo foi não apresentar evolução da dilatação nesta uma hora, e o máximo alcançado neste grupo foi de 5 centímetros de dilatação. Para o grupo II (evolução espontânea), a média da dilatação foi de 1,65, mediana de 1, desvio-padrão de 1,66, mínimo de zero (não evolução da dilatação) e máximo de 6. Considerando a distribuição dos valores apresentados para esta variável em cada grupo estudado, no período de uma hora, não houve diferença significativa entre os grupos ( $p$ 0,53), conforme teste Mann Withney.

A média do tempo em horas de trabalho de parto, do início da fase ativa (4 centímetros de dilatação cervical) até o parto, para o grupo I (misoprostol) foi de 5,9 horas, mediana de 5 e desvio-padrão de 4,2. Para o grupo II (evolução espontânea), a média foi de 5,6 horas, mediana de 6 e desvio-padrão 2,6. O tempo mínimo e máximo para o grupo I foi de 1 hora e 17 horas, respectivamente, enquanto para o grupo II foi de 1 hora e 10 horas, respectivamente. Apesar de se observar uma tendência do grupo I (misoprostol) apresentar 
uma maior duração de tempo de trabalho de parto (do início fase ativa ao parto) do que o grupo II (evolução espontânea), aplicando-se o teste Mann Whitney, não se apresentou diferença significativa $(p=0,713)$.

Corroborando com a análise da evolução do trabalho de parto para cada grupo estudado, analisamos as variáveis: indicação de ocitocina e analgesia após o término da coleta de dados até a ocorrência do parto, bem como o tipo de parto ocorrido e as razões das indicações de cesariana.

A indicação de ocitocina, a partir do término da coleta de dados, foi de $35 \%$ (7) para o grupo I (misoprostol) e 100\% (20) para o grupo II (evolução espontânea). Para comparar os grupos, foi utilizado o teste Qui-Quadrado, com $\alpha=0,05$ de significância, onde houve diferença estatisticamente significante entre os grupos $(p 0,000)$, ou seja, o número de parturientes do grupo II (evolução espontânea) recebeu maior indicação de ocitocina que o grupo I (misoprostol).

Com relação a indicação analgésica, todas as parturientes de ambos os grupos receberam analgesia. O tipo de analgesia por grupo ficou assim distribuído: no grupo I, $55 \%$ (11) peridural e $45 \%$ (9) raqui, enquanto no grupo II, $85 \%$ (17) receberam peridural e 15\% (3) raqui. Com relação a raqui no grupo I, duas delas $10 \%$ receberam indicação da anestesia ao ser indicado parto cesárea. Foi utilizado o teste Qui-Quadrado, com $\alpha=0,05$ de significância, para comparar os grupos em relação a indicação da analgesia, onde houve diferença estatisticamente significante ( $p$ 0,038). Portanto, no grupo II (evolução espontânea) apresentou um número maior de indicações da anestesia peridural, comparado com o grupo I (misoprostol). Quando se fala em anestesia raqui o grupo I (misoprostol), apresentou uma indicação maior que o grupo II (evolução espontânea). 
A média de comprimidos de misoprostol, utilizados durante todo o trabalho de parto, foi de 3,45; mediana de 3, desvio-padrão de 1,27, mínimo de comprimidos administrados foi 2 e máximo de 7.

A média de comprimidos de misoprostol utilizada pelas parturientes que realizaram parto normal foi de 2,9, com mediana de 3 e desvio-padrão de 0,87. O mínimo de comprimidos utilizados foi de 2 e o máximo de 4. Para aquelas que realizaram o parto cesárea, obtiveram uma média de 4 comprimidos, mediana de 4, desvio-padrão de 1,41; mínimo de 2 e máximo de 7 comprimidos.

Figura 3 - Número de comprimidos de misoprostol utilizados durante todo o trabalho de parto e o tipo de parto, na segunda fase do estudo. Ribeirão Preto, 2006

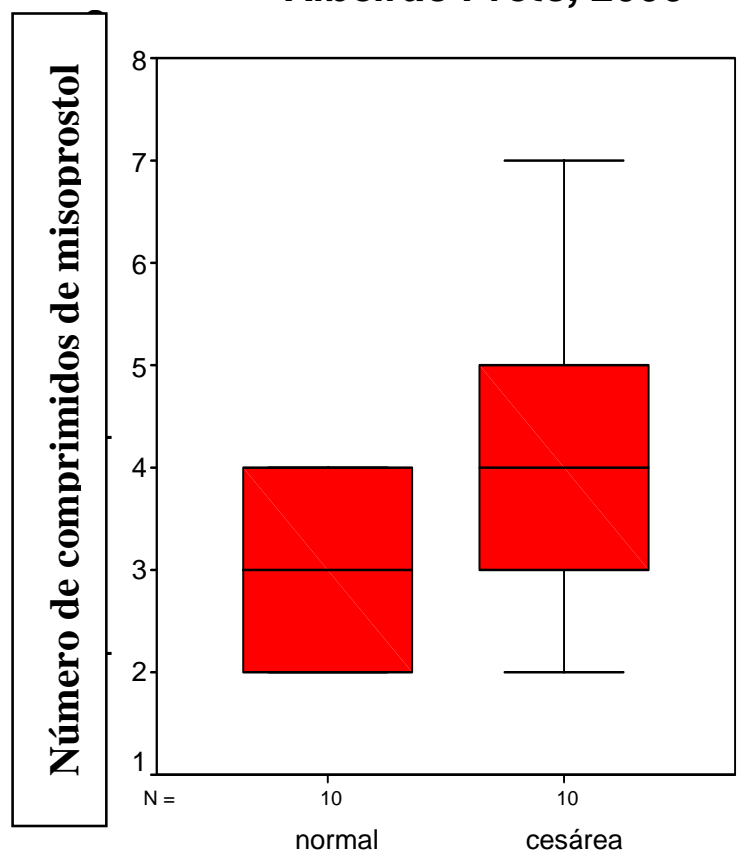

Tipo de Parto

Quanto ao tipo de parto, verificamos que entre as parturientes do grupo I (misoprostol) que foram submetidas ao parto cesariana e ao parto normal, obtiveram o mesmo percentual, ou seja, 50\% (10) de cada. O grupo II (evolução espontânea) obteve 
para a maioria das parturientes $80 \%$ (16) de parto normal e $20 \%(4)$ de parto cesariana. Para comparar os grupos e a ocorrência de parto cesárea, foi realizado o teste Qui-Quadrado, onde houve diferença estatisticamente significante ( $p$ 0,047), portanto o grupo I (misoprostol) apresentou uma maior indicação de cesáreas que o grupo II (evolução espontânea).

Dentre as parturientes que receberam o misoprostol, 6 parturientes do grupo I (misoprostol) foram excluidas do estudo, devido a indicação de cesárea, antes de completar 4 centímetros de dilatação, ou seja, participaram apenas da primeira fase da coleta de dados. Tal informação nos possibilita observar que entre as parturientes que usaram o misoprostrol no trabalho de parto, o número de cesarianas é ainda maior do que foi considerado, com base nos resultados apresentados.

Analisando as razões da indicação da cesariana para cada um dos grupos estudados, verificamos que: no grupo I (misoprostol), 35\% (7) foram por falha de indução, 10\% (2) por sofrimento fetal e 5\% (1) por desproporção céfalo-pélvica enquanto no grupo II (evolução espontânea) foi de 10\% (2) por sofrimento fetal, 5\% (1) por desproporção céfalopélvica e 5\% (1) por parada secundária da dilatação.

Para avaliação da dor às contrações uterinas manifestadas pelas parturientes dos dois grupos: grupo I (misoprostol) e grupo II (evolução espontânea) foram utilizados os mesmos instrumentos de avaliação da dor e procedimentos de coleta de dados da primeira fase. 


\section{Avaliação da topografia da dor}

A topografia da dor foi avaliada, através de dois diagramas corporais (vista anterior e posterior), em três momentos: no início do estudo (T0), meia hora depois (T1) e ao completar uma hora (T2), conforme Tabela 2.

Tabela 2 - Freqüência (F) e Percentual $(P)$ da manifestação de dor, segundo a topografia das regiões do corpo nos três momentos da coleta de dados, na fase ativa do trabalho de parto. Ribeirão Preto, 2006

\begin{tabular}{|c|c|c|c|c|c|c|c|c|c|c|c|c|}
\hline \multirow{4}{*}{$\begin{array}{l}\text { Regiões } \\
\text { do corpo }\end{array}$} & \multicolumn{12}{|c|}{ Momentos da coleta de dados } \\
\hline & \multicolumn{4}{|c|}{ TO } & \multicolumn{4}{|c|}{ T1 } & \multicolumn{4}{|c|}{ T2 } \\
\hline & \multicolumn{2}{|c|}{ Grupo I } & \multicolumn{2}{|c|}{ Grupo II } & \multicolumn{2}{|c|}{ Grupo I } & \multicolumn{2}{|c|}{ Grupo II } & \multicolumn{2}{|c|}{ Grupo I } & \multicolumn{2}{|c|}{ Grupo II } \\
\hline & $F$ & $\mathbf{P}$ & $F$ & $\mathbf{P}$ & $F$ & $\mathbf{P}$ & $F$ & $\mathbf{P}$ & $F$ & $\mathbf{P}$ & $F$ & $\mathbf{P}$ \\
\hline 1.pubiana & 12 & $60 \%$ & 18 & $90 \%$ & 17 & $85 \%$ & 20 & $100 \%$ & 18 & $90 \%$ & 20 & $100 \%$ \\
\hline 2. inguinal & 6 & $30 \%$ & 6 & $30 \%$ & 12 & $60 \%$ & 15 & $75 \%$ & 16 & $80 \%$ & 16 & $80 \%$ \\
\hline $\begin{array}{l}\text { 3.quadril } \\
\text { ant. }\end{array}$ & 1 & $5 \%$ & 4 & $20 \%$ & 2 & $10 \%$ & 6 & $30 \%$ & 4 & $20 \%$ & 15 & $75 \%$ \\
\hline $\begin{array}{l}\text { 4.baixo } \\
\text { ventre }\end{array}$ & 0 & $0 \%$ & 2 & $10 \%$ & 0 & $0 \%$ & 2 & $10 \%$ & 1 & $5 \%$ & 4 & $20 \%$ \\
\hline 5.abdomin & 0 & $0 \%$ & 1 & $5 \%$ & 0 & $0 \%$ & 0 & $0 \%$ & 0 & $0 \%$ & 0 & $0 \%$ \\
\hline 6. Iombar & 15 & $75 \%$ & 0 & $0 \%$ & 18 & $90 \%$ & 0 & $0 \%$ & 19 & $95 \%$ & 1 & $5 \%$ \\
\hline 7. sacral & 7 & $35 \%$ & 19 & $95 \%$ & 14 & $70 \%$ & 20 & $100 \%$ & 16 & $80 \%$ & 20 & $100 \%$ \\
\hline $\begin{array}{l}\text { 8.quadril } \\
\text { post. }\end{array}$ & 0 & $0 \%$ & 5 & $25 \%$ & 0 & $0 \%$ & 9 & $45 \%$ & 0 & $0 \%$ & 16 & $80 \%$ \\
\hline
\end{tabular}




\section{Avaliação dos descritores de dor}

Considerando a avaliação da dor, segundo os descritores, os Quadros 6, 7 e 8, indicam os cinco descritores selecionados pelas parturientes em cada momento da coleta e posição atribuída a cada descritor por grupo estudado.

Quadro 6 - Freqüência (F), percentual $(P)$ e ordenação em postos (OP) dos cinco descritores de dor, ordenados pelas parturientes, no início da coleta de dados (T0). Ribeirão Preto, 2006

\begin{tabular}{|c|c|c|c|c|c|c|c|c|}
\hline \multirow{3}{*}{ Descritores de dor } & \multicolumn{8}{|c|}{ T0 } \\
\hline & \multicolumn{3}{|c|}{ Grupo I } & \multicolumn{3}{|c|}{ Grupo II } & \multicolumn{2}{|c|}{ Total } \\
\hline & $F$ & $\mathbf{P}$ & OP & $F$ & $\mathbf{P}$ & OP & $F$ & $\mathbf{P}$ \\
\hline Alucinante & 4 & $20 \%$ & $10^{\mathrm{a}}$ & 5 & $25 \%$ & $7^{\mathrm{a}}$ & 9 & $22,5 \%$ \\
\hline Aniquiladora & 1 & $5 \%$ & $9^{\mathrm{a}}$ & 1 & $5 \%$ & $10^{\mathrm{a}}$ & 2 & $5 \%$ \\
\hline Brutal & 8 & $40 \%$ & $5^{a}$ & 11 & $55 \%$ & $4^{a}$ & 19 & $47,5 \%$ \\
\hline Colossal & 0 & $0 \%$ & - & 2 & $10 \%$ & $9^{a}$ & 2 & $5 \%$ \\
\hline Desesperadora & 10 & $50 \%$ & $3^{a}$ & 13 & $65 \%$ & $2^{\mathrm{a}}$ & 23 & $57,5 \%$ \\
\hline Desumana & 7 & $35 \%$ & $6^{a}$ & 5 & $25 \%$ & $7^{\mathrm{a}}$ & 12 & $30 \%$ \\
\hline Dilacerante & 0 & $0 \%$ & - & 1 & $5 \%$ & $10^{\mathrm{a}}$ & 1 & $2,5 \%$ \\
\hline Enlouquecedora & 9 & $45 \%$ & $4^{\mathrm{a}}$ & 11 & $55 \%$ & $4^{a}$ & 20 & $50 \%$ \\
\hline Fulminante & 1 & $5 \%$ & 9 & 3 & $15 \%$ & $8^{a}$ & 4 & $10 \%$ \\
\hline Insuportável & 8 & $40 \%$ & $5^{a}$ & 12 & $60 \%$ & $3^{a}$ & 20 & $50 \%$ \\
\hline Intensa & 16 & $80 \%$ & $1^{a}$ & 15 & $75 \%$ & $1^{a}$ & 31 & $77,5 \%$ \\
\hline Monstruosa & 8 & $40 \%$ & $5^{a}$ & 6 & $30 \%$ & $6^{\mathrm{a}}$ & 14 & $35 \%$ \\
\hline Que cega & 0 & $0 \%$ & - & 0 & $0 \%$ & - & 0 & 0 \\
\hline Terrível & 12 & $60 \%$ & $2^{a}$ & 10 & $50 \%$ & $5^{a}$ & 22 & $55 \%$ \\
\hline Tremenda & 6 & $30 \%$ & $8^{a}$ & 5 & $25 \%$ & $7^{a}$ & 11 & $27,5 \%$ \\
\hline
\end{tabular}


Quadro 7 - Freqüência $(F)$, percentual $(P)$ e ordenação em postos $(O P)$ dos cinco descritores de dor ordenados pelas parturientes, durante a primeira meia hora (T1) da coleta de dados. Ribeirão Preto, 2006.

\begin{tabular}{|c|c|c|c|c|c|c|c|c|}
\hline \multirow{3}{*}{ Descritores de dor } & \multicolumn{8}{|c|}{ T1 } \\
\hline & \multicolumn{3}{|c|}{ Grupo I } & \multicolumn{3}{|c|}{ Grupo II } & \multicolumn{2}{|c|}{ Total } \\
\hline & $F$ & $\mathbf{P}$ & OP & $F$ & $\mathbf{P}$ & OP & $F$ & $\mathbf{P}$ \\
\hline Alucinante & 6 & $30 \%$ & 5 & 4 & $20 \%$ & 7 & 10 & $25 \%$ \\
\hline Aniquiladora & 1 & $5 \%$ & 8 & 4 & $20 \%$ & 7 & 5 & $12,5 \%$ \\
\hline Brutal & 4 & $20 \%$ & 6 & 8 & $40 \%$ & 4 & 12 & $30 \%$ \\
\hline Colossal & 0 & $0 \%$ & - & 2 & $10 \%$ & 8 & 2 & $5 \%$ \\
\hline Desesperadora & 10 & $50 \%$ & 3 & 12 & $60 \%$ & 2 & 22 & $55 \%$ \\
\hline Desumana & 6 & $30 \%$ & 5 & 6 & $30 \%$ & 5 & 12 & $60 \%$ \\
\hline Dilacerante & 0 & $0 \%$ & - & 0 & $0 \%$ & - & 0 & 0 \\
\hline Enlouquecedora & 9 & $45 \%$ & 4 & 11 & $55 \%$ & 3 & 20 & $50 \%$ \\
\hline Fulminante & 2 & $10 \%$ & 7 & 4 & $20 \%$ & 7 & 6 & $15 \%$ \\
\hline Insuportável & 10 & $50 \%$ & 3 & 12 & $60 \%$ & 2 & 22 & $55 \%$ \\
\hline Intensa & 16 & $80 \%$ & 1 & 13 & $65 \%$ & 1 & 29 & $72,5 \%$ \\
\hline Monstruosa & 9 & $45 \%$ & 4 & 6 & $30 \%$ & 5 & 15 & $37,5 \%$ \\
\hline Que cega & 0 & $0 \%$ & - & 1 & $5 \%$ & 9 & 9 & $22,5 \%$ \\
\hline Terrível & 13 & $65 \%$ & 2 & 12 & $60 \%$ & 2 & 25 & $62,5 \%$ \\
\hline Tremenda & 4 & $20 \%$ & 6 & 5 & $25 \%$ & 6 & 10 & $25 \%$ \\
\hline
\end{tabular}


Quadro 8 - Freqüência $(F)$, percentual $(P)$ e ordenação em postos $(O P)$ dos cinco descritores de dor ordenados pelas parturientes, ao completar uma hora (T2) da coleta de dados. Ribeirão Preto, 2006.

\begin{tabular}{|c|c|c|c|c|c|c|c|c|}
\hline \multirow{3}{*}{ Descritores de dor } & \multicolumn{8}{|c|}{ T2 } \\
\hline & \multicolumn{3}{|c|}{ Grupo I } & \multicolumn{3}{|c|}{ Grupo II } & \multicolumn{2}{|c|}{ Total } \\
\hline & $F$ & $\mathbf{P}$ & OP & $F$ & $\mathbf{P}$ & OP & $\mathbf{F}$ & $\mathbf{P}$ \\
\hline Alucinante & 6 & $30 \%$ & 5 & 7 & $35 \%$ & 4 & 13 & $32,5 \%$ \\
\hline Aniquiladora & 1 & $5 \%$ & 8 & 4 & $21,1 \%$ & 6 & 5 & $12,8 \%$ \\
\hline Brutal & 7 & $35 \%$ & 4 & 5 & $25 \%$ & 5 & 12 & $30 \%$ \\
\hline Colossal & 0 & $0 \%$ & - & 1 & $5 \%$ & 9 & 1 & $2,5 \%$ \\
\hline Desesperadora & 10 & $50 \%$ & 3 & 9 & $45 \%$ & 3 & 19 & $47,5 \%$ \\
\hline Desumana & 4 & $20 \%$ & 6 & 4 & $20 \%$ & 6 & 8 & $20 \%$ \\
\hline Dilacerante & 0 & $0 \%$ & - & 1 & $5 \%$ & 9 & 1 & $2,5 \%$ \\
\hline Enlouquecedora & 13 & $65 \%$ & 2 & 13 & $65 \%$ & 2 & 26 & $65 \%$ \\
\hline Fulminante & 3 & $15 \%$ & 7 & 4 & $20 \%$ & 6 & 7 & $17,5 \%$ \\
\hline Insuportável & 13 & $65 \%$ & 2 & 13 & $65 \%$ & 2 & 26 & $65 \%$ \\
\hline Intensa & 16 & $80 \%$ & 1 & 16 & $80 \%$ & 1 & 32 & $80 \%$ \\
\hline Monstruosa & 3 & $15 \%$ & 7 & 3 & $15 \%$ & 7 & 6 & $15 \%$ \\
\hline Que cega & 0 & $0 \%$ & - & 2 & $10 \%$ & 8 & 2 & $5 \%$ \\
\hline Terrível & 16 & $80 \%$ & 1 & 13 & $65 \%$ & 2 & 29 & $72,5 \%$ \\
\hline Tremenda & 3 & $15 \%$ & 7 & 4 & $20 \%$ & 6 & 7 & $17,5 \%$ \\
\hline
\end{tabular}




\section{Avaliação da intensidade da dor por meio da VAS}

A Escala Analógica Visual foi apresentada a todas as contrações uterinas durante esta uma hora do estudo. O Quadro 9 apresenta a mensuração da intensidade da dor manifestada pelas parturientes de ambos os grupos, nos três momentos de coleta dos dados: no início do estudo (T0), meia hora depois (T1) e ao completar uma hora (T2).

Quadro 9 - Média aritmética (MA), mediana (M), desvio-padrão (DP), mínimo (Mi) e máximo (Má), da intensidade da dor manifestada pela parturiente, por meio da VAS, na primeira meia hora (T1) e no término (T2) da coleta de dados, na segunda fase do estudo. Ribeirão Preto, 2006

\begin{tabular}{|l|c|c|c|c|}
\hline \multirow{3}{*}{\begin{tabular}{c}
\multirow{2}{*}{$\begin{array}{c}\text { Intensidade } \\
\text { Dor }\end{array}$} \\
\cline { 2 - 5 }
\end{tabular}} & \multicolumn{4}{|c|}{ Momentos da Coleta de Dados } \\
\cline { 2 - 5 } & Grupo I & Grupo II & Grupo I & Grupo II \\
\hline Média & 6,80 & 7,12 & 7,55 & 7,8 \\
\hline Mediana & 6,66 & 6,88 & 7,87 & 7,77 \\
\hline Desvio-padrão & 1,44 & 1,26 & 1,60 & 1,08 \\
\hline Mínimo & 2,8 & 5,11 & 3 & 6,33 \\
\hline Máximo & 9,83 & 10 & 10 & 10 \\
\hline
\end{tabular}

A intensidade da dor se apresenta ascendente para ambos os grupos, considerando os três momentos de coleta de dados. $\mathrm{Na}$ análise comparativa entre os grupos quanto a intensidade da dor manifestada pela parturiente, mensurada através da Escala Analógica Visual (VAS), empregando-se uma análise de Variância (ANOVA) com medidas repetidas, para um nível de significância $\alpha=0,05$, verificamos, com base na figura 2 , que os escores de dor obtidos com a VAS, aumentaram de um momento para o outro, considerando o momento do início ao final da coleta de dados, sendo a diferença estatisticamente 
significante $($ p 0,000). Entretanto, apesar de haver uma tendência de maiores intensidades de dor referida pelas parturientes do grupo II (evolução espontânea), não houve diferença estatisticamente significante entre os grupos ( $\mathrm{p} 0,457)$.

Figura 4 - Intensidade de dor manifestada pela parturiente, por meio da VAS, do início ao fim da coleta de dados, na segunda fase do estudo.

Ribeirão Preto, 2006

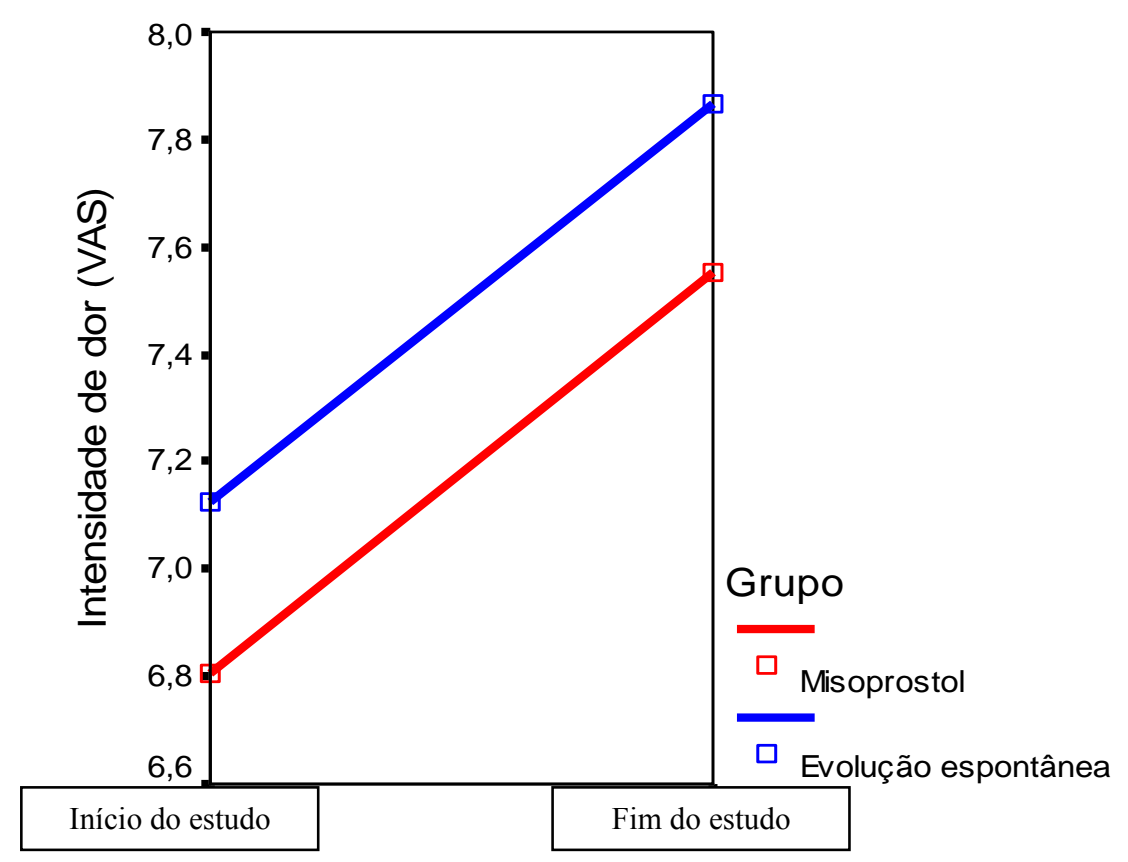

Tempo

Considerando a variável obstétrica, número de contrações uterinas para ambos os grupos, nos permite ampliar a análise da intensidade de dor referida pelas parturientes do grupo II (evolução espontânea) comparadas as do grupo I (misoprostol). Nas tabelas, 3 e 4, estão apresentados os dados relacionados ao número de contrações e a intensidade da dor referida considerando: média aritmética (AM), mediana (M), desvio padrão (DP), mínimo (Mi) e máximo (Má) durante a primeira meia hora de coleta de dados e após uma hora de coleta de dados, respectivamente. 
Tabela 3 - Intensidade de dor da contração uterina, manifestada pelas parturientes, por meio da VAS, em relação ao número de contrações, durante a primeira meia hora (T2) da coleta de dados. Ribeirão Preto, 2006

\begin{tabular}{|c|c|c|c|c|}
\hline \multirow{3}{*}{$\begin{array}{l}\text { Intensidade da } \\
\text { dor } \\
\text { - VAS }\end{array}$} & \multicolumn{2}{|c|}{$\begin{array}{c}\text { Misoprostol } \\
\left(n^{\circ} \text { parturiente e }\right. \\
n^{\circ} \text { de contrações uterinas) }\end{array}$} & \multicolumn{2}{|c|}{$\begin{array}{c}\text { Evolução Espontânea } \\
\text { ( }{ }^{\circ} \text { parturiente e } \\
n^{\circ} \text { de contrações uterinas) }\end{array}$} \\
\hline & 13 & 07 & 12 & 08 \\
\hline & $\begin{array}{c}\text { Até } 9 \\
\text { contrações }\end{array}$ & $\begin{array}{c}10 \mathrm{a}+ \\
\text { contrações }\end{array}$ & $\begin{array}{c}\text { Até } 9 \\
\text { contrações }\end{array}$ & $\begin{array}{c}10 \mathrm{a}+ \\
\text { contrações }\end{array}$ \\
\hline Média & 6,27 & 7,8 & 6,56 & 7,97 \\
\hline Mediana & 6,33 & 8 & 6,33 & 8,17 \\
\hline Desvio-padrão & 1,25 & 1,28 & 1,05 & 1,12 \\
\hline Mínimo & 2,8 & 5,92 & 5,11 & 6,58 \\
\hline Máximo & 8 & 9,83 & 9,33 & 10 \\
\hline
\end{tabular}

Tabela 4 - Intensidade de dor da contração uterina, manifestada pelas parturientes por meio da VAS, em relação ao número de contrações uterinas durante a primeira hora (T2) da coleta de dados. Ribeirão Preto, 2006.

\begin{tabular}{|c|c|c|c|c|}
\hline \multirow{3}{*}{$\begin{array}{l}\text { Intensidade da } \\
\text { dor } \\
\text { - VAS - }\end{array}$} & \multicolumn{2}{|c|}{$\begin{array}{c}\text { Misoprostol } \\
\text { ( } n^{\circ} \text { parturiente e } \\
n^{\circ} \text { de contrações uterinas) }\end{array}$} & \multicolumn{2}{|c|}{$\begin{array}{c}\text { Evolução Espontânea } \\
\text { ( } n^{\circ} \text { parturiente e } \\
n^{\circ} \text { de contrações uterinas) }\end{array}$} \\
\hline & 13 & 07 & 12 & 08 \\
\hline & $\begin{array}{c}\text { Até } 9 \\
\text { contrações }\end{array}$ & $\begin{array}{c}10 \mathrm{a}+ \\
\text { contrações }\end{array}$ & $\begin{array}{c}\text { Até } 9 \\
\text { contrações }\end{array}$ & $\begin{array}{c}10 \mathrm{a}+ \\
\text { contrações }\end{array}$ \\
\hline Média & 6,88 & 8,8 & 7,34 & 8,66 \\
\hline Mediana & 7 & 8,93 & 7,06 & 8,55 \\
\hline Desvio-padrão & 1,42 & 1,11 & 0,92 & 0,82 \\
\hline Mínimo & 3 & 6,73 & 6,33 & 7,67 \\
\hline Máximo & 8,25 & 10 & 9,67 & 10 \\
\hline
\end{tabular}


6. Discussão 
Este estudo objetivou avaliar o efeito do misoprostol (prostaglandinas) na manifestação da dor, referida pela parturiente, durante a indução do trabalho de parto. A introdução do uso do misoprostol como parte dos protocolos de assistência obstétrica teve ampla aceitação a partir do início da década de 1990, em nosso país. O Ministério da Saúde, em seus manuais, passa a recomendar o seu uso rotineiro no preparo cervical e indução do trabalho de parto em gestações antes do início espontâneo do trabalho de parto, principalmente nos casos de pós-datismos, entre outras indicações.

O papel fisiológico das prostaglandinas na parturição, em termos do amadurecimento do colo e indução do trabalho de parto, é cientificamente comprovado (HOFMEYR, 2003). O misoprostol atua sobre a matriz extracelular, com dissolução das fibras colágenas, aumento do ácido hialurônico e aumento do conteúdo de água da cérvice. Além disso, relaxa o músculo liso da cérvice e facilita a dilatação, ao mesmo tempo em que permite o acréscimo do cálcio intracelular, promovendo contração uterina. Todos estes mecanismos permitem o progressivo esvaecimento e dilatação cervical, concomitante ao aumento da atividade uterina, o que garante na maior parte dos casos uma indução bem sucedida do trabalho de parto (ARIAS, 2000). Tendo por base a literatura científica sobre a fisiologia da dor no trabalho de parto e parto, a distensão, estiramento e talvez a lesão do colo uterino são fatores causais na manifestação da dor no trabalho de parto (REZENDE ,1992; NEME, 2000; MATHIAS \& TORRES, 2000; ABUSHAIKHA, 2005). Frente a estas considerações, questionamos se a ação do misoprostol sobre o músculo liso do colo, estimulando o amadurecimento cervical, poderá intensificar a dor referida pelas parturientes? 
Os resultados obtidos em nosso estudo permitem fazer algumas considerações a respeito desta questão.

Inicialmente analisando os resultados da primeira fase do estudo, que teve por objetivo avaliar a primeira manifestação de dor, a contração uterina da gestante, resultante do uso do misoprostol para indução de trabalho de parto, verificamos que o tempo decorrido entre a aplicação da droga e a primeira queixa de dor pela parturiente, relacionada à contração uterina, ocorreu em média 2,4 horas, mediana de 2 e desvio-padrão de 0,68 . Tal resultado é compatível com o descrito na literatura, sobre a absorção do misoprostol, quando administrado via vaginal. Conforme Farah (2001), a absorção do misoprostol atinge nível plasmático máximo em torno de 2 horas após a administração.

Aquino, (2003), apresentou em seu estudo uma média de tempo entre o início da indução com misoprostol até a manifestação do trabalho de parto (3 contrações em 10 minutos) 253 minutos, portanto por volta de 4 horas para o grupo misoprostol.

$\mathrm{Na}$ fase latente do trabalho de parto espontâneo, momento em que se encontram as parturientes estudadas nesta primeira fase do estudo, as contrações são fracas e regulares (BURROUGHS,1995), sendo um período que chega a durar em torno de 20 horas (BRASIL, 2001). Em nosso estudo, verificamos características de irregularidade das contrações uterinas para parturientes que receberam misoprostol. Após a primeira manifestação de contração uterina, seguiam-se grandes períodos de ausência chegando a durar mais de 12 horas, até completarem os 4 centímetros de dilatação e regularidade das contrações que caracterizam a entrada na fase ativa do trabalho de parto. 
Vale destacar que o comprimido de misoprostol é utilizado em doses individuais, via vaginal, conforme a resposta uterina. Tal resposta à droga está na dependência de vários fatores tais como: indicação da indução, idade, idade gestacional, paridade, peso, altura, índice de massa corpórea, dilatação cervical e escore de Bishop iniciais, dose total de misoprostol, entre outros fatores apontados na literatura. Considerando as parturientes de nosso estudo, a indicação do uso do misoprostol seguiu o protocolo da instituição, o qual se leva em consideração o índice de Bishop menor que 6. Observamos que todas as parturientes tiveram indicação coerente à exigida com o protocolo, o índice mínimo foi de 2 e o máximo de 4. A indicação teve como justificativa principal o pós-datismo, sendo a média de idade gestacional de 41,05 semanas, mediana de 41 semanas.

$\mathrm{Na}$ avaliação da dor segundo a topografia do corpo, o ponto de dor focalizado pela maioria das parturientes foi a região pubiana, o que sugere, a princípio, estar relacionado com efeitos locais, na região do colo uterino. Neste sentido, na musculatura lisa do colo uterino o efeito da droga é relaxante, alterando a estrutura do colágeno. Entretanto, não houve relato de sensação contínua de dor, portanto associamos a ocorrência da dor á contração uterina. Verificamos que, no decorrer de uma hora de coleta de dados (3 momentos), houve aumento no percentual de parturientes que referiram dor nas regiões pubiana, sacral e inguinal. Outra região foi indicada pelas parturientes, região do quadril anterior 10\% (2), porém apenas no momento em que completou 1 hora da coleta.

A dor na região pubiana sugere, a princípio, estar relacionada com efeitos locais, na região do colo uterino. Neste sentido, na musculatura lisa do colo uterino, o efeito da droga é relaxante, alterando a estrutura do colágeno. Entretanto, não houve relato de sensação contínua de dor, portanto associamos a ocorrência da dor à contração uterina. 
Sobre os 15 descritores de dor utilizados no estudo, oriundos do trabalho de Sant Ana (1999) e classificados no estudo de Pereira (2001), com qualidade sensoriais: fulminante, dilacerante e intensa; como afetiva: aniquiladora, alucinante, enlouquecedora, desumana, desesperadora, terrível, monstruosa e que cega; avaliativa: colossal, insuportável, brutal e tremenda, as parturientes de nosso estudo foram orientadas a selecionar cinco descritores de dor que qualificassem a dor referida, sobre os quais traçamos as considerações que se seguem.

Mediante a classificação de Pereira (2001), ficam assim distribuídos os descritores selecionados pelo grupo de parturientes (misoprostol), sobre a dor referida na fase latente do trabalho de parto: o descritor, intensa, foi indicado nos três momentos da coleta de dados ocupando, na ordem em postos, o primeiro posto nos dois primeiros momentos da coleta e o terceiro posto no terceiro momento, tal descritor apresenta qualidade sensorial. Terrível e tremenda ocuparam o segundo e terceiro postos, respectivamente nos dois momentos iniciais da coleta, sendo o primeiro de qualidade afetiva e o segundo avaliativa. No terceiro momento da coleta de dados, foi indicado no primeiro posto o descritor brutal, de qualidade avaliativa. No segundo posto, o descritor desumana, de qualidade afetiva e para o terceiro posto, juntamente com o descritor intensa, os descritores: alucinante, terrível e tremenda, sendo os dois primeiros de qualidades afetivas e o último avaliativa.

Ferreira (2004) utilizou-se, pela primeira vez, destes descritores de dor em situação de trabalho de parto, porém na fase ativa, e aplicou o instrumento de coleta de dados de forma diferente ao do nosso estudo, o que impossibilita comparações.

Em nosso estudo, observamos que a lista de 15 descritores não se mostrou adequada a este momento do trabalho de parto, visto que as parturientes tinham dificuldades de eleger 
as palavras que melhor descreviam a dor sentida por elas. Tal constatação se deve ao fato de que para os três momentos de coleta de dados, um número reduzido de parturientes selecionou algum descritor que qualificasse a dor sentida, além de só escolherem três palavras para descrever a dor, apesar da insistência da pesquisadora solicitando que escolhessem cinco palavras.

Em relação à mensuração da intensidade da dor manifestada pela parturiente pela da VAS, a cada contração uterina durante uma hora, após a primeira manifestação de dor, podemos observar que o misoprostol é uma droga efetiva para ativar as contrações uterinas com tendência a aumentar a freqüência e intensidade das mesmas e produzir dilatação progressiva do colo uterino, como apontado em vários estudos (MORAES FILHO, 2005; CECCATI, 2005).

Sobre o efeito do misoprostol na indução do trabalho de parto, correspondente à fase latente, em nossos achados verificamos pelas médias aritméticas (MA) e medianas (M) uma tendência crescente da intensidade da dor. Na primeira meia hora (T1): a MA foi de 2,06 e M de 2, DP de 0,95 e ao término de uma hora (T2): a MA foi de 2,56 e M de 2,16, DP de 1,31. Aplicando o teste de Wilcoxon, pode-se dizer que o aumento da dor da contração uterina foi estatisticamente significante ( $\mathrm{p}$ de 0,004$)$, comparando-se os dois momentos de coleta.

Na literatura, não existem estudos que avaliem a intensidade de dor na fase latente do trabalho de parto em mulheres submetidas ao uso do misoprostol, o que impossibilita comparação com os nossos resultados, entretanto há estudos com parturientes em evolução espontânea de trabalho de parto na fase considerada, utilizando-se da VAS, onde se identificam maiores intensidades de dor referida pelas parturientes. 
A este respeito, Almeida (2005) verificou em seu estudo que a intensidade de dor manifestada pela parturiente/primípara, durante a fase latente do trabalho de parto, em evolução espontânea tem escores de 2 a 4 . A média da intensidade de dor foi de 3,47.

Outro estudo, de Caton (2002), observou a intensidade média de dor de 5,14, por meio da VAS em primíparas e secundíparas na fase latente de trabalho de parto, sem utilização de métodos farmacológicos de alívio de dor.

Observamos também a progressão da dilatação do colo, pois no início da coleta a média de dilatação era de $0,55 \mathrm{~cm}$ e mediana de $0,5 \mathrm{~cm}$ e após 1 hora, a dilatação média eleva-se para $1,05 \mathrm{~cm}$ e mediana de $1 \mathrm{~cm}$.

Analisando os dados da segunda fase do estudo que teve por objetivo comparar dois grupos de parturientes: misoprostol (parturientes que estão sendo induzidas com misoprostol) e evolução espontânea (trabalho de parto sem intervenção), a análise dos dados se refere ao início da fase ativa do trabalho de parto, mais especificamente na primeira hora. Tal como na primeira fase do estudo, buscamos avaliar os efeitos do misoprostol com relação à dor manifestada em parturientes submetidas a esta droga.

Comparando o grupo I (misoprostol) e o grupo II (evolução espontânea), em termos da topografia da dor manifestada pelas parturientes, verificamos que a maioria das parturientes referiu dor na região pubiana, e a segunda região mais pontuada foi a região sacral em ambos os grupos. Segue-se em menor percentual de parturientes nos dois grupos, a indicação da região inguinal. Como ocorrido para as duas regiões anteriores descritas, observamos que, no decorrer dos três momentos de coleta, à um aumento no percentual de parturientes que se queixam de dor nestas regiões. Outras regiões foram indicadas pelas parturientes tais como: baixo ventre, quadril anterior e posterior e lombar. Entretanto, á 
uma distribuição diferente em termos percentuais e momento da coleta de dados, para cada um dos grupos, ao se considerar na região lombar e posterior.

A região lombar foi apontada pela maioria das parturientes do grupo I (misoprostol), nos três momentos de coleta de dados, entretanto tal região teve pontuação nula para o grupo II (evolução espontânea) em dois momentos da coleta e 5\% no último momento. Aplicando o teste de significância, Qui-quadrado, houve associação nos dois primeiros momentos da coleta, sendo caracterizada a dor nesta região para o grupo I (misoprostol). Segundo Greenhill e Friedman, (1974), a sensação da contração uterina, no momento do trabalho de parto, é usualmente percebida, numa primeira instância, na região lombar e posteriormente na região perineal. Sabatino, (1996), relata que a sensação da dor e sua distribuição pelo corpo se dá nas regiões lombar (8,2\%) e abdominal (22,9\%). Afirma que o fato mais importante é que ambas foram assinaladas em pouco mais da metade dos questionários $(56,6 \%)$, como sendo as regiões mais sentidas durante o trabalho de parto.

Outra visível diferença entre os grupos está na indicação da região do quadril posterior, em que apenas o grupo II (evolução espontânea) fez referência à queixa de dor nesta região nos três momentos de coleta. Para esta região, aplicando o teste Qui-quadrado, houve associação positiva nos três momentos da coleta de dados para a região quadril posterior.

Na comparação entre os grupos, pelo teste Qui-quadrado, com nível de significância de $\alpha 0,05$, considerando as regiões do corpo que foram mais apontadas em relação à presença de dor, no início da coleta de dados, não houve associação estatisticamente significativa entre os grupos para as regiões: pubiana (p 0,28), inguinal (p 1,0), quadril anterior ( $\mathrm{p} 0,151)$, baixo ventre ( $\mathrm{p} 0,147)$, porém apresentou-se diferença estatisticamente 
significante nas seguintes regiões: abdominal, lombar e quadril posterior $(p, 0,00)$ e sacral ( $p$ $0,017)$.

Meia hora depois do início da coleta de dados, não houve associação estatisticamente significava entre os grupos para as regiões: inguinal ( $p$ 0,315), quadril anterior (p 0,114) e baixo ventre (p 0,311). A associação foi estatisticamente significante para as regiões: pubiana $(\mathrm{p} 0,072)$, abdominal $(\mathrm{p} 0,000)$, lombar $(\mathrm{p} 0,008)$, sacral $(\mathrm{p} 0,001)$ e quadril posterior ( $\mathrm{p} 0,000)$.

Ao término de uma hora da coleta de dados, não houve associação estatisticamente significativa entre os grupos para as seguintes regiões: pubiana $(\mathrm{p} 0,147)$, inguinal $(\mathrm{p} 1,0)$, baixo ventre (p 0,151) e lombar ( p 0,350). Pode-se dizer que a comparação entre os grupos foi estatisticamente significante nas regiões: quadril anterior, abdominal, sacral e quadril posterior (p 0,000).

A região lombar, dentre as apresentadas no diagrama do corpo, apresentou-se como a região mais pontuada por um maior número de parturientes do grupo I (misoprostol) comparado ao grupo II (evolução espontânea), para as demais regiões, os maiores percentuais de parturientes queixosas são do grupo II. Podemos dizer que para as parturientes do grupo II, a dor se apresenta mais difundida nas diferentes regiões do que no grupo I. Acreditamos que são necessários estudos que busquem elucidar a dor lombar no grupo misoprostol, tendo por base as ações farmacológicas da droga, nas estruturas da pelve.

Analisando a propagação da dor para outras regiões do corpo, esta se mostra presente para ambos os grupos, considerando os três momentos da coleta de dados. 
Nenhuma parturiente de ambos os grupos, misoprostol e evolução espontânea, relatou regressão da dor assinalada na primeira avaliação.

Utilizando de classificação topográfica e desenho metodológico semelhante (critérios amostrais, procedimento de coleta de dados) ao usado em nosso estudo, Ferreira (2004) realizou um estudo sobre o efeito de dois recursos não farmacológicos de avaliação da dor na primeira hora da fase ativa do trabalho de parto. Para o grupo-controle $(n=10)$, cujos resultados são passíveis de serem comparados com os do nosso estudo, obtiveram-se os seguintes achados: no início do estudo, 7 (70\%) referiram dor na região lombossacral, não houve modificação desses percentuais nas outras duas avaliações. Durante o estudo, $5(50 \%)$ das parturientes, do grupo-controle, tiveram dor na região lombossacra e também no baixo ventre. Um percentual pequeno de parturientes apresentou, durante o estudo, dor somente no baixo ventre, $1(10 \%)$. Poucas parturientes apresentaram, em qualquer uma das três avaliações, dor irradiada para os glúteos, 2 (20\%).

Estudos anteriores sobre a dor percebida ante as contrações uterinas no trabalho de parto, utilizando de outras denominações de região do corpo, podem ser encontrados na literatura. Leon (1967) descreve que as sensações das contrações uterinas, inicialmente, são sentidas nas regiões laterais e anteriores do abdome, enquanto num momento posterior (quando o trabalho de parto está mais avançado), são sentidas em regiões mais inferiores. Por outro lado Greenhill \& Friedman (1974) referem que a sensação da contração uterina, no período de dilatação cervical, é percebida na região lombar e posteriormente na região perineal. Burroughs (1995) afirma que o desconforto causado pelas contrações uterinas geralmente tem início na parte inferior das costas irradiando-se para o abdome, estendendo- 
se à área da região do baixo ventre. A dor lombar é grande, visto a compressão do feto e do útero nos filamentos nervosos desta região (ADACHI, 2003).

Melzack e Schaffelberg (1987) realizaram um estudo com 46 mulheres, em relação à dor durante o trabalho de parto, utilizando o questionário de avaliação clínica da dor de McGill. Ao realizar a análise dos dados obtidos, constataram que $74 \%$ das mulheres referiram dores na região sacral; 44\% nas costas e 100\% das mulheres referiram dor abdominal.

Sabatino (1996) realizou um estudo com 132 mulheres, nulíparas com gestação de baixo risco, com o objetivo de identificar a região do corpo de maior percepção das contrações uterinas, durante o trabalho de parto e durante o parto. Obteve como resultado, para aquelas que estavam em trabalho de parto (122 parturientes), referem a sensação de dor às contrações na região lombar + abdominal, 69 (56,6\%); abdominal 28 (22,9\%); lombar + abdominal + outras $13(10,6 \%) ;$ lombar em $10(8,2 \%)$ e outras $2(1,7 \%)$

Bajaj (2002) compara a dor da contração uterina durante o início do trabalho de parto, no período menstrual com estímulo de distensão da dilatação, por meio de um balão. Foi apresentado a essas mulheres, um desenho do corpo (vista frente e costas), de modo que elas marcassem a região que sentiam dor. Concluem os autores que a dilatação cervical produz uma dor reflexa mais comumente localizada no hipogástrio e nas regiões posteriores (T10-L1 e S2-S4).

Considerando a classificação das qualidades da experiência dolorosa, utilizando da lista dos 15 descritores (PEREIRA, 2001), é que apresentamos a análise dos descritores de maior atribuição, na segunda fase deste estudo. 
Observamos que, nos três momentos de coleta, as parturientes de ambos os grupos selecionaram cinco descritores que qualificassem a dor sentida, fato que difere da primeira fase do estudo, realizado apenas com as parturientes do grupo I (misoprostol), o que demonstra que tais descritores mostram-se apropriados para qualificar a dor nesta fase do trabalho de parto. Analisando a distribuição dos descritores classificados nos cinco postos dos três momentos de coleta de dados podemos verificar que no início do estudo (T0), para ambos os grupos foram selecionados os cinco descritores: intensa (sensorial), terrível (afetiva), desesperadora (afetiva), enlouquecedora (afetiva) e insuportável (avaliativa), embora em postos diferentes.

O descritor intensa ocupa o primeiro posto em ambos os grupos, bem como o descritor enlouquecedor no quarto posto. Os demais estão assim ordenados: terrível está no segundo posto para o grupo I e quinto para grupo II, desesperador está no terceiro posto para o grupo I e segundo posto para o grupo II, e insuportável foi ordenado no quinto posto para o grupo I e terceiro para o grupo II.

Na meia hora (T1), de coleta de dados é possível observar o descritor intensa (sensorial) que se manteve no primeiro posto para ambos os grupos. No grupo I (misoprostol), observamos que se mantiveram os descritores selecionados no início do estudo, obedecendo a mesma ordem, ou seja, terrível (afetiva), desesperadora (afetiva), enlouquecedora (afetiva), exceção ao descritor insuportável (avaliativa) que passou a ocupar o terceiro posto, junto com desesperadora. Houve acréscimo de novos descritores: monstruosa (afetiva), no quarto posto junto com enlouquecedora, e desumana e alucinante no quinto posto. No grupo II, também se observa a manutenção dos mesmos descritores no início do estudo para os três primeiros postos, ou seja, intensa (sensorial), desesperadora 
(afetiva), insuportável (avaliativa) e enlouquecedora (afetiva), dentre os descritores novos selecionados incluem: brutal (avaliativa), no quarto posto e, desumana (afetiva) e monstruosa (afetiva), no quinto posto. Os três descritores novos selecionados para ambos os grupos ocupam o quarto e quinto postos, sendo dois coincidentes (monstruosa e desumana).

Na fase T1 da coleta de dados, observamos a evidência dos mesmos descritores selecionados nos dois grupos de parturientes, à exceção dos descritores alucinante (presente entre os cinco descritores selecionados para o grupo I, mas ausente entre os cinco descritores para o grupo II) e brutal (presente entre os cinco descritores selecionados para o grupo II, mas ausente entre os cinco descritores para o grupo I).

Ao completar uma hora de coleta de dados, notamos que a manutenção do descritor, intensa (sensorial), se mantém no primeiro posto para ambos os grupos e que os mesmos descritores que qualificaram a dor sentida na fase anterior se mantiveram entre os três primeiros postos para ambos os grupos, tais como: grupo I (intensa, terrível, desesperadora, insuportável), acrescido do descritor, enlouquecedora e no grupo II (intensa, desesperadora, insuportável, enlouquecedora), acrescido do descritor, terrível. Nos outros postos incluemse os descritores brutal e alucinante (grupo I) e descritores alucinante e brutos (grupo II), ocupando o quarto e quinto postos. Neste último momento da coleta de dados, completado uma hora do estudo, observamos que os descritores mais selecionados para ambos os grupos foram os mesmos, apenas alternando a ordem em postos para alguns descritores.

O descritor intensa esteve presente no primeiro posto nos três momentos de coleta de dados. Outro aspecto a se destacar, é que comparando os descritores selecionados pelas parturientes nos três momentos da segunda fase do estudo e nos três momentos da primeira 
fase do estudo, notamos que foi crescente o número de descritores selecionados para descrever a dor referida pelas parturientes.

A qualificação da dor para o grupo I e II apresenta similaridades, visto que a maioria das parturientes de cada grupo a descreve como sensitiva. Outra semelhança entre os grupos é a predominância de descritores de qualidade afetiva, entre os cinco primeiros classificados. O componente afetivo da dor está ligado, principalmente ao caráter desagradável da sensação dolorosa, algo que é possível até evoluir para estados mais diferenciados como angústia e depressão.

Melzack (1987) utilizou, no seu trabalho, os descritores de dor da versão reduzida do questionário de dor McGill, os que obtiveram maior atribuição em relação à dor no primeiro estágio do trabalho de parto, foram cólica, dolorida e exaustiva, tendo como qualidade sensitiva os dois primeiros descritores e afetivo o outro. Apesar de nossos achados também apresentarem como qualidade de maior atribuição a sensitiva, para as duas palavras usadas pelo autor, não existem similares entre os descritores por nós utilizados.

Outro estudo, como o de Dias (1996), analisou como as parturientes categorizam a dor sentida, nas três diferentes fases do trabalho de parto, solicitando às mesmas que marcassem, no quadro de palavras, aquelas que melhor caracterizassem a dor no momento da contração uterina. Esse quadro se constituiu de vinte categorias de palavras, subdivididas em áreas: sensorial, afetiva, evolutiva e mista. Na fase ativa do trabalho de parto, a prevalência de palavras escolhidas ficou assim distribuídas: 44,66\% sensorial, 24,66\% mista, 21,64\% afetiva e 9,04\% evolutiva. Apesar de evidenciar a qualidade sensorial da dor, tal como em nossos achados, não é possível fazermos uma análise comparativa entre os dados, pelas razões já evidenciadas. 
Ferreira (2004), como já mencionado anteriormente, utilizou dos mesmos descritores usados em nosso estudo, no decorrer do início da fase ativa do trabalho de parto, mas adotando outro procedimento de coleta e análise. Para as parturientes do grupocontrole (sem intervenção) e experimental (uso de medidas não farmacológicas de alívio da dor no parto) diferentemente de nosso estudo, eram apresentados os 15 descritores, solicitando que as mesmas atribuíssem uma nota, de 1 a 7 , para as quinze palavras. Foram utilizados cálculo estatístico a média aritmética e desvio-padrão. O grupo I (controle) apresentou qualidade avaliativa para os dois primeiros descritores e afetiva para o terceiro descritor. No grupo II (massagem), os primeiros dois descritores de maior atribuição foi considerado como afetivo e avaliativo em seguida. O grupo III (ENT) apresentou como avaliativa, nos dois primeiros descritores, e afetiva para o terceiro. Por utilizar diferente metodologia de aplicação dos descritores e análise, há impossibilidade de comparações.

$\mathrm{Na}$ avaliação da dor manifestada pelas parturientes, mensurada por meio da VAS, observamos uma tendência ascendente na intensidade da dor para ambos os grupos. Durante a primeira meia hora (T1), para o grupo I (misoprostol) a média é de 6,80; a mediana é de 6,66 e o desvio-padrão de 1,44, enquanto no grupo II (evolução espontânea) a média é de 7,12; a mediana é de 6,88 e o desvio-padrão 1,26. A maior intensidade de dor referida na primeira meia hora no grupo I foi de 9,83 e no grupo II, 10 e a menor do grupo I foi de 2,80 e do grupo II, 5,11.

Em relação à dor relatada pela parturiente do grupo I (misoprostol), ao término da primeira hora, a média foi de 7,55; mediana de 7,87 e desvio-padrão de 1,59. A média apresentada no grupo II (evolução espontânea) foi de 7,86; a mediana de 7,77 e desvio- 
padrão de 1,08 . No final de uma hora, 10 foi a maior dor referida no grupo I e no grupo II. A menor dor registrada no grupo I foi 3 e no grupo II, 6,33.

Observamos que as parturientes do grupo II (evolução espontânea) manifestaram maiores intensidades de dor durante a primeira meia hora e ao concluir 1 hora da coleta de dados do que o grupo I (misoprostol). Pela análise de variância (ANOVA) com medidas repetidas, não houve diferença estatisticamente significante entre os grupos, p 0,457.

A ausência de estudos anteriores de mensuração da intensidade da dor, manifestada por mulheres submetidas ao uso do misoprostol no trabalho de parto, impossibilita comparação com os nossos achados. Entretanto, estudos anteriores utilizaram a VAS para mensurar a dor manifestada por parturientes sem qualquer ação de intervenção no trabalho de parto, à semelhança das mulheres de nosso estudo, (grupo de evolução espontânea), o que nos permite fazer algumas considerações sobre nossos achados para este grupo específico.

Almeida (2005) realiza um estudo em Goiânia, com 36 primigestas de baixo risco, que foram alocadas por amostragem aleatória por sorteio: o grupo-controle (GC) e o experimental (GE). As parturientes do GC recebiam assistência de enfermagem de rotina e as do GE receberam assistência de enfermagem individualizada, com orientação e estímulo à utilização de técnicas de respiração e relaxamento durante o processo de parturição. Tinha como objetivo principal verificar a intensidade de dor referida pelas parturientes durante as três fases do trabalho de parto. A escala utilizada para mensuração da intensidade da dor foi a VAS. Na fase ativa do trabalho de parto, houve predominância dos escores de dor, para o GC de escores de 6 a 8, com média de 6,88, com aumento gradativo da dor no decorrer das fases do trabalho de parto. 
Caton, et al. (2002), na Itália, ao pesquisarem a intensidade da dor por meio da VAS, em um grupo de parturientes primíparas e secundíparas e obtiveram intensidade média de dor na fase ativa de 8,23 .

Para Brown, et al. (1989), nos Estados Unidos, ao avaliarem em primíparas a intensidade de dor referida por meio da VAS obtiveram média igual a 6, no período de 2 a 5 centímetros de dilatação cervical.

Nos três estudos acima apresentados, as parturientes foram avaliadas quanto à intensidade da dor manifestada na fase ativa do trabalho de parto, entretanto é preciso considerar as variações da dor no início e final da fase. Em nosso estudo, no início da fase ativa os escores, para o grupo espontâneo, foram de 7,12 (T1) a 7,8 (T2).

Para a análise da intensidade da dor, considerando o número de contrações uterinas para ambos os grupos, distribuímos as parturientes em cada grupo, separadamente, quanto ao número de até nove contrações uterinas e 10 ou mais contrações uterinas. Verificamos a mesma distribuição numérica em cada grupo, ou seja, um maior número de parturientes com até nove contrações uterinas em ambos os grupos.

Durante a primeira meia hora de coleta de dados, a intensidade da dor para as parturientes nos grupos I e II, com até nove contrações uterinas, ficou assim distribuída: para o grupo I a média da intensidade da dor foi de 6,27, mediana de 6,33 e desvio-padrão de 1,25 e para o grupo II a média foi de 6,56; mediana de 6,33 e desvio-padrão de 1,05. Para as parturientes de ambos os grupos com 10 ou mais contrações uterinas, o grupo I obteve a média de 7,8; mediana de 8 e desvio-padrão de 1,28. Para o grupo II, a média foi de 7,97; mediana de 8,17 e desvio-padrão de 1,12. Portanto, podemos dizer que quem tem mais de dez contrações uterinas, apresenta uma tendência maior na intensidade de dor, do 
que aquelas que têm de cinco a nove contrações uterinas. Ao comparar os dois grupos, neste momento do estudo, pelo teste Mann-Whitney, o posto médio do grupo I $(19,52)$ com o grupo II $(21,48)$, em relação à intensidade de dor e o número de contrações, podemos dizer que não foi estatisticamente significante (p 0,574).

Considerando o segundo momento da coleta, verificamos que se manteve a mesma distribuição numérica de parturientes, em ambos os grupos, quanto ao número de contrações uterinas até nove contrações e dez ou mais contrações. Quanto à intensidade da dor para os grupos I e II relacionado ao número de contrações uterinas com até nove contrações uterinas, para o grupo I a média da intensidade da dor foi de 6,88 , mediana de 7 e desvio-padrão de 1,42 e para o grupo II a média foi de 7,34; mediana de 7,06 e desviopadrão de 0,92. Considerando as parturientes de ambos os grupos com 10 ou mais contrações uterinas, o grupo I obteve a média de 8,8; mediana de 8,93 e desvio-padrão de 1,11. Para o grupo II, a média foi de 8,66 ; mediana de 8,55 e desvio-padrão de 0,82 .

Ao comparar os dois grupos, neste momento do estudo, pelo teste Mann-Whitney, o posto médio do grupo I $(16,33)$ com o grupo II $(24,68)$, em relação à intensidade de dor e ao número de contrações, podemos dizer que é estatisticamente significante (p 0,021). Portanto, pode-se dizer que quanto maior o número de contrações, maior a intensidade de dor o que justificaria o fato de a tendência do grupo II (evolução espontânea) apresentar maiores intensidades de dor que o grupo de parturientes do grupo I (misoprostol).

Diante desses achados, não é possível afirmar que o misoprostol manifeste na parturiente maior intensidade de dor, durante o trabalho de parto, comparativamente à dor manifestada em um trabalho de parto de evolução espontânea, conforme suposto no início deste estudo em razão de observações empíricas numa fase preliminar do uso desta droga 
(onde nessa época, os comprimidos de $200 \mathrm{mg}$ de misoprostol eram fracionados com uma lâmina de bisturi, até obterem a dose aproximada de $25 \mathrm{mg}$ ) em que as mulheres se mostravam mais queixosas em relação à intensidade da dor.

O efeito do misoprostol no amadurecimento do colo é cientificamente comprovado e em condições de induzir e acelerar este processo poderia ter efeitos mais intensos no que se refere à dor, pois segundo os autores (REZENDE,1992; NEME, 2000 E MATHIAS \& TORRES, 2000) há uma estreita correlação entre a intensidade dolorosa do trabalho de parto e o grau de dilatação cervical.

Almeida (2005) refere ainda que a intensidade da dor aumentou gradativamente no decorrer das fases do trabalho de parto, seguindo o padrão fisiológico do seu fator gerador, a contratibilidade uterina.

Rowlands (1998) relata que durante a primeira e segunda fases do trabalho de parto, a dor é predominantemente mediada por mecanismos de distensaão do segmento uterino com contribuição dos mecanismos de dilatação do colo uterino e da própria contração uterina. Na fase final do trabalho de parto, a dor já é mais localizada no períneo, ânus e reto, podendo, também, ser sentida nas coxas e pernas.

Avaliando a evolução da dilatação cervical no decorrer de uma hora de coleta de dados, considerando que a dilatação inicial no início da coleta foi de $4 \mathrm{~cm}$ para ambos os grupos, segundo critério de inclusão no estudo (segunda fase), verificamos que, no grupo I (misoprostol), a média foi de 1,3 centímetros, mediana de 1, desvio-padrão de 1,42 e, no grupo II (evolução espontânea), a média da dilatação foi de 1,65, mediana de 1, desviopadrão de 1,66. Apesar de não observar, pelo teste Mann Withney, que não houve diferença 
significativa entre os grupos $(\mathrm{p}=0,53)$, a dilatação do colo entre as parturientes do grupo II teve uma pequena vantagem sobre a do grupo I. É preciso considerar que a ação da droga sobre o colo uterino está na dependência de vários fatores tais como: idade gestacional, paridade, dilatação cervical e escore de Bishop como preditores do sucesso da indução (WING, 2002). Vale considerar a condição de ser indicado o uso de misoprostol em casos de pós-datismo, como observado para as parturientes de nosso estudo que já evidenciam certa inércia de hipoatividade uterina, requerendo estímulo extra para entrar em dinâmica.

Outro aspecto a ser considerado por vários autores é o aparente aumento de hiper estimulação uterina pela ação do misoprostol (HOFMEYER, 2000). Cunnighan (1997) e Farah (1997) consideram taquissistolia diante da presença de 6 contrações por dois períodos consecutivos de 10 minutos. No trabalho de Aquino, 2003, houve uma prevalência maior de taquissistolia no grupo misoprostol (29 casos) que no grupo ocitocina (9 casos), esta diferença foi estatisticamente significante. Em análise aos nossos achados, não observamos nenhum caso de taquissistolia durante a coleta de dados, para o grupo misoprostol. Moraes Filho (2005) relata que quando utiliza-se a dose do comprimido de misoprostol recomendada de $25 \mu \mathrm{g}$ de até $6 / 6 \mathrm{hs}$, a possibilidade de alteração da contratibilidade uterina e de síndrome de hiperestimulação é baixa, ficando em torno dos $7 \%$ e $3 \%$, respectivamente.

Estudo de Hofmeyr, 2005, comparou os efeitos da ocitocina endovenosa e o misoprostol por via vaginal, observou que o segundo está associado a um maior sucesso da indução do trabalho de parto, embora também a um aumento da hipercontratilidade uterina, mas sem repercussões sobre a freqüência cardíaca fetal. 
A literatura considera que o período de trabalho de parto parece ser encurtado diante do uso do misoprostol, cujo período tem sido em torno de 12 horas (IE ROUX, 2002). Wing (2002) definem como sucesso da indução, a ocorrência de parto vaginal dentro de 24 horas depois da dose inicial de misoprostol.

Em nosso estudo, a média do tempo em horas de trabalho de parto, do início da fase ativa (4 centímetros de dilatação cervical) até o parto, para o grupo I (misoprostol) foi de 5,9 horas, mediana de 5, desvio padrão de 4,2. Para o grupo II (evolução espontânea), a média foi de 5,6 horas, mediana de 6 e desvio padrão 2,6. Apesar de se observar uma tendência do grupo I (misoprostol) apresentar uma maior duração de tempo de trabalho de parto do que o grupo II, aplicando-se o teste Mann Whitney, não apresentou diferença significativa $(p=0,713)$.

Farah (1997) confirmou a segurança e eficácia do misoprostol, mostrando que 83\% das pacientes evoluíam para o parto durante as primeiras 24 horas da indução.

No trabalho de Araújo, 1999, o intervalo entre a primeira inserção do comprimido de $25 \mu \mathrm{g}$ do misoprostol e o parto foi de 444,9 minutos (7,41 horas). Neste estudo mostraram que $82 \%$ das pacientes tiveram parto nas primeiras 24 horas e $32,1 \%$ das pacientes no grupo de $25 \mu \mathrm{g}$ tiveram parto após uma única dose.

O intervalo de tempo do início da indução a ocorrência do parto normal, no trabalho de Aquino, 2003, mostrou uma diferença estatisticamente significante entre o grupo misoprostol $(10,6 \mathrm{hs})$ e ocitocina $(14,8 \mathrm{hs})$. A média do intervalo de tempo foi menor para o grupo misoprostol. 
Com relação ao nosso estudo, a média de tempo do início da indução a realização do parto, para o grupo misoprostol foi de 13,45 .

Chang (2002) realizou um estudo, em Taiwan, com 90 primíparas, em idade gestacional de 37 a 42 semanas de gestação, sem complicações durante a gravidez, submetida a partos normais sem nenhum procedimento/ medicação para alívio da dor; com o objetivo de avaliar através da escala analógica visual a mensuração da dor durante o trabalho de parto. Através da Escala Analógica Visual, não encontrou correlação entre duração do trabalho de parto e a dor do trabalho de parto.

O uso do misoprostol em dose apropriada é seguro e eficiente para amadurecimento cervical e indução do trabalho de parto. A grande maioria dos estudos publicados recomenda a dose de $25 \mu \mathrm{g}$ a cada 4 a 6 horas, na dose total máxima de $100 \mu \mathrm{g}$, como já é recomendada pelo Colégio Americano de Obstetras e Ginecologistas - ACOG, 2000 (WING, 1995; WING, 1996; PATEL, 2000, AQUINO, 2003; HOFMEYER, 2003). Neste estudo, a média de comprimidos de misoprostol, utilizado durante todo o trabalho de parto, foi de 3,45; mediana de 3, desvio padrão de 1,27, mínimo de comprimidos administrados foi 2 e máximo de 7, o que se mostrou apropriado ante o recomendado.

A eficiência deve ser analisada em termos, também, dos resultados obstétricos, particularmente quanto ao uso de ocitocina, indicação de parto cesariana nos grupos de parturientes estudadas.

Chamamos atenção para o fato de que 6 parturientes do grupo I (misoprostol) foram excluidas do estudo, devido a indicação de cesárea, antes de completar 4 centímetros de dilatação, ou seja, participaram apenas da primeira fase da coleta de dados. Tal informação nos possibilita observar que entre as parturientes que usaram o misoprostol no 
trabalho de parto, o número de cesarianas é ainda maior do que foi considerado, com base nos resultados apresentados.

Vale a pena enfatizar, que a Mater é uma maternidade de baixo risco e a taxa elevada de cesárea, em mulheres que foram submetidas ao uso do misoprostol neste estudo, se dá devido as particularidades dessa amostra, visto que a porcentagem de cesáreas em

A literatura traz a importância e a eficiência do uso do misoprostol na indução do trabalho de parto, no sentido de diminuir a incidência de cesárea advinda do insucesso do uso da ocitocina na indução do trabalho de parto (MACEDO, 1998).

Uma revisão sistemática publicada na biblioteca Cochrane avaliou 45 ensaios clínicos randomizados nos quais a administração de misoprostol por via oral e vaginal foi comparada com placebo ou indução por outros métodos. Como resultado evidenciado foi que o uso do misoprostol é mais efetivo do que os métodos convencionais para o amadurecimento do colo e indução do parto, associando-se a maior freqüência de partos vaginais dentro de 24 horas e menor necessidade de utilização de ocitocina (HOFMEYR, 2003).

Cabe aqui enfatizar, que o parto cesárea, quando bem indicado, também é um parto humanizado, desde que a indicação visa minimizar complicações da gestante/ parturiente e do feto. No entanto, sabe-se que o parto cesárea apresenta riscos ainda mais elevados que no parto normal. As causas tradicionais de morte materna são as hemorragias e as infecções. Outras complicações associadas ao procedimento incluem o tromboembolismo, a infecção. 
Analisando as razões da indicação da cesariana para cada um dos grupos estudados, verificamos que: no grupo I (misoprostol), 35\% (7) foram por falha de indução ${ }^{*}, 10 \%$ (2) por sofrimento fetal e 5\% (1) por desproporção céfalo-pélvica enquanto no grupo II (evolução espontânea) foi de 10\% (2) por sofrimento fetal, 5\% (1) por desproporção céfalopélvica e 5\% (1) por parada secundária da dilatação. Tal achado evidencia que embora não se observe diferenças significativas entre os dois grupos no que se refere ao perfil das contrações uterinas e evolução da dilatação e mesmo na dor manifestada pelas parturientes, o que demonstra ser efetiva a ação do misoprostol como indutor do trabalho de parto, a resultante deste processo, não se mostra satisfatória quando se tem por finalidade o parto normal.

Moraes Filho (2005), relata que um dos principais obstáculos do êxito da indução é representado pelas condições desfavoráveis do colo uterino. Baixos escores cervicais (Bishop), tem sido associado a um aumento da falha de indução de trabalho de parto, ao seu prolongamento e ao elevado índice de parto cesárea (ROUSE, 2000; FEITOSA, 2006).

Neste estudo, a média do índice de Bishop foi de 2,4 e mediana de 2, o que podemos considerar um índice baixo, mostrando que quanto mais baixo, mais desfavorável está este colo uterino, portanto mais difícil e trabalhoso será o trabalho de parto.

\footnotetext{
* Entende-se por falha de indução ou distócia funcional, aquela que decorre de contrações uterinas não eficientes (falta motor). A correção deve ser feita inicialmente por técnicas humanizadas de estímulo ao parto normal, como por exemplo, estimulando a deambulação, promovendo ruptura artificial da bolsa das águas e posteriormente a indicação de ocitocina (BRASIL, 2003). Após ter esgotado todas as tentativas possíveis para aumentar as características das contrações uterinas tornando-as eficiente, de modo a permitir a evolução do trabalho de parto, dilatando o colo uterino, provocando esvaecimento do colo, auxiliando na descida da apresentação fetal, é que indica-se cesárea por falha de indução.
} 
O índice de cesariana, no estudo de Araújo (1996), para o grupo que utilizaram 25 $\mu \mathrm{g}$ de misoprostol foi de $18 \%$ e encontra-se de acordo com outros estudos, como o de Farah (1997) que tiveram uma incidência de $14 \%$.

Há de se considerar, neste estudo, entretanto, o uso excessivo de ocitocina, durante o desenrolar do trabalho de parto (após terminarmos a coleta dos dados), particularmente para o grupo II (evolução espontânea), 85\% (17) contra 35\% (7) do grupo I (misoprostol).

Vários estudos tem mostrado que a infusão contínua de ocitocina é eficiente, quando o intuito é corrigir a falha de indução e consequentemente diminuir a indicação de cesáreas. (CAMPOS, 1994; KRAMER, 1997; ESCUDERO, 1997).

Dentre as situações indesejáveis está a repercussão sobre o feto, a presença de mecônio é um indicativo de sofrimento fetal. Em nosso estudo 10\% do grupo I tiveram indicação de cesariana em razão de sofrimento fetal.

A respeito da presença de mecônio no líquido amniótico, a literatura refere que há um risco aumentado de eliminação de mecônio intraparto quando é utilizado o misoprostol, em comparação com outros métodos, porém os desfechos neonatais não são afetados (HOFMEYR, 2005). A possibilidade de mecônio aumenta de acordo com o aumento da dose utilizada. Quando usada $50 \mu \mathrm{g}$ de quatro em quatro horas, a incidência de mecônio é de 21,5\%, enquanto que o esperado para o trabalho de parto espontâneo é de $12 \%$. (CAMPOS, 1994; WING, 1995; SCISCIONE, 2001; AQUINO, 2001). Durante o desenrolar do trabalho de parto, foram excluídas do estudo, 4 parturientes do grupo I (misoprostol) e 2 do grupo II (evolução espontânea) que ao apresentar ruptura de bolsa (artificial ou espontânea), apresentaram mecônio. 
Finalmente, é importante salientar que, neste estudo, os grupos foram constituídos atendendo a critérios rígidos, de modo a evitar vieses nos resultados obtidos. Devemos, entretanto, considerar que isto se constituiu em limitação ao nosso tamanho amostral, ficando reduzido em razão do curto tempo para realização da investigação. 
7. Conclusão 
- O tempo decorrido entre a aplicação do misoprostol via vaginal na indução do trabalho de parto e a primeira queixa de dor pela parturiente (média 2,4 horas), relacionada à contração uterina, ocorreu no tempo previsto, considerando que a absorção do misoprostol atinge nível plasmático máximo em torno de 2 horas após a administração.

- Na fase latente do trabalho de parto, entre as parturientes que fizeram uso do misoprostol, a maioria das parturientes referiu dor na região pubiana, requerendo estudos que permitam associar os resultados, referentes ao local da dor, por parturientes em evolução espontânea de trabalho de parto.

-A lista de 15 descritores da dor não se mostrou adequada a este momento do trabalho de parto (fase latente), visto que as parturientes tinham dificuldades de eleger as palavras que melhor descreviam a dor sentida por elas, o que sugere a necessidade de aplicação de outros descritores de dor.

- A mensuração da intensidade da dor manifestada pela parturiente por meio da Escala Analógica Visual (VAS), a cada contração uterina durante uma hora, após a primeira manifestação de dor na fase latente do trabalho de parto, revelou padrão de dor ascendente, o que corrobora para o efetivo efeito do misoprostol em ativar as contrações uterinas.

- O descritor referente à queixa de dor que se manteve no primeiro posto, em todos os momentos de coleta de dados, para o grupo I e II é o de qualidade sensitiva. Dentre os cinco descritores selecionados, predominam os descritores de qualidade afetiva, para ambos os grupos. 
- Na fase ativa do trabalho de parto, especificamente na primeira hora em que ocorreu a coleta de dados deste estudo, a dor referida em termos da localização nas diferentes regiões do corpo foi para ambos os grupos, misoprostol e evolução espontânea: pubiana, inguinal e sacra. A região lombar foi apontada pela maioria das parturientes do grupo I (misoprostol), diferindo do grupo II (evolução espontânea) que teve baixo e nulo percentual de parturientes que referiram dor nesta região. Em contrapartida, a região do quadril posterior só foi pontuada pelo grupo II (evolução espontânea). Há propagação da dor para outras regiões do corpo, considerando os três momentos da coleta de dados e nenhuma parturiente de ambos os grupos relatou regressão da dor no local assinalado na primeira avaliação.

- A mensuração da intensidade da dor por meio da Escala Analógica Visual (VAS), ao longo de uma hora da coleta de dados no início da fase ativa, revelou padrão ascendente, para ambos os grupos. Entretanto, as parturientes do grupo II (evolução espontânea) manifestaram maiores intensidades de dor, quando observamos os resultados comparativos ao do grupo I (misoprostol). Apesar desta observação, a diferença entre os grupos não foi significativa pelos testes estatísticos aplicados. Em resposta a nossa hipótese inicial de que o misoprostol manifesta na parturiente maiores intensidades de dor durante o trabalho de parto comparativamente à dor manifestada em um trabalho de parto de evolução espontânea, esta não foi confirmada. Acreditamos que a PADRONIZAÇÃO do fracionamento do comprimido em doses exatas de $25 \mu \mathrm{g}$, contribuiu para tal resultado. 


\section{Referências Bibliográficas}




\section{REFERÊNCIAS}

ABUSHAIKHA, L.; OWEIS, A. Labour pain experience and intensity: a Jordanian perspective. International Journal of Nursing Practice. v.11, p. 33-38, 2005.

ACOG-American College of Obstetricians and Gynecologists. Committee Opinion. Induction of labor with misoprostol. Int J Gynaecol Obstet. v.69, n.1, p.77-8. 2000.

ADACHI, K; SHIMADA, M; USUI, A. The relationship between the parturient's positions and perceptions of labor pain intensity. Nursing research. v.52, n.1, p.47-51, 2003.

AFONSO, C.E e CABRAL, S.B. Atividade física no pré natal e no parto como forma de relaxamento e alívio da dor. Saúde Coletiva. v.2, n.7, p.93-98, 2005.

ALEXANDER, J.M.; SHARMA, S.K.; MCINTIRE, D.D.; WILEY, J.; LEVENO, K.J. Intensity of llabor pain and cesarean delivery. Anesth.Analg. v.92, n.6, p.1524-8, 2001.

ALMEIDA, Nilza Alves Marques et al. The use of respiration and ralaxation techniques for pain and anxiety relief in the parturition process. Rev. Latino-Am. Enfermagem., Ribeirão Preto, v. 13, n. 1, 2005.

ALMEIDA, N.A.M.; SOUSA, J.T; BACHION, M.M.; SILVEIRA, N.A. The use of respiration and ralaxation techniques for pain and anxiety relief in the parturition process. Rev. Latino-Am. Enfermag. Revista Latino Americana de Enfermagem. Ribeirão Preto, v.13, n.1. p.52-58, 2005.

AQUINO, M.M.A. Misoprostol versus ocitocina para indução do parto: ensaio clínico controlado aleatorizado. 2001. X p. Tese (Doutorado) - Faculdade de Ciências Médicas, Universidade Estadual de Campinas, Campinas, 2001.

AQUINO, Márcia Maria Auxiliadora de; CECATTI, José Guilherme. Misoprostol versus oxytocin for labor induction in term and post-term pregnancy: randomized controlled trial. Med. J., São Paulo, v. 121, n. 3, 2003.

ARAUJO, D.A.C.; OLIVEIRA, L.C.N.; OLIVEIRA, I.N.; PORTO, D.P.; OLIVEIRA, S.V.; JUNQUEIRA, H.O; ANDRADE, A.T.L. Indução do parto com misoprostol: comparação entre duas doses. Rev.Bras.Ginecol.Obstet. v.21, n.9, p.527-31, 1999.

ARIAS F. Pharmacology of oxytocin and prostaglandins. Clin Obstet Gynecol. v.43, n.3, p.455-68, 2000.

BAJAJ, P; DREWES, AM; GREGERSEN,H; PETERSON, P; MADSEN, H; ARENDTNIELSEN. Controlled dilatation of the uterine cervix - na experimental visceral pain model. Pain. V.99, P.433-442, 2002. 
BLANCHARD, K.; CLARK, S.; WINIKOFF, B.; GAINES, G.; KABANI, G.; SHANNON, C. Misoprostol for women's health: a review. Obstet. Gynecol. v.99, p.31632, 2002.

BOND M, GARDNER ST, CHRISTIAN J, SIGAL JJ. Empirical study of self-rated defense styles. Arch Gen Psychiatry. v.40(3), p.:333-8, 1983.

BONICA, J.J. The management of pain. Philadelphia: Lea \& Febiger, 1953.

BONICA, J.J. Peripheral mechanisms and pathways of parturition pain. Br.J.Anaesth., v.51, n.3s, p.753-758, 1979.

BORRÉ ARRIETA, O; RODRIGUEZ YANCES, B; MENDIVIL CIODARO, C; ANGARITA PENARANDA, W; BORRÉ ARRIETA, J. Iduccion del tabajo de parto con misoprostol vs oxitocina/ Induction the labor with misoprostol vs oxitocin. Rev.Colomb.Obstet.Ginecol. v.51, n.1, p.8-11, 2000.

BOULVAIN, M; KELLY, A; LOHSE, C; STAN, C; IRION, O. Mechanical methods for induction of labour. Cochrane Database Syst Rev, v.4: CD001233, 2001.

BRASIL. Ministério da Saúde. Portaria 344-12/05/98 da ANVISA. DOU de 22/06/2001. Seção 1, p.150.

BRASIL. Ministério da Saúde. Secretaria de Políticas de Saúde. Área Técnica de Saúde da Mulher. Parto, aborto e puerpério: assistência humanizada à mulher. Brasília, 2003.

BROWN, ST.; CAMPBELL, D.; KURTZ, A. Characteristics of labour pain at two stages of cervical dilation. Pain. v.38, p. 289-95, 1989.

BURROUGHS, A. Uma introdução à Enfermagem materna. 6. ed. Porto Alegre: Artes Médicas, 1995

BUCCELlATO, C. A.; STIKA, C. S.; FREDERIKSEN, M.C. - A randomized trial of misoprostol versus extra-amniotic sodium chloride infusion with oxytocin for induction of labor. Am. J. Obstet. Gynecol., v.182, p.1039-44, 2000.

BUSSER, D.; MORAS, G.; ASRIAS, F. A randomized comparison between misoprostol and dinoprostone for cervical ripening and labor induction in patientas with unfavorable cervices. Obstet.Gynecol. v.89, n.4, p.581-5,1997.

CAMPOS, G.A, GUZMÁN, S, RODRIGUEZ, J.G, VOTO, L.S; MARGULIES, M. Misoprostol - un análogo de la PGE1 - para la inducción de parto a término: estudio comparativo y randomizado con oxitocina. Rev.Chil.Obstet.Ginecol. v59, n.3, p.190-6, 1994. 
CANO A, CARRILLO M, BAQUERO R, LOZANO F, SARMIENTO A, PINZÓN W. Cervicometría transvaginal como factor predictor de éxito en indución del trabajo de parto con misoprostol. Rev Colomb Obstet Ginecol . v.51, p.214-7, 2000.

CARDOSO, R.P.S. Descritores de Dor Crônica: um estudo psicofísico. 2004. 55 f. Tese (Doutorado) - Escola de Enfermagem de Ribeirão Preto, Universidade de São Paulo, Ribeirão Preto, 2004.

CECCATI, J.G; PARPINELLi, M.A. Indução do parto. In:GUARIENTO, A.; MAMED, J.AS.V., EDITORES. Medicina Materno-Fetal. São Paulo, Atheneu. p.1439-52, 2001.

CECCATI, JG; TEDESCO, R.P; BESTETI PIRES, H.M; CALDERON, I.M; FAÚNDES, A. Effectiveness and safety of a new vaginal misoprostol product specifically labeled for cervical ripening and labor induction. Acta Obstet Ginecol Scand. In press 2005

CHANG, M.Y; CHEN, S.H; CHEN, C.H. Factors related to perceived labor pain in primiparas. Kaohsiung J Med Sci, v.18, p.604-9, 2002.

COELHO, H.L.L. O que está em jogo no caso Cytotec. Ciência Hoje. v.13; p.60-2, 1991.

COELHO, H.L.L.et al. Selling abortifacients over the couter in pharmaies in Fortaleza, Brazil. Lancet. v.338, p.247, 1991.

COUSINS, M.J.; PHILLIPS, G.D. Neurological mechanisms of pain and the relationship of pain: Anxiety and sleep. In: COUSIN, M.J.; PHILLIPS, G.D. Acute pain management. New York: Churchill Livingstone, p. 21-48, 1986.

DIAS, M.D. A mulher e o parto: respostas frente á dor. 1996. 84 f. Dissertação (Mestrado) - Universidade Federal da Paraíba, João Pessoa, 1996.

DUARTE, G.; CUNHA, S.P.; MAUAD, F.F.; NOGUEIRA, A. A.; BEREZOWSKI, A. T.; RODRIGUES, R. Indução e estimulação do parto. Protocolos de condutas em gestação de alto risco. Ribeirão Preto: FUNPEC. p.189-92, 2003.

DUARTE, G.; VIERA, C.S.; MAZZARO, L.Z.; NOGUEIRA, A. A.; MAUAD, F.F.; CUNHA, S.P. Misoprostol para indução do trabalho de parto com feto vivo. Femina. v.31, n.2, 2003.

ESCUDERO, F; CONTRERAS, H. A comparative trial of labor induction with misoprostol versus oxytocin. Int.J.Gynecol.Obstet. v.57, n.2, p.139-43, 1997.

FEITOSA, Francisco Edson de Lucena et al . Nova formulação de misoprostol sublingual na indução do trabalho de parto. Rev. Assoc. Med. Bras., São Paulo, v. 52, n. 4, 2006. 
FERREIRA, C.H.J. Avaliação de dois recursos não farmacológicos para o alívio da dor durante o trabalho de parto. 2004. 100 p. Tese (Doutorado) - Escola de Enfermagem de Ribeirão Preto, Universidade de São Paulo, Ribeirão Preto, 2004.

FISHER SA, MACKENZIE VP, DAVIES GA. Oral versus vaginal misoprostol for induction of labor: a double-blind randomized controlled trial. Am J Obstet Gynecol. 185:906-10. 2001

FISHUBURNE Jr., J.I. Danforth's obstetrics and gynecology. In: SCOTT, J.R. et al. (Ed.). Obstetric analgesia and anesthesia. Philadelphia: Lippncott Williams \& Wilkins. v. 8, p. 111-129, 1999.

FONSECA, W.V.C.; et al. Misoprostol and congenital malformations. Lancet. v.337, p.762-3, 1991.

FRIDH, G.; KOPARE, T.; GASTON-JOHANSSON, F.; TURNER NORVELL, K. Factors associated with more intense labour pain. Res. Nurs. Health, v.11, p. 117-24, 1988.

GARCIA, M.T. SOUZA, E.; SANTOS, J.F.K.; MATAR, R.; CAMANO, L. Indução do Parto. Femina, v.8, p. 271-6, 2000.

GOLDYNE, M.E. Prostaglandinas e outros eicosanóides. In: KATZUNG, B.G. Farmacologia básica e clínica. 2. ed. Rio de Janeiro: Guanabara, p. 245-55, 1986.

GRAVES, C.R. Fármacos que provocam contração ou relaxamento do útero. In: GOODMAN, H.; GILMAN, W.S. As bases farmacológicas da terapêutica. New York: McGraw-Hill Interamericana, p. 693 - 700, 1996.

GREENHILL, J.P. \& FRIEDMAN, E.A. Biological Principles and Modern Practice of Obstetrics. Filadelphia: W.B. Saunders Company. p.35-65, 1974

GREENHILL, J. P. \& FRIEDMAN, E. A. - Obstetrícia. Rio de Janeiro, Interamericana, p.184-197, 198-209, 1976.

HOFMEYR, G.J.\& GULMEZOGLU, A.M. Vaginal misoprostol for cervical ripening and labour iinduction in late pregnancy (The Cochrane Review). In: The The Cochrane Library, Issue 2, 2000. Oxford: Update Software

HOFMEYR, G.J; NIKODEM, V.V; de JAGER, M; DRAKELY, A. A Side-effects of oral misoprostol in the third stage of labour - a randomized placebo-controlled trial. S.Afri.Med.J. v.91, n.5, p.432-5, May, 2001.

HOFMEYR GJ, GULMEZOGLU AM. Vaginal misoprostol for cervical ripening and induction of labour. Cochrane Database Syst Rev 2003;(1): CD000941. 
HOFMEYR, G.J.\& GULMEZOGLU, A.M. Vaginal misoprostol for cervical ripening and iinduction of labour. Cochrane Database Syst Rev. 2005, (2): CD000941.

HOW HY, LEASEBURGE L, KHOURY JC, SIDDIQI TA, SPINNATO JA, SIBAI BM. A comparison of various routes and dosages of misoprostol for cervical ripening and the induction of labor. Am J Obstet Gynecol. v. 185, p. 911-5, 2001

KATZ, V.L.; FARMER, R.M.; DEAN, C.A.; CARPENTER, M.E. Use of misoprostol for cervical ripening. South Med. J., v.93, p. 881-4, 2000.

KLOSTERGAARD, K.M; TERP, M.R; POULSEN, C; et al. Labor pain in relation to fetal weigth in primiparas. Eur J Obstet Gynecol Reprod Biol., v.99, p.195-8, 2001.

KRAMER, R.L; GILSON, G.J, MORRISON, D.S; MARTIN, D; GONZALES, J.L; QUALLS, C.R. A randomized trial of misoprostol and oxytocin for induction of labor: safety and efficacy. Obstet.Gynecol. v.89(3), p.387-91, 1997.

LOESER, J.D.; MELZACK, R. Pain: An overview. Lancet, v.353, P.1607-1909, 1999.

LOWE, N.K. The nature of labor pain. Am J Obstet Gynecol, v:186, p.16-24, 2002.

LUDINGTON, E; DEXTER, F. Statistical analysis of total pain using the Visual Analog Scale and application to studies of analgesic effectiveness during childbirth. Anesth Analg, v. 87, p.723-7, 1998.

MACEDO, R.M; ÁVILA, I; GONÇALVES, M.M. A randomized trial of misoprostol and placebo for cervical ripening and induction of labor. Rev.Brasil.Ginecol.Obstet. v.20, p.457-62, 1998 .

MAcGUIRE, D.B. The mesurement of clinical pain. Nurs. Res., v.33, n.3, p. 152-6, 1984.

MATHIAS, R.S.; TORRES, M.L.A. Analgesia e anestesia. In: NEME, B (ed.). Obstetrícia básica. 2. ed. São Paulo: SARVIER, p. 1035-65, 2000.

MELZACK, R.; WALL, P.D. Pain mechanisms: a new theory. Science, n. 150, p. 971-8, 1965.

MELZACK, R. The McGill Pain Questionnaire: major properties and scoring methods. Pain, v.1, p.277-299, 1975.

MELZACK, R.; KINCH, R.; DOBKIN, P.; LEBRUN,.H ; TAENZER, P. Severity of labour pain: influence of physical as well as psychological variables. Can Med Assoc J, v.130, p .579-84, 1984.

MELZACK, R. Labor pain as a model of acute pain. Pain. V.53, p.117-120, 1993. 
MELZACK, R.; KATZ, J. Pain measurement in persons. In: MELZACK, R.; WALL, P.D. (Eds.). Textbook of pain. 3. ed. Edinburg: Churchill Livingstone. p. 337-56, 1994.

MORAES FILHO, O.B.; CECATTI, J.G.; FEITOSA, F.E.L. Métodos para indução do parto. Rev. Bras. Ginecol. Obstet., Rio de Janeiro, v. 27, n. 8, 2005.

MUZONZINI, G; HOFMEYR, G.J. Bucal or sublingual misoprostol for cervical ripening and induction of labour. Cochrane Database Syst Rev. 2005, (2): CD004221.

NEME, B. Analgesia e anestesia: técnicas em Obstetrícia. Obstetrícia básica. 2. ed. São Paulo: Sarvier, p.1035-65, 2000.

O'BRIEN, W.F. \& CEFALO, R.C. - Labor and delivery. In: GABBE, S.G.; NIEBYL, J.R.; Obstetrics: normal \& problem pregnancies. New York, Churchill Livingstone, p.371396, 1996.

O'DRISCOLL, K; FOLEY, M AND MACDONALD, M. Active management of labor as an alternative to cesarean section for dystocia Obstetrics \& Gynecology. The American College of Obstetricians and Gynecologists. v.63, p.485-490, 1984.

ORGANIZAÇÃO MUNDIAL DA SAÚDE. Assistência ao parto normal: um guia prático. Relatório de um grupo técnico. Genebra, 1996. (OMS/SRF/MSM/96.124)

OSORIO-DE-CASTRO, CLAUDIA GARCIA SERPA et al . Uso indicado e uso referido de medicamentos durante a gravidez. Cad. Saúde Pública., Rio de Janeiro, v. 20, 2004.

PATEL, A; GILLES, J.M; MOFFETT, D; MAHRAM, R; DIRO, M; BURKETT, G. Can misoprostol be interchanged with oxytocin for augmentation of labor? Obstet.Gynecol. v.95(Suppl.), p.105, 2000.

PEREIRA, R.I.C.; CECATTI, J.G.; OLIVEIRA, A.S. Dor no trabalho de parto: fisiologia e o papel da analgesia peridural. Rev. C. Méd. Campinas, v.7, n.3, p. 79-84, 1998.

PEREIRA, L.V.; GIUNTINI, P.B.; SANT'ANA, R.P.M.; FALEIROS SOUZA, F.A.E. Magnitude estimates of pain descriptors. Psychologica. Ribeirão Preto, v.28, p.269-276, 2001.

PIMENTA, C.A.M. Aspectos culturais, afetivos e terapêuticos relacionados à dor no câncer. 1995. 133f. Tese ( Doutorado) - Escola de Enfermagem, Universidade de São Paulo. São Paulo, 1995.

PIMENTA, C.A.M.; TEIXEIRA, M.J. Avaliação da dor. Rev. Medicina. São Paulo, v.76, n.1, p. 27-35,1997.

REZENDE, J. Obstetrícia. 8. ed. Rio de Janeiro: Guanabara Koogan, 1998. 
ROUSE, DJ; OWEN, J; HAUTH, JC. Criteria for failed labor induction: prospective evaluation of a standardized protocol. Ostet Gynecol. v. 96, p.671-7, 2000.

ROWLANDS, S; PERMEZEI, M. Physiology of pain in labour. Baillieres Clin.Obstet.Gynecol. v.12, n.3, p. 347-362. 1998

RUST, O.A; GREYBUSH, M; ATLAS, R.O; JONES, K.J; BALDUCCI, J. Preduction cervical ripening. A randomized trial of intravaginal misoprostol alone vs. a combination of transcervical Foley balloon and intravaginal misoprostol. J.Reprod.Med. v.46, n.10, p.899-904, Oct, 2001.

SABATINO, H.; SERPA, J.F; DIAS, A.L; TORRESAN, R.Z. Sensação da contração uterina referida durante o trabalho de parto e parto. J. brasileiro de Ginec., v.106, n.11/12, p. 429-34, 1996.

SABATINO, H.; SABATINO, L.C.; SERPA, J.F.; DIAS, A.L.V. Análise da região, da intensidade dolorosa e do comportamento, referidos durante o parto. In: SABATINO, H.; DUNN, P.M.; CALDEYRO-BARCIA, R. Parto humanizado: formas alternativas. Campinas: Editora da UNICAMP, p. 225-46, 2000.

SANT'ANA, R.P.M. Estimação de magnitude de descritores de dor. 1999. 91f. Dissertação (Mestrado) - Escola de Enfermagem de Ribeirão Preto, Universidade de São Paulo, Ribeirão Preto,1999.

SCAVONE, L. Impactos das tecnologias médicas na família. Dar a vida e cuidar da vida. Feminismo e Ciências Sociais. São Paulo, Unesp. n.5.p.89-99, 2004.

SCISCIONE, A.C; NGUYEN, L; MANLEY, J; POLLOCK, M;MAAS, B; COLMORGEN, G. A randomized comparison of transcervical foley catheter to intravaginal misoprostol for preinduction cervical ripening. Obstet Gynecol. v.97(4), p. 603-7, 2001.

SAMPAIO, Z.S.; ALENCAR JUNIOR, C.A.; FEITOSA, F.E. de L. et al. Fatores associados ao parto vaginal em gestantes de alto risco submetidas à indução do parto com misoprostol. Rev. Bras. Ginecol. Obstet., Cidade, v. 26, n. 1, p. 21-9, jan./fev. 2004.

SAMPAIO, Z.S. Indução do parto a termo com feto vivo com misoprostol vaginal: ensaio clínico aberto. Rev. Bras. Ginecol. Obstet., Rio de Janeiro, v. 26, n. 7, 2004. Disponível em: <http://www.scielo.br. Acesso em: 15 Ago 2006.

SANCHEZ-RAMOS, L; KAUNITZ, A.M.; DEL VALLE, G.O.; DELKE, I; SCHROEDER, P.A.; BRIONES, D.K. Labour induction with the prostaglandin E1 methyl analogue misoprostol versus oxytocin: a randomized trial. Obstet.Gynecol. v.81, n.3, p.332-6, 1993. 
SOAFER, B. Dor: manual prático. 2. ed. Tradução de J. E. Figueiredo. Rio de Janeiro: Revinter, 1994.

SONG, J. Use of misoprostol in obstetrics and gynecology. Obstet. Gynecol. Surv., Cidade, v. 55, p. 503-10, 2000.

SURITA FGS, CECATTI JG, PARPINELLI MA, PINTO E SILVA JL. Misoprostol versus laminaria for cervical ripening in fetal death. Rev Ci Méd. No prelo 2002.

SURITA, F.G. de C.; CECATTI, J.G.; KRUPPA, F. et al. Métodos de preparo cervical para indução do trabalho de parto. Rev. Bras. Saude Mater. Infant., Cidade, v. 4, n. 2, p. 12533, abr./jun. 2004.

TANG, O.S.; SCHWEER, H; SEYBERTH, H.W.; LEE SWH, HO.PC. Pharmacokinetics of different routes of administration of misoprostol. Human.Reprod. v.17, p.332-6, 2002.

TEDESCO, R.P; CECATTI, J.G.; MAIA FILHO, N.L. Efetividade de duas diferentes doses de misoprostol por via vaginal para preparo cervical e indução do parto. Rev. Bras. Ginecol. Obstet., Rio de Janeiro, v. 24, n. 10, 2002.

TEIXEIRA, M.J.; PIMENTA, C.A.M.; CROSSI, S.A.A.; CRUZ, D.L.M. Avaliação da dor: fundamentos teóricos e análise crítica. Rev. Méd., v. 78, p. 85-114, 1999.

WALDENSTROM, U.; BERGMAN, V.; VASELL,G. The complexity of labor pain: experience of 278 women. J. Psychosom. Obstet. Gynaecol., v.17, n.4, p. 1804-28, 1996.

WARE V, RAYNOR BD. Transvaginal ultrasonographic cervical measurement as a predictor of successful labor induction. Am J Obstet Gynecol . v.182, p.1030-2, 2000.

WATERS, B.L; CNM, RN, RAISLER, J.CNM. Ice Massage for the Reduction of Labor Pai. J Midwifery Womens Health. v.48(5), p.317-321, 2003.

WING, D.A.; JONES, M.M.; RAHALL, A.; GOODWIN, T.M.; PAUL, R.H. A comparison of misoprostol and prostaglandin E2 gel for preinduction ripening cervical and labour induction. Am. J. Obstet. Gynecol., v.172, p. 1303-10, 1995.

WING, D.A; PAUL, R.H. A comparison of differing dosing regimes of vaginally administred misoprostol for preinduction ripening cervical and labour induction. Am. J. Obstet. Gynecol., v.175(1), p. 158-64, 1996.

WING, D.A; HAM, D.; PAUL, R.H. A comparison of orally administered misoprostol with vaginally administered misoprostol for cervical ripening and labour induction. Am.J.Obstet.Gynecol. v.180, n.5, p.1155-60, 1999. 
WING, D.A. Labour induction with misoprostol. Am.J.Obstet.Gynecol. v.181, n.2, p.33945, 1999.

WING, D.A. A benefit-risk assessment of misoprostol for cervical ripening and labour induction. Drug Saf. V.25, n.9, p.665-76, 2002.

ZIEGEL, E.E.C. MECCA S. Enfermagem Obstétrica. $7^{\text {a }}$ Edição, Rio de Janeiro, Ed. Interamericana, 1980.

ZIEMAN, M.; FONG, S. K.; BENOWITZ, N. L.; BANSKTERM, D.; DARNEY, P.D.Absorption kinetics of misoprostol with oral or vaginal administration.Obstet. Gynecol., v.90, p. 88-92, 1997. 
9. Anexos 


\section{ANEXO I}

Diário Oficial

Quinta-feira, 18 de Dezembro de 2003 - 5

\section{EDITAIS}

SECRETARIA DA SAÜDE

DIVISÃO DE VIGILÃNCIA SANITÁRIA

A partir desta data ficará publicado:

- O indeferimento do processo $n^{\circ} 02.03$.

04 1029-7, referente ao Auto de Infraçāo $n^{\circ}$

0277. do estabelecimento SAVEGNAGO

SUPERMERCADO LTDA estabelecido á

Av. Cel, Quito Junqueira $n^{9} 622$, neste municipio.

Notificação que o processo n 02.03. 043686.5 to exinto sem julgamento do merito dado a sua intempestividade. conforme art. 433 do Decreto Estadual $n^{8} 12.342$ 78 , do estabelecimento SUPERMERCADO GIMENES LTDA, situado a Av. Cap. Satomão $n^{2} 2333$, neste municipio.

O indeferimento do processo $n^{:} 0203$.

043516-8. referents ao Auto de Infracâo $n^{\text {? }}$ 0279, doestabelecimento WAL MART BRA. SIL LTDA., situado a Av. Presidiente Caste10 Branco $n^{\circ} 2400$, neste municipio.

$O$ indeferimento 00 processo r.: 02.03 . $043076-0$, referente à Notificacẵo n $n^{\circ} 705$, do estabelesinetio CARREFOÚR COMSER. CIO E INOLUSTRIA LTDA, situado à Av. Cel. Femando Ferreira Leite $n^{2} 1540$, neste municipio.

- O indelerimento do processo ns 02.03 042994-0, referente as A:to je infraç̄os n 0278, do estabelecimenio COMERCIAL KADOSATO LTDA, situado a Rue Amado Bueno $n^{\circ} 496$, neste municisio.

CARLOS A. D'AVIII ADE OLIVEIRA Chefe da VISAISNS

Cód. 09.1120-7

SECRETARIA DA SAÚDE

DIVISÄO DE VIGI ȦNCIA SANITÁRIA COMUNICADO VISA

Referente a: Cadjesto peze 0 cortếrcio de retinöidos de uso sistînin

Data de Protocoio: 21 no $2: 03$

Razăo Social: DROGACENTER DISTR!-

BUIDORA DE MEDICAMENTOS LTDA

CNPJ/CPF: $55.992 .3=2.5001-30$

Endereço: Av. D. Peċol. 616

Municipio: Ribeirảo Preto - 1=:50

Resp. Legal: Mition J:Pi:

CPF: 0716461480-C

Resp. Técnico:

Viviane Cristina VEsia Lut.tese

CRF-SP 29.178

O Diretor da VISA-SMS.

INDEFERE $c$ pecisis de zane rializaçâa

de medicamerics contendo substânias retinoldes de uso sist3miso ista C2 da Portaria 344/98)

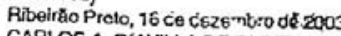

CARLOS A. D'AVILLA DE OLIVEIRA

Chele da VISASMS

Cod. 08.1120-7
SECRETARIA DA SAÚDE

DIVISĀO DE VIGILANCIA SANITÁRIA COMUNICADO VISA

Referente a: Cadastro para o comércio

de retinóides de uso sistémico.

Data de Protocolo: 22/10/2003

Razāo Social:

SALOMĀO VINCO E SILVA LTDA.ME

CNPIICPF: 53.672.044/0001-24.

Enderego:

Av. Coronet Quito Junqueira, 236

Municipio: Ribeirăo Preto - UF: SP

Resp. Legal: Salomẫo Vinco

Resp. Técrico:

Maria Lygia de Oiveira Campos.

CRF.SP 7.447

O Diretor da VISA-SMS,

INDEFERE o pedido de comercializaçâo

de medicamentos contendo substảncias

reứnóides de uso sistėmico (lista C2 da Por taria 344/38)

Ribeirão Preto, 16 de dezembro de 2003 CARLOS A D'AVILLA DE OLIVEIRA

Chele da VISANSMS

Cód. 09.1120-7

\section{SECRETARIA DA SAÚDE}

DIVISÃO DE VIGILANCIA SANITÁRIA COMUNICADO VISA

Referente a: Cadastro para o comércio de retinbides de uso sistermico,

Data de Protocolo: 16/12/2003

N ${ }^{2}$ CEVS: $354340201-524000165-1-9$

Razāo Social:DROGACENTER DISTRIBUIDORA DE MEDICAMENTOS LTDA CNPJ/CPF: 055.992358/0018-88 Endereço: Av. Treze de Maio, $816 \cdot \mathrm{Jd}$

Paulista

Municipio: Ribeirão Preto - UF: SP CEP: $14090-000$

Resp. Legal:

Maurício Roosevelt Marcondes

CPF: 015.416.928-53

Resp. Técnico:

Denise Louzada Delrnondes Roque

CPF: 394.262 .50141

C.Z: Conselho Prof. CRF

$N^{2}$ inscr: 10.680 - UF: SP

$O$ Diretor da VISA-SMS,

INDSFERE o pedióo de comercializaçáo

de medicamentos contendo substánicia retiróides de uso skstémico (lista C2 da Po: tariz 344/88).

Ribeirä́o Preto, 16 de dezembro de $20 \mathrm{C} 3$ CARLOS A. D'AVILA DE OLIVEIRA

Cholo da VASASMS

cod 09.1120-7
SECRETARIA DA SAÚDE

DIVISĀO DE VIGILȦNCIA SANITÁRIA COMUNICADO VISA

Comunicado de Auturizaçã̃o para uso de Misoprostol.

Data de Protocolo: 12/12/2003

$N^{2}$ CEVS: $354340200-851-000127-1-0$

Razão Social: FUNDAÇĀO MATERNN-

DADE SINHẢ JUNQUEIRA.

CNPJ/CPF: 056.014.830/0002-03

Enderego: Av. Wanderley Tatto, 330 Quin.

tino Faccill

Municipio: Ribeiråo Preto - UF: SP

CEP: $14050 \cdot 250$

Resp. Legal: João Paulo Musa Pessoa

CPF: 015.404.408-34

Resp. Técrico:

Andréa Cristina Furquim Viana

CPF: 164.067 .318 .08

C8O: 06710 Conselho Prof. CRF

NG Inser: 25257 - UF: SP

O Diretor da VISA-SMS

DEFERE o pedido de cadastramento 00 reierido estabelecimento hospitalar para utilizacáa de medicamentos que contesm a substencia MISOPROSTOL (lista C1 da Portaria 344/98).

O(s) responsável(s) assume(m) cumprir a legislação vigente e observar as boas prá. ticas referentes as atividades prestadas. respondendo civil e criminalmente pelo năo cymprimento de tais exiosncias ficando incuusive sujeito(s) ao cancelamento deste documento

- Ribeirăo Preto, 16 de dezembro de 2003 CARLOSA. D'AVILIA DE OLIVEIRA

Chefe da VISASSMS

Cod. 09.1120-7

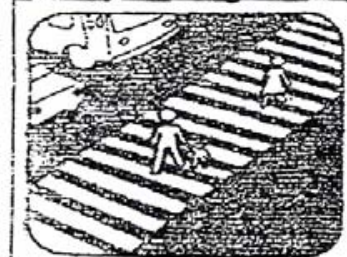

Respeite o trânsito, sua faixa de pedestres, sua mão, aś vias preferenciais. Dê passag̉em a quem pedir. Ultrapasse pela esquerda. Isto mostra que vocé, além de educado, ć bom motorista. Faça de seu veículo um instrumento de lazer e de trabalho, nunca de aborrecimentos para voce é para os outrof 


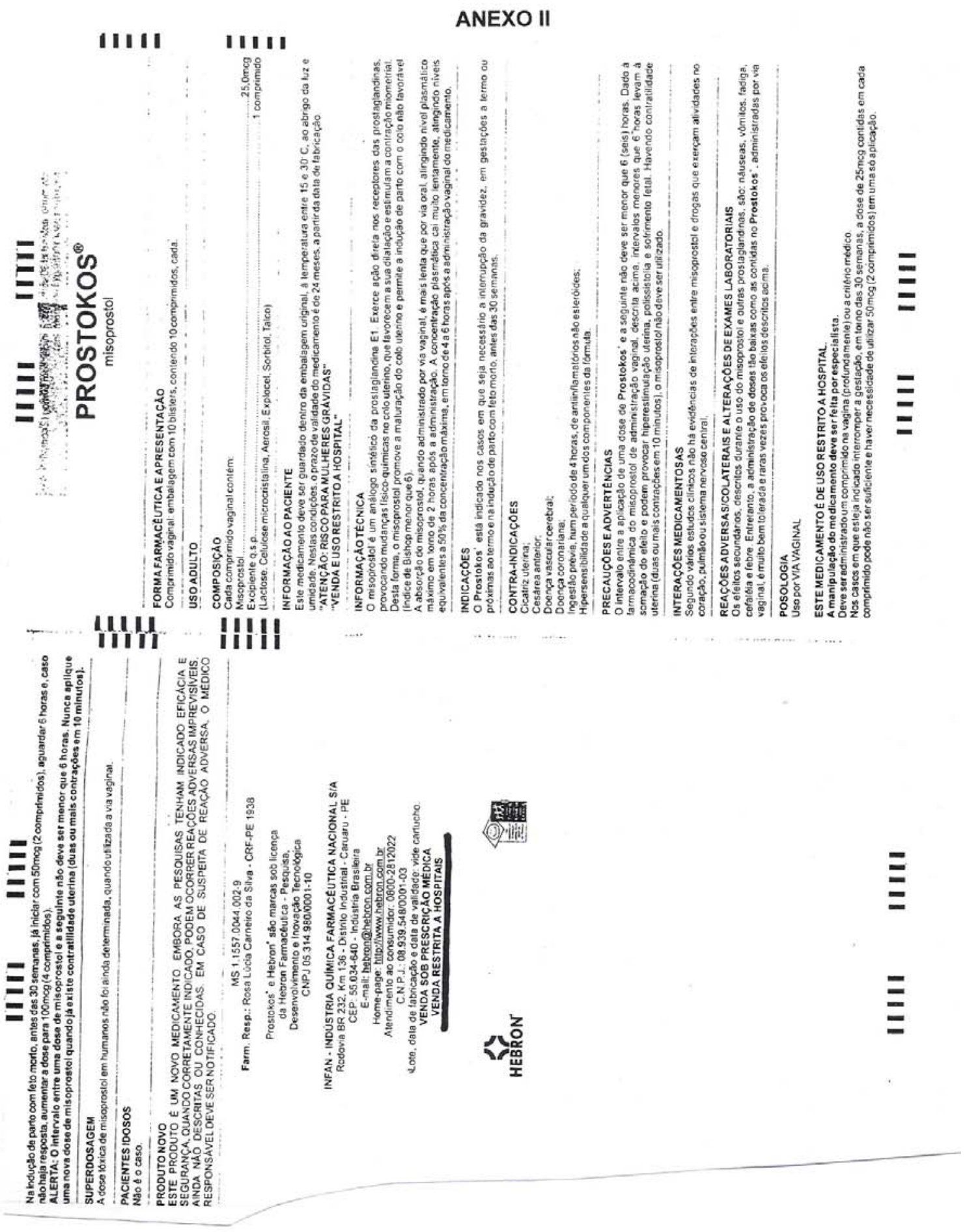




\section{ANEXO III}

\section{Questionário de Dor Mc'gill (versao brasuleira de Pimenta e Teixeira, 1997)} "Algumas das palavras que cu vou ier descrevem a sua dor atual. Diga-me quais palavras melhor descreve a
sua dor. Não cscolha aquelas que não se aplicam. Escolha somente uma palavra de cada grupo. a mais adequada
para a descrição de sua dor. Caso nenhuma palavra expresse a sua dor. você pode dizer nenhuma.".

\begin{tabular}{|c|c|c|c|c|}
\hline & i & 2 & 3 & 4 \\
\hline 1 & II VIISRAC & $\left(\|, P^{P}() \mathrm{N} \mid \mathrm{Al}\right) \wedge$ & ( ) I ^(iUH.IIAI)A & ( IHINA \\
\hline$i$ & $12 \mathrm{HR} 1 \mathrm{MOR}$ & 1 12.cikrotii: & 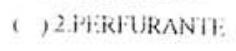 & 1,2CORTANII: \\
\hline I & B.THISANT: & 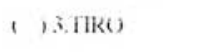 & 1, BIACADA & 1 IBSIRAGALA \\
\hline 1 & 1.1.ATHINii: & & ( I4PINIIALAI)A & \\
\hline 1 & ISCONIOBATHA & & 1, JIMIANCYA & \\
\hline 1 & GCOMGIPANCADA & & & \\
\hline & 5 & 6 & 7 & 8 \\
\hline 1 & 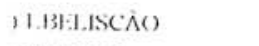 & ( ) HHS(IN)A & ( IICAIOR & 1 IIIOKMICIAMI:NII \\
\hline ' & $12 \operatorname{PRISSAN}()$ & ( i2.J'UXNO) & ( )2.0UI:IMACAO) & ( ) $2 . C O C A: 1 R A$ \\
\hline ( & $13 . M() R 1) \|) \wedge$ & ( IB.LM TORCAO & ( ) B.FERVI:NII: & $(1 ; . \wedge R \mid x) R$ \\
\hline ( & I COLKA & & () 4.IM BRASA & ( ) A.EERROAI)A \\
\hline
\end{tabular}

( ISISMAGAMIENTO

i i

1 IIMAL. LOCAL.I7.ADA ( ) I.SLENSIVEI

( ) 2.DOLORIDA

( ) 2.ESTICADA

( ) I.CANSATIVA

12

- jimacifucada

( ) BESFOLANTI:

( ) A.DOIDA

( ) 4.RACIIANDO

( ) S.PESADA

is

( ) I.CASTIGANTE

( ) 2.ATORMENTA

( ) 3.ATERRORIZANTE

( ) 4.MALDITA

( ) 5.MORTAL.

$$
17
$$

14

15

16
( ) I.AMEDRONTADA ( ) 1.MISERAVEI
( ) I.CHATA
( ) 2.APAVORANTE
( ) 3.CRUEL
( ) 2.ENLOUQUECEDORA ( ), QUE INCONOODA
( ) 3.DESGASTANTE
( ) 4.FORTE
( ) 5 INSUPORTȦVEL

18

19

( ) IESPALHA

( ) 2.IRRADIA

( ) I.APERTA

( ) I.FRIA

20

( ) 3.PENETRA

( ) 2.ADORMECE

( ) 2.GELADA

( ) I.ABORRECDA

( ) 3.REPUXA

( ) 3.CONGELANTE

( ) 2.DA NAUSEA

( ) 4 A.TRAVESSA

( ) A.ESPREME

) 3.AGONIZANTE

( ) S.RASGA

( ) A.PAVOROSA

( ) S.TORTURANTE

\section{PONTUAÇÃO DO QUESTIONÁRIO DE MC'GILL}

Nủmero de Descritores Escolhidos (NWC)

Sensorial

Afetiva:

Avaliativa:

Miscclânca:

Total:
Indice Quantitativo de Dor (PRI)

Sensorial:

Afetiva:

Avaliativa:

Miscelânca:

Total: 


\section{ANEXO IV}
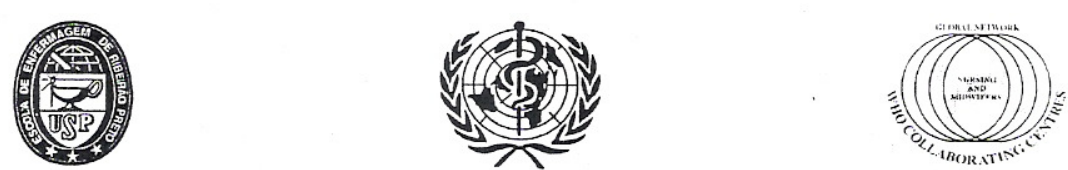

ESCOLA DE ENFERMAGEM DE RIBEIRÃO PRETO - UNIVERSIDADE DE SÃO PAULO CENTRO COLABORADOR DA ORGANIZAÇÃO MUNDIAL DA SAÚDE PARA O DESENVOLVIMENTO DA PESQUISA EM ENFERMAGEM

Avenida Bandeirantes, 3900 - Campus Universitário - Ribeirão Preto - CEP 14040-902 - São Paulo - Brasil FAX: $55-16-633-3271 / 55-16-630-2561-$ TELEFONES: $55-16-633-0379 / 602-3382$

\section{COMITÊ DE ÉTICA EM PESQUISA DA EERPIUSP}

Of.CEP-EERP/USP - 166/2005

Prezada Senhora,

Ribeiräo Preto, $1^{\circ}$ de dezembro de 2005

Comunicamos que o projeto de pesquisa, abaixo especificado foi analisado e considerado APROVADO AD REFERENDUM pelo Comitê de Ética em Pesquisa da Escola de Enfermagem de Ribeirão Preto da Universidade de São Paulo, em $1^{\circ}$ de dezembro de 2005.

Protocolo: $\quad \mathrm{n}^{\circ} 0566 / 2005$

Projeto: Um Estudo Comparativo dos Efeitos da Ocitocina e do Misoprostol na Intensidade da Dor da Contração Manifestada pela Parturiente no Início da Fase Ativa do Trabalho de Parto.

Pesquisadores: Juliana Villela Bueno (Mestranda)

Ana Márcia Spanó Nakano (Orientadora)

Em atendimento à Resolução 196/96, deverá ser encaminhado ao CEP o relatório final da pesquisa e a publicação de seus resultados, para acompanhamento, bem como comunicada qualquer intercorrência ou a sua interrupção.

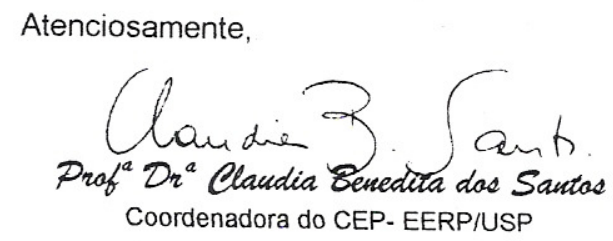

$11 \mathrm{~m}^{\mathrm{a}}$. Sra.

Profa. Dra. Ana Márcia Spanó Nakano

Departamento de Enfermagem Materno-Infantil e Saúde Pública

Escola de Enfermagem de Ribeirão Preto-USP 


\section{ANEXO V}

$\mathrm{N}^{\circ}$

DADOS DA PARTURIENTE

\section{Na admissão/Internação:}

Nome: RG:

Estado civil : Idade:

Endereço: Telefone:

Procedência:.

Cor:

Ocupação: Escolaridade:

Paridade: Idade gestacional:

Doenças: ..Vícios:

Fez uso de algum medicamento ? Fez pré natal?

Local: Inicio do Pré-natal: Qtas consultas?

Curso de preparação p/parto: Local do curso:

Qual o seu maior medo durante o trabalho de parto?

Horário internação: dilatação: Bolsa:

DU:

Bishop:

\begin{tabular}{|l|l|l|l|l|}
\hline & Horário & Dilafaçắo/ esvaeci & DU & \\
\hline $1^{\circ} \mathrm{miso}$ & & & & \\
\hline $2^{\circ} \mathrm{miso}$ & & & & \\
\hline $3^{\circ} \mathrm{miso}$ & & & & \\
\hline $4^{\circ} \mathrm{miso}$ & & & & \\
\hline
\end{tabular}

Tempo do $1^{\circ}$ miso até nascimento:

Parto. dia: às: 


\section{ANEXO VI}

Data:

Hora: - Início do estudo. Dilatação:
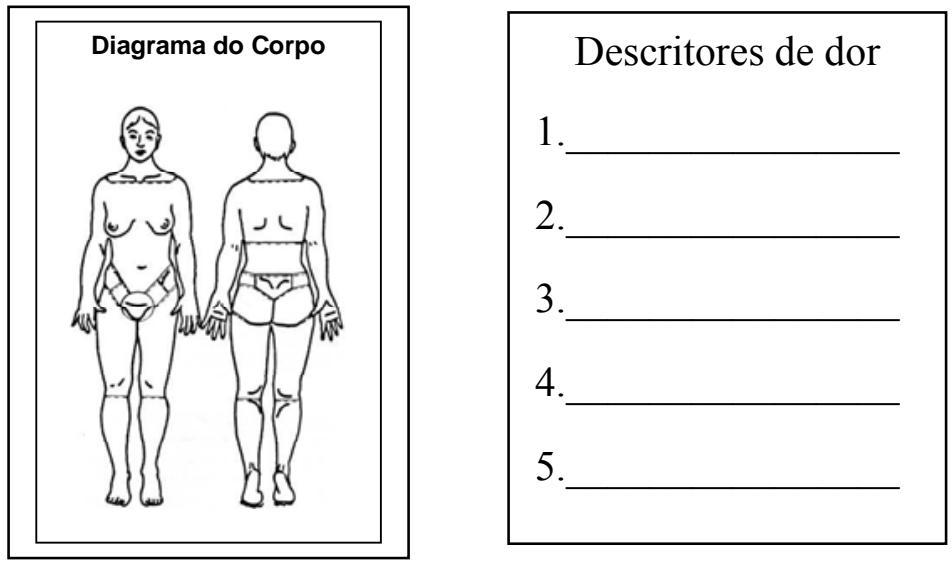

Hora: - Meia hora depois
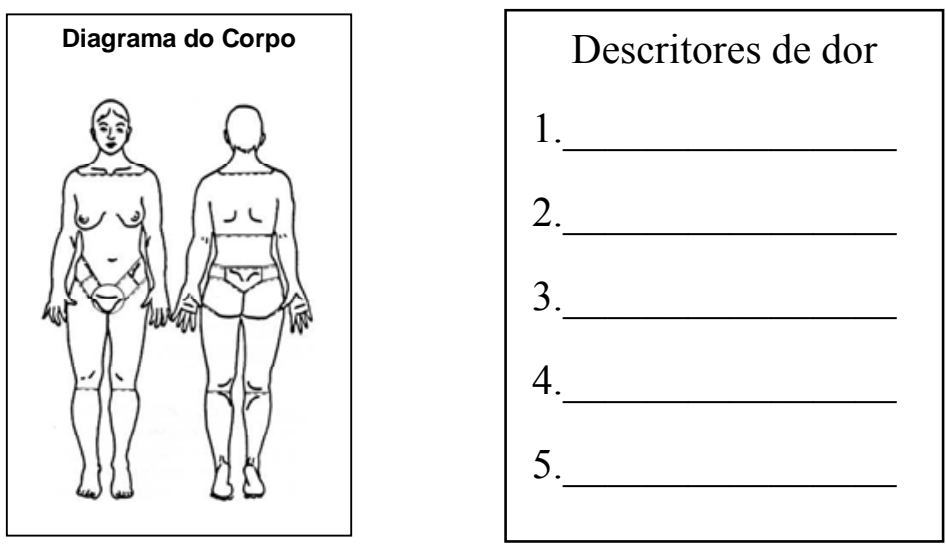

Hora: - Uma hora depois. Fim do estudo. Dilatação:

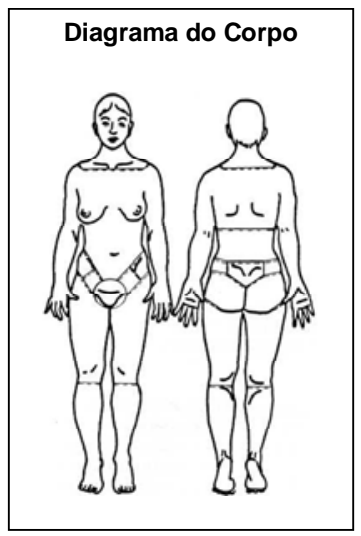

No
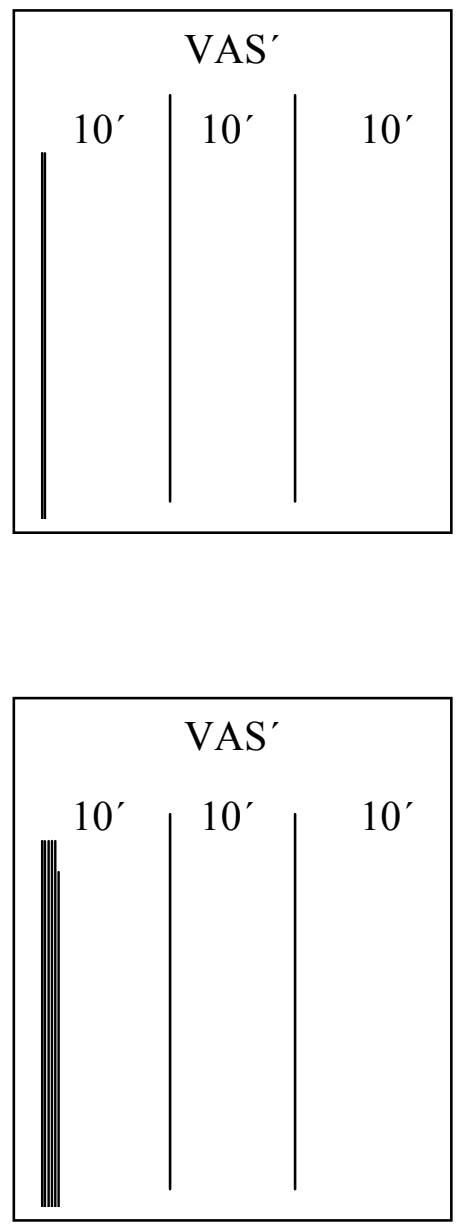


\section{ANEXO VII}

\section{Definição dos Descritores de Dor (Estimação de Categorias)}

1. Alucinante: 1.Que alucina; que faz perder o tino; a razão; o entendimento; alucinatório. 2. Estonteante.

2. Aniquiladora: 1. Que reduz a nada; que nulifica; anula. 2. Que destroe; mata;extermina.

3. Brutal : 1. Próprio de bruto; da natureza de bruto. 2. Cruel; desumana; bárbara. 3. Impiedosa; violenta. 4. Medonha; terrível.

4. Colossal: 1. Que tem proporção de colosso. 2. Enorme; agigantada. 3. Imensurável; incomensurável; vastíssima. 4. Extraordinária; prodigiosa.

5. Desesperadora: 1. Que desespera; que faz desesperar; desesperante; desesperativa. 2. Aquela que faz desesperar.

6. Desumana : 1. Que não é humana; ferina; bestial; desnaturada. 2. Que denota desumanidade; bárbara; cruel.

7. Dilacerante: 1. Que dilacera.2. Que tortura; aflitiva; cruel.

8. Enlouquecedora: 1. Que endoidece; que torna louca; que faz perder a razão.

9. Fulminante: 1. Que fulmina; despede raios; fulminadora. 2. Que assombra. 3. Cruel; terrível; atroz.

10. Insuportável: 1. Não suportável; intolerável. 2. Incomoda; molesta.

11. Intensa: 1. Forte; impetuosa. 2. Dura; árdua; penosa. 3. Violenta; rude; excessiva.

12. Monstruosa: 1- Enorme; extraordinária.

13. Que cega: 1. Que faz perder a razão; que faz alucinar-se.

14. Terrível: 1. Que infunde ou causa terror; terrificante. 2. Extraordinária; estranha. 3. Muito grande; enorme. 4. Muito ruim; péssima.

15. Tremenda: 1 . Terrível. 2. Fora do comum; extraordinária. 
ANEXO VIII

$\mathbf{N}^{\mathbf{0}}$

Grupo

DADOS DA PARTURIENTE

Na admissão

Nome:

Estado civil : Idade:

Endereço: ..Telefone:

Procedência:. ..Cor:

Ocupação: ..Escolaridade:

Paridade: .Idade gestacional:

Doenças:.

Fez pré natal?. .Local: ..Inicio do Pré-natal:

Quantas consultas pré natal ?...........Fez uso de algum medicamento ?

Horário da internação:

Número de comprimidos de miso utilizados:.

Tipo de parto: dia: hora:

Tempo em hs de TP: 


\section{ANEXO IX}

No:.............................Iniciais:

Data:

Internação: dilatação:......... Bolsa:........ Horário:.

DU:

Horário internação:

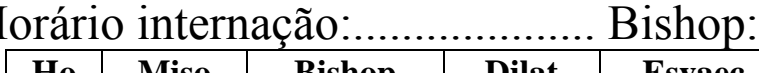

Bishop

\begin{tabular}{|c|c|c|c|c|c|c|c|c|}
\hline $\begin{array}{c}\text { Ho } \\
\text { ra }\end{array}$ & Miso & Bishop & Dilat & Esvaec & De lee & Fase TP & DU & VAS \\
\hline & & & & & & & & \\
\hline & & & & & & & & \\
\hline & & & & & & & & \\
\hline & & & & & & & & \\
\hline & & & & & & & & \\
\hline & & & & & & & & \\
\hline & & & & & & & & \\
\hline & & & & & & & & \\
\hline & & & & & & & & \\
\hline & & & & & & & & \\
\hline & & & & & & & & \\
\hline & & & & & & & & \\
\hline & & & & & & & & \\
\hline & & & & & & & & \\
\hline & & & & & & & & \\
\hline & & & & & & & & \\
\hline & & & & & & & & \\
\hline & & & & & & & & \\
\hline & & & & & & & & \\
\hline & & & & & & & & \\
\hline & & & & & & & & \\
\hline & & & & & & & & \\
\hline & & & & & & & & \\
\hline & & & & & & & & \\
\hline & & & & & & & & \\
\hline & & & & & & & & \\
\hline & & & & & & & & \\
\hline & & & & & & & & \\
\hline & & & & & & & & \\
\hline & & & & & & & & \\
\hline & & & & & & & & \\
\hline & & & & & & & & \\
\hline & & & & & & & & \\
\hline & & & & & & & & \\
\hline & & & & & & & & \\
\hline & & & & & & & & \\
\hline & & & & & & & & \\
\hline & & & & & & & & \\
\hline & & & & & & & & \\
\hline & & & & & & & & \\
\hline
\end{tabular}

Horário Nascimento:

Tempo do $1^{\circ}$ miso até nascimento: 


\section{ANEXO $X$}

Assinale o local ou os locais da dor: T1

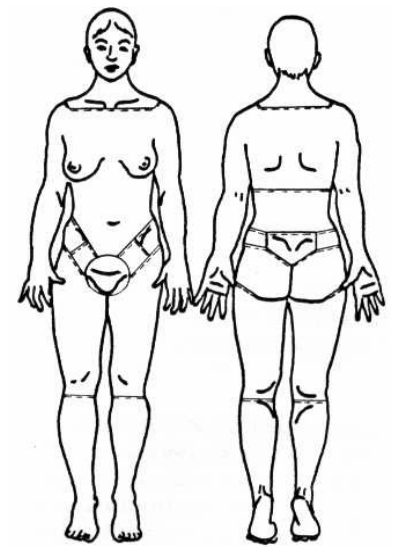

Assinale o local ou os locais da dor: T2

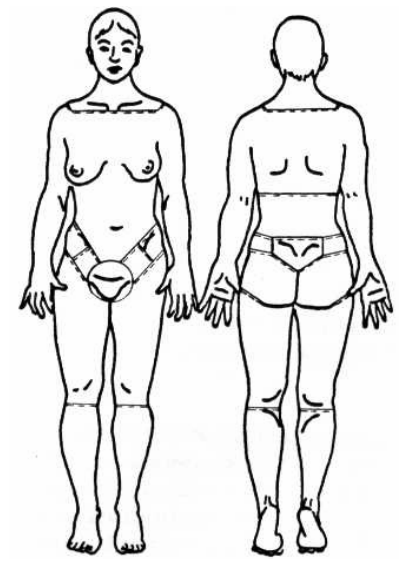

Assinale o local ou os locais da dor: T3

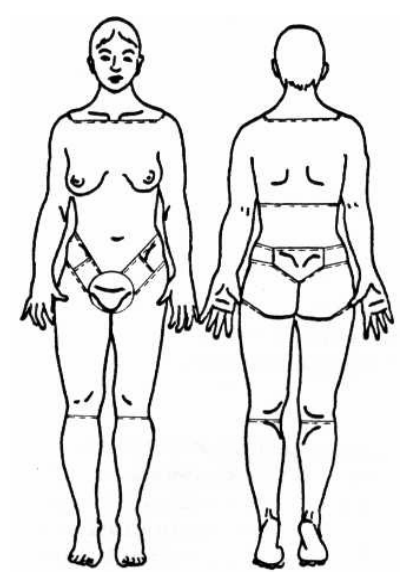




\section{ANEXO XI \\ TERMO DE CONSENTIMENTO LIVRE ESCLARECIDO}

$\mathbf{N}^{\mathbf{o}}$

Nome do trabalho: Um estudo dos efeitos do misoprostol na intensidade da dor manifestada pela parturiente, no início da fase ativa do trabalho de parto.

Pesquisador e responsável pela coleta de dados: Juliana Villela Bueno (COREn 59.476). Qualquer dúvida, poderá entrar em contato pelo telefone (0xx16) 3610.0912 ou 9964.9619.

\section{Informações sobre a pesquisa:}

Este trabalho tem como objetivo medir, através de escalas, a dor da contração durante o trabalho de parto.

Ele justifica-se, pois a dor, muitas vezes é sub-avaliada durante o trabalho de parto, não existindo uma medição desta. Como pensamos que a dor possa ser um empecilho para o bom desenvolvimento do trabalho de parto, avaliar este momento é de extrema importância e a sua colaboração é fundamental. Gostaríamos de convidá-la a participar desta pesquisa.

Todas as instruções serão dadas mais detalhadamente antes das avaliações.

Você receberá todos os esclarecimentos necessários antes e durante o decorrer da pesquisa. Você poderá desistir de participar do projeto a qualquer momento, sem que você deixe de ser tratada como as demais assistidas na instituição. Também manteremos o absoluto sigilo das informações obtidas e a segurança plena de que você não será identificada.

Você não terá nenhum tipo de despesa material ou financeira durante $o$ desenvolvimento da pesquisa.

Não existe nenhuma evidência científica ou indício de que os procedimentos para avaliação da dor possam causar algum tipo de risco, dano físico ou mesmo constrangimento moral e ético a você ou ao seu feto.

O estudo será interrompido caso haja necessidade de realização de qualquer procedimento que vise assegurar o bem estar materno-fetal

Tenho ciência do exposto acima e desejo participar da pesquisa.
Ribeirão Preto, de 2006.

Nome da paciente:

R.G

\section{Participante do estudo}

Juliana Villela Bueno

Pesquisadora 


\section{ANEXO XIIa}

\section{Instruções gerais sobre o estudo}

Estamos realizando um estudo para saber o quanto de dor você estará sentindo durante um período, de uma hora, durante o trabalho de parto. Estarei mostrando a você uma escala que vai de 1 a 10, onde através dela você deverá me dizer, após cada contração, o quanto de dor esta sentindo.

Estarei também mostrando um desenho do corpo humano, em 3 momentos diferentes da pesquisa e você irá apontar onde é que sente dor.

Também irei apresenta-la, 15 palavras que podem definir a dor e você deverá coloca-las em ordem, a ordem de intensidade de dor.

Estaremos com você, neste estudo até que você atinja $4 \mathrm{~cm}$ de dilatação. Gostaríamos de convida-lá a participar. 


\section{ANEXO XIIb}

\section{DADOS DE MENSURAÇÃO E AVALIAÇÃO DA DOR}

\section{Instruções gerais (Diagrama do corpo)}

Estamos interessados em estudar em que região do corpo você, parturiente, sente dor, durante as contrações uterinas.

Estarei mostrando a você, o desenho de um corpo, de frente e de costas, e você deverá prestar atenção, durante a contração uterina, em que região do corpo irá manifestar essa dor. Ao terminar esta contração, você deverá apontar para mim, no desenho, quais regiões foram estas.

Se em algum momento da coleta de dados, você desejar interromper o experimento, avise-nos e ele será encerrado, sem que haja prejuízo algum á vocês.

Agradeço portanto, pela disponibilidade em participar da realização deste estudo. 


\section{ANEXO XIIC \\ DADOS DE MENSURAÇÃO E AVALIAÇÃO DA DOR}

\section{Instruções gerais (Estimação de categorias)}

Este experimento tomará alguns minutos de seu tempo, e você estará colaborando com a realização deste estudo.

A tarefa que você irá realizar não é difícil de ser completada. Todavia, se em algum momento você desejar interromper o experimento, avise-nos e ele será interrompido e encerrado sem acarretar qualquer dano á vocês.

Estamos interessados em estudar como você, parturiente, avalia através de adjetivos (algumas palavras) a dor sentida em determinados momentos do trabalho de parto.

Inicialmente iremos apresentar á você, a definição das 15 palavras (adjetivos) que podem definir a dor.

Sua tarefa será colocar em ordem de intensidade de dor estes adjetivos. Das 15 palavras, escolherá as 5 que melhor definem a dor que está sentindo no momento de cada contração uterina.

Alguma dúvida? Caso tenha, esclareça verbamente conosco.

Nossos agradecimentos 


\section{ANEXO XIId DADOS DE MENSURAÇÃO E AVALIAÇÃO DA DOR}

\section{Instruções gerais (Escala Analógica Visual)}

Estamos realizando um estudo para saber o quanto de dor você estará sentindo durante um período, do trabalho de parto. Estarei mostrando a você uma escala que vai de 0 a 10, onde através dela, você deverá nos dizer, após cada contração, o quanto de dor está sentindo. Onde zero representa ausência de dor e 10 a maior dor que poderia suportar.

As outras notas intermediárias de 1 a 9 deverão ser utilizadas para indicar graus intermediários de intensidade de dor sentida nos períodos da avaliação.

Este instrumento, tomará poucos minutos do seu tempo, e você estará colaborando com a realização deste estudo.

A tarefa que você irá realizar não é difícil de ser completada. Todavia, se em algum momento você desejar interromper o experimento, avise-nos e ele será interrompido e encerrado. 


\section{ANEXO XIII}

\section{PROTOCOLOS DE CONDUTA MATER MATERNIDÂDE DO COMPLEXO AEROPORTO}

Ribeirão Preto, 19 de setembro de 2005.

Vimos através desta informar que a partir de 01 de outubro de 2005 a MATER passará a induzir os casos de pós-datismo em gestação de baixo-risco com 42 semanas de gestação e não com 41 semanas. Lembramos que partir de 40 semanas a paciente deverá seguir protocolo de consulta assim descrito: com 40semamas, 41 semanas. 41 semanas+3dias, 41 sem+6dias e 42 semanas, dia da internação. Em todas as consultas deverão ser realizadas avaliações da vitalidade fetal por cardiotografia, perfil biofisico fetal e amnioscopia conforme protocolos já estabelecidos. Frente a alterações de exames da vitalidade deverá ser discutida a interrupção da gestação. A indução com 42semanas seguirá o protocolo para indução do trabalho de parto. Este protocolo de gestação de baixo risco é seguido no Hospital das Clínicas pelo Departamento de Ginecologia e Obstetrícia. Setor de Obstetrícia.

Gratos pela compreensão e cientes da colaboração agradecem,

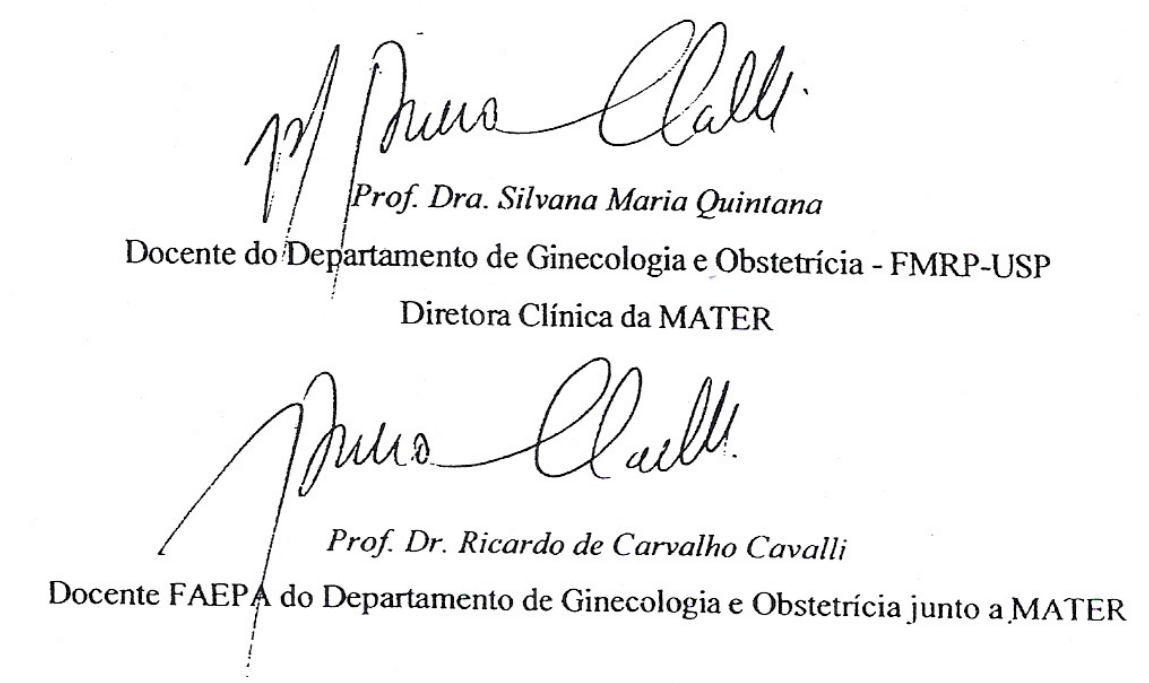




\begin{abstract}
ANEXO XIV
Garantimos manter o caráter confidencial das informações obtidas e a não identificação dos participantes na pesquisa.

Certos de estar contribuindo com o conhecimento nesta área para a melhoria da assistência prestada a gestante/ parturiente durante o trabalho de parto, conto com a sua preciosa colaboração.

Atenciosamente,
\end{abstract}

\title{
Enfermeira Obstétrica Juliana Villela Bueno
}

\section{Contato:}

Maternidade do Complexo Aeroporto - Mater

Endereço: Avenida Wanderlei Taffo, 330 - Quintino II

CEP: 14070-250 - Ribeirão Preto - SP

Telefone: (0xx-16) 3962.8203.

Tenho ciência do exposto acima e desejo participar da pesquisa.

Ribeirão Preto, de 2006.

Assinatura do entrevistado 